\title{
TEACHER PERCEPTIONS OF INFORMATION AND COMMUNICATION TECHNOLOGIES IN A SECONDARY SCHOOL IN SAMOA
}

By

FARITA TEPORA AFAMASAGA-WRIGHT

A thesis submitted to the Victoria University of Wellington in fulfilment of the requirements of the degree of Master in Education

Victoria University of Wellington

2008 


\begin{abstract}
This study explored teacher perceptions of information and communication technologies in one secondary school in Samoa, in order to gain insight into recent government initiatives to introduce computers and other ICTs in schools. Phenomenology as an approach was deemed appropriate to the focus of this research in that it provided the framework for an in-depth exploration of how teachers view themselves within a particular event in the development of education in Samoa: the integration of ICTs in schools. Underpinning this study were assumptions about the nature of knowledge as being socially constructed as well as contextually situated. The research sought understanding of the phenomenon from the perspective of one group of participants. Data was gathered using lengthy semi-structured interviews in the Samoan language which were then translated into English for the purpose of data analysis. Significant findings include: lack of clarity amongst teachers regarding ICT in education policies, government rationale and strategies to achieve policy; teacher rationale for the introduction of ICT in schools included improvement of teaching and learning, student future employment and improved student access to technology. Teacher perceptions of ICT were mostly positive noting that its use contributed to higher levels of student interest, engagement, independent learning and motivation. As well, ICTs were mainly used to support teacher-centred pedagogies and contributed to the efficiency of teacher preparation. While teachers were keen to use ICTs in their classes, they were hindered by lack of ICT skills and insufficient pedagogical knowledge. Teachers perceived several obstacles to effective integration of ICTs in classrooms, which included: insufficient student and teacher access to computers; timetabling restrictions; a user pays system; maintenance and running costs; student plagiarism from the web and access to inappropriate sites as well as inadequate teacher professional development for the use of ICTs.
\end{abstract}




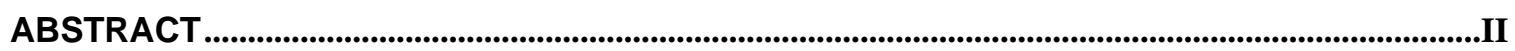

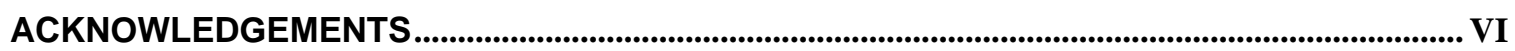

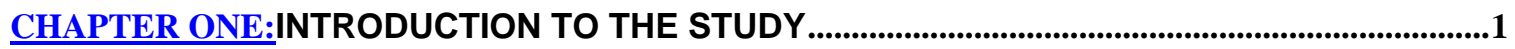

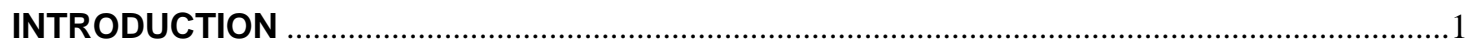

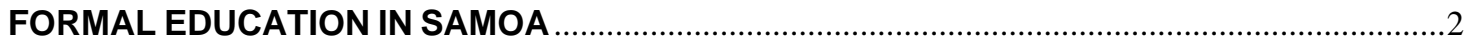

INFORMATION AND COMMUNICATION TECHNOLOGIES POLICY AND ..................................

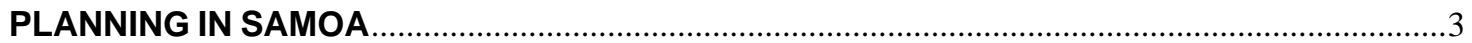

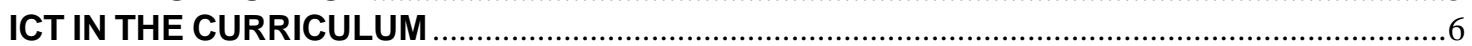

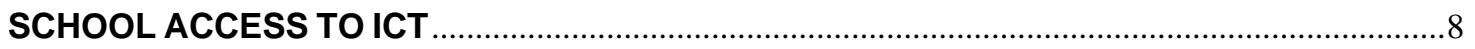

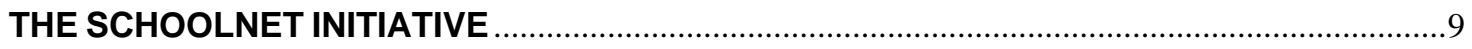

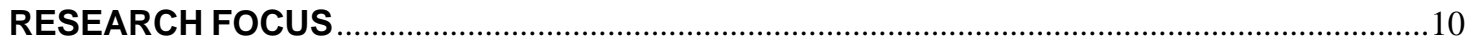

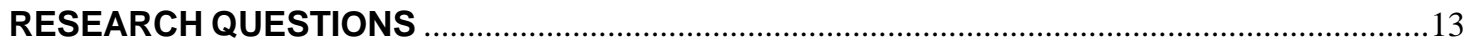

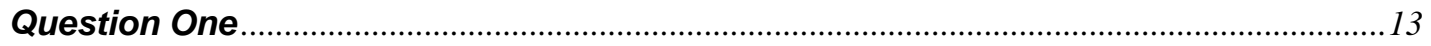

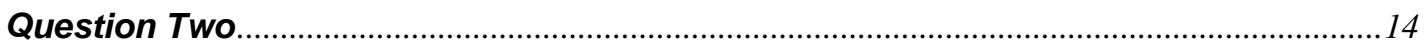

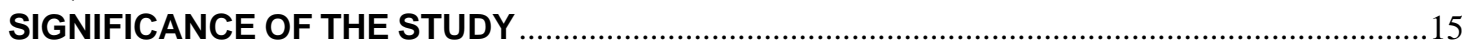

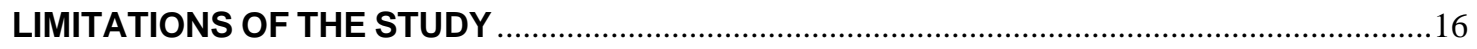

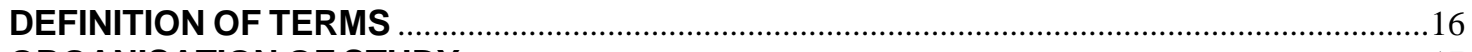

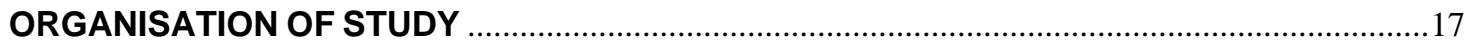

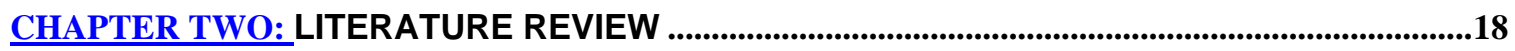

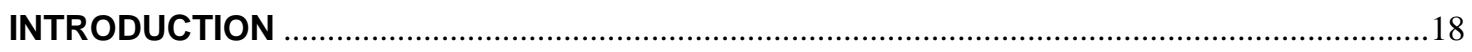

INFORMATION AND COMMUNICATION TECHNOLOGY IN EDUCATION: BACKGROUND

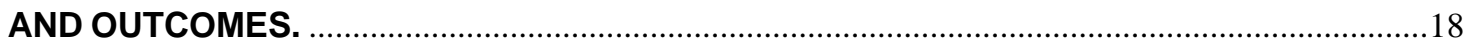

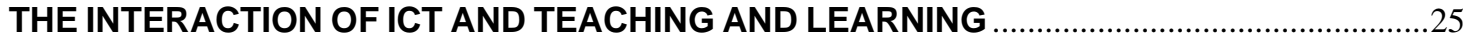

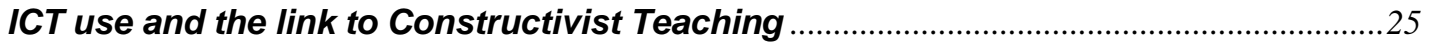

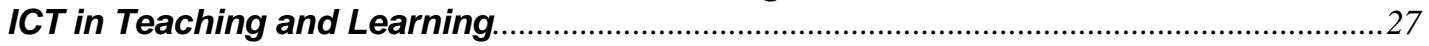

Teacher and Instructor Perceptions of ICT in Teaching and Learning ................................

THE TEACHER AND INTEGRATION OF INFORMATION AND ................................................

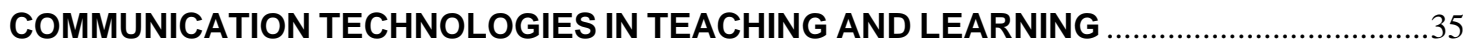

OTHER FACTORS (APART FROM THE TEACHER) INFLUENCING THE .................................43

INTEGRATION OF TECHNOLOGY INTO TEACHING AND LEARNING …............................43

TEACHER PROFESSIONAL DEVELOPMENT FOR INTEGRATION OF ICT IN .....................48

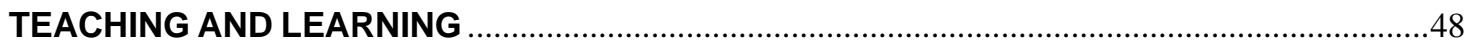

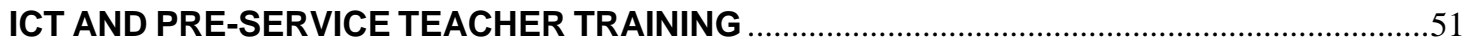

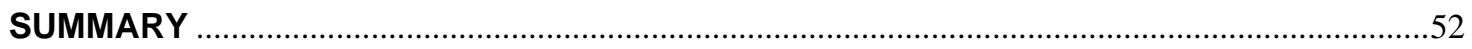

CHAPTER THREE: THE RESEARCH METHODOLOGY ...............................................................53

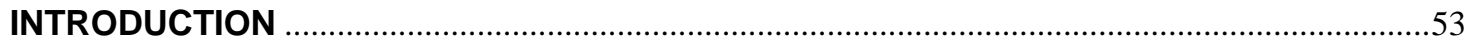

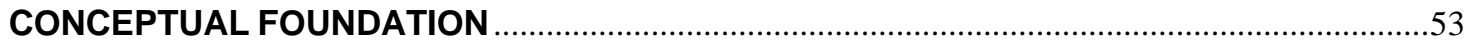

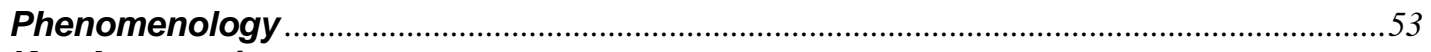

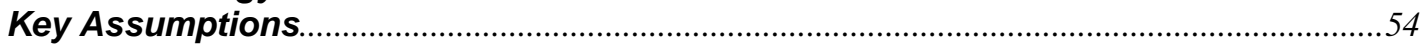

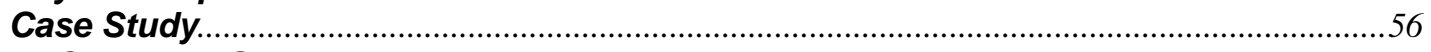

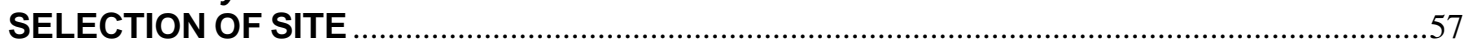

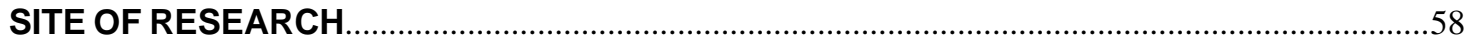

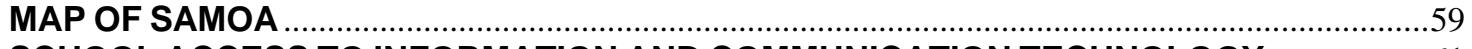

SCHOOL ACCESS TO INFORMATION AND COMMUNICATION TECHNOLOGY ................61

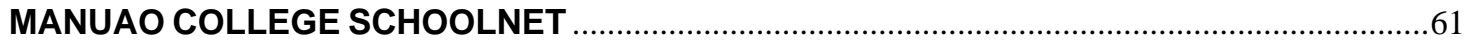

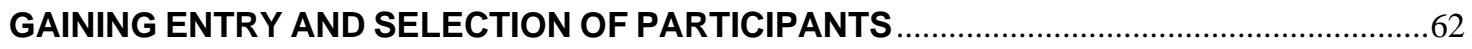

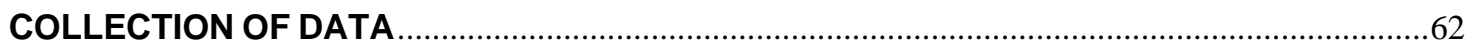

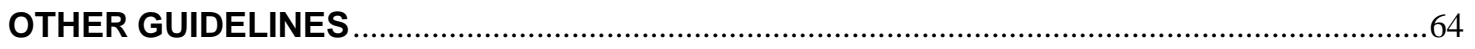

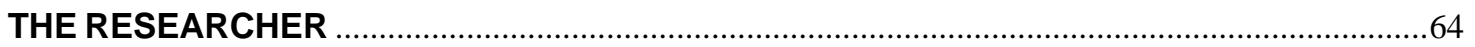


DATA ANALYSIS

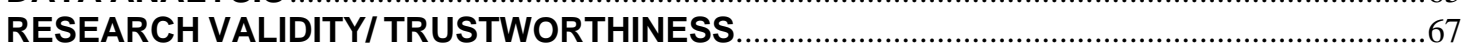

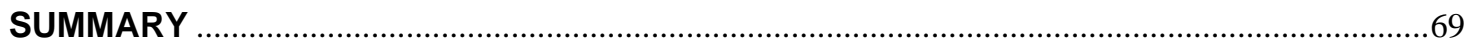

CHAPTER FOUR: DESCRIPTION OF DATA ...................................................................................70

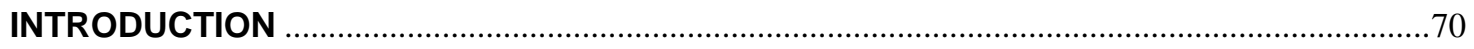

HOW MANUAO COLLEGE CAME TO BE PART OF SAMOA SCHOOLNET .............................70

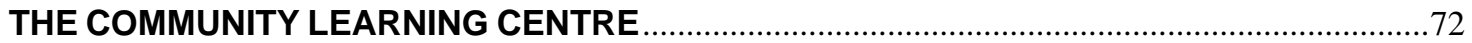

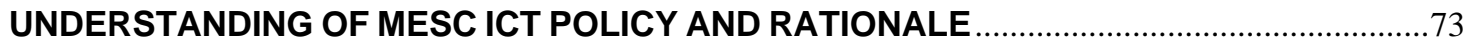

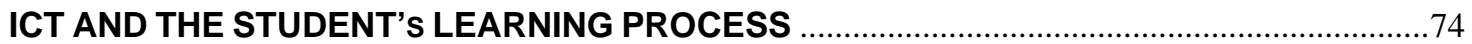

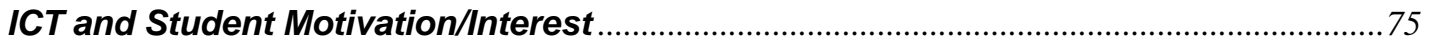

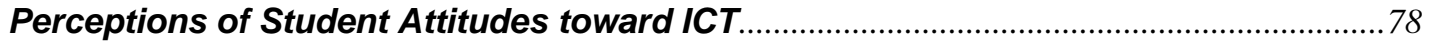

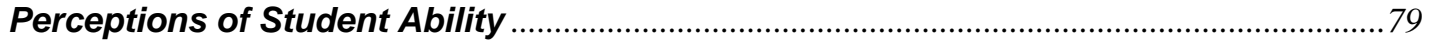

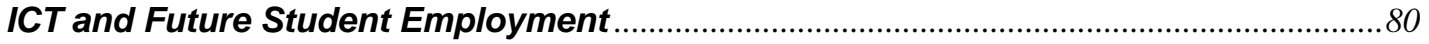

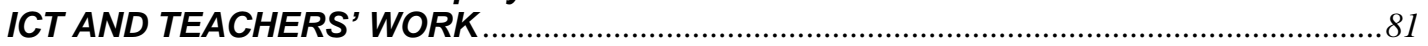

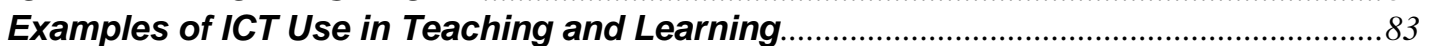

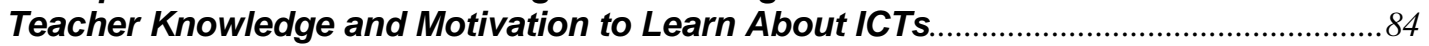

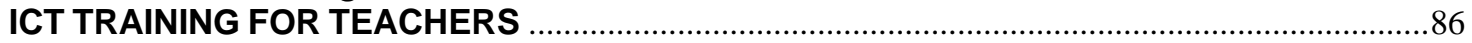

OBSTACLES TO EFFECTIVE USE OF ICTS TO ENHANCE TEACHING AND.........................89

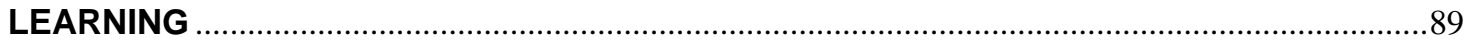

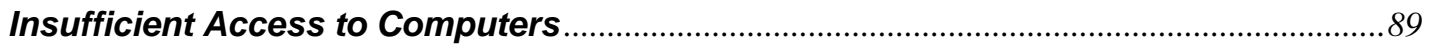

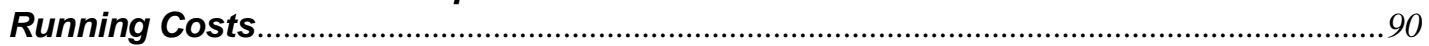

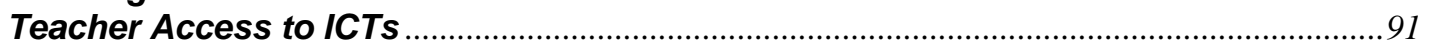

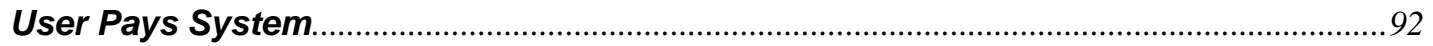

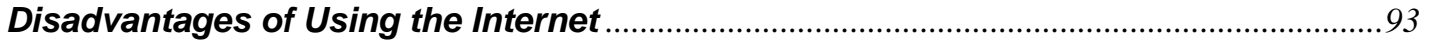

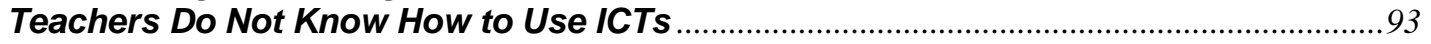

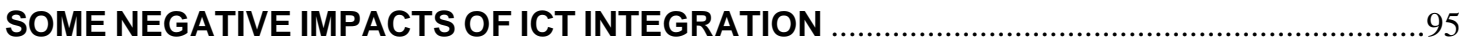

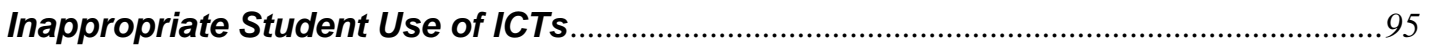

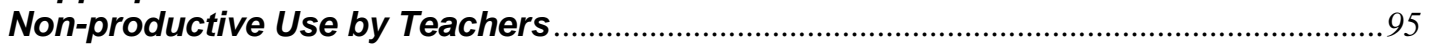

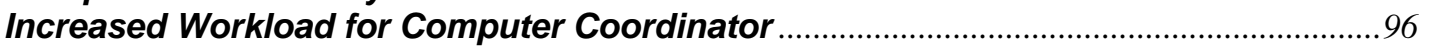

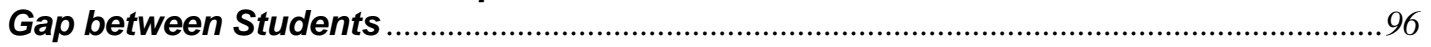

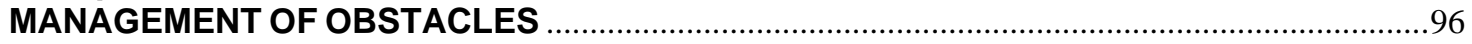

TEACHER SUGGESTIONS FOR IMPROVEMENT OF ICT INTEGRATION AT ........................97

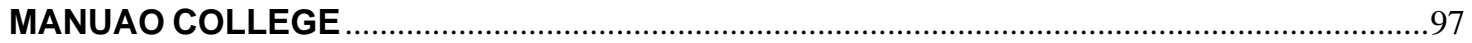

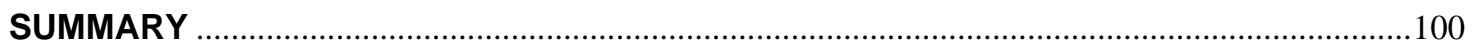

CHAPTER FIVE: ANALYSIS AND INTERPRETATION OF FINDINGS ...........................................101

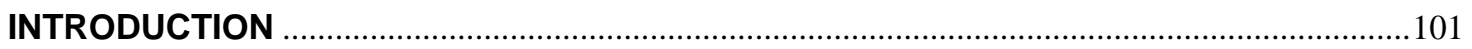

PERCEPTIONS OF THE RATIONALE FOR SCHOOL INTEGRATION OF ICT ......................101

PERCEPTIONS OF THE RELATIONSHIP BETWEEN ICT AND STUDENT ............................103

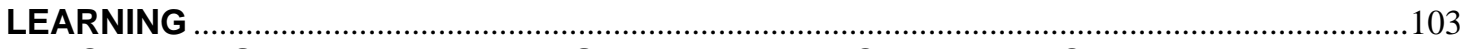

PERCEPTIONS OF THE RELATIONSHIP BETWEEN ICT AND TEACHING .........................106

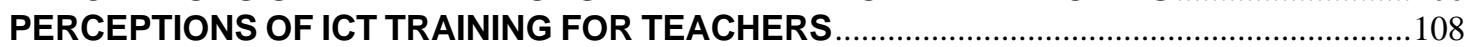

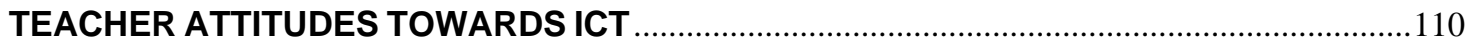

PERCEPTIONS OF OBSTACLES TO EFFECTIVE USE OF ICT IN TEACHING ....................110

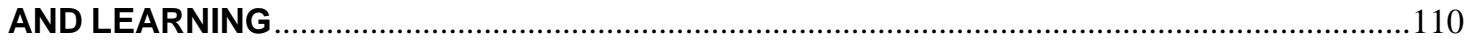

TEACHER SOLUTIONS TO MANAGE PERCEIVED OBSTACLES ..........................................111

SUMMARY ..............................................................................................................................................113

CHAPTER SIX: SUMMARY OF FINDINGS, IMPLICATIONS AND REFLECTIONS.....................114

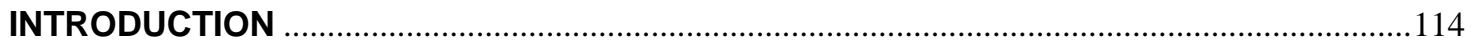

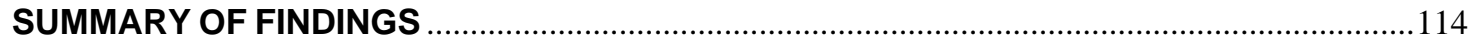

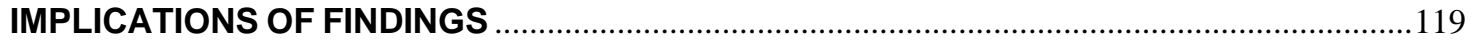

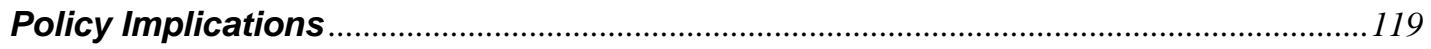

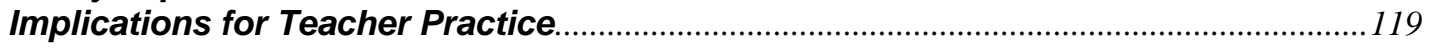


Implications for Research

REFLECTIONS ON THIS STUDY

APPENDIX 1: LETTER TO SAMOA MINISTRY OF EDUCATION SPORTS AND CULTURE..123 APPENDIX 2: INFORMATION FOR RESEARCH PARTICIPANTS \& CONSENT FORM ...........125 APPENDIX 3: GUIDING QUESTIONS FOR INTERVIEWS WITH TEACHERS AND PRINCIPALS...............................................................................................................................................128

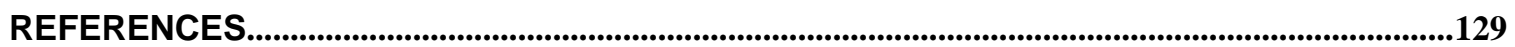




\section{ACKNOWLEDGEMENTS}

I express my deep gratitude and appreciation to those who agreed to participate in this research, for their time expended and courage in sharing their insights with a fledgling researcher. It is to them that I am most indebted, and I can only hope that the product of our collaboration benefits each one as much as I have benefited from the process.

I have been immeasurably enriched by working under the supervision of $\mathrm{Dr}$ Kabini Sanga, whose unique mixture of encouragement and challenge, at times letting me find own my way, while providing timely wisdom and support in my research journey, has enabled me to complete this project. I have learnt more from Dr Kabini Sanga than can ever be contained in this thesis.

At times my studies were carried out at great cost to those closest to me. I thank my family for their prayers, understanding and support.

I have also gained much insight from colleagues at Victoria University of Wellington; their different perspectives complemented and completed my own.

Not the least by all means, I acknowledge NZAID scholarship funding which made these studies and this research project possible.

I acknowledge the Creator and source of all wisdom, Yahweh, my God, in whom I trust. 


\section{CHAPTER ONE \\ INTRODUCTION TO THE STUDY}

\section{INTRODUCTION}

New technology and their implications for education have excited the minds of educators, politicians and innovators alike all over the world as early as the beginning of the 19th century. It began with printed school texts, continued with books and film, not to mention radio broadcasting, and has progressed to computers and associated software, DVDs, data projectors, and other kinds of technology that are being developed even as these words are put on paper.

The pace of technological innovation has not been the same all over the world. For reasons of access to capital, human and natural resources among others, there has existed and continues to be a technological disparity between economically developed and less-economically developed nations. Issues which policy makers and innovators in economically developed nations faced up to decades ago now absorb the minds of their counterparts in less-economically developed nations. A readily evoked example is that of the issue of using stem cells from aborted foetuses in New Zealand, compared to the issue of having sufficient equipment to carry out pregnancy ultrasounds in Samoa.

Whenever a new technology which meets a recognisable need is introduced into society and markets, given that it is available at a price affordable for the everyday consumer, the new technology rapidly acquires the status of the ubiquitous. Everyday examples include mobile phones, TVs, and automobiles, and the unassuming computer. The education sector has traditionally been slower than other sectors to incorporate new technology such as computers into their everyday practice. However, while all forms of information and communication technologies are now commonplace in every sector of industry, 
educators in economically developed nations still grapple with the question of how to effectively integrate such technologies into education and into schools, for the purpose of enhancing the teaching and learning experience. In that respect they are similar to their counterparts in less-economically developed nations.

Samoa is usually referred to as a less-economically developed nation, and it adopted a national policy of .Information and Communication Technologies for every Samoan almost 5 years ago (Government of Samoa, 2002, p.1). This policy was written in 2002, and four years later, its focus appeared in the education policy documents governing the present period (Samoa Ministry of Education, Sports and Culture, 2006a). The present ministry vision for Information and Communication Technologies in education is that of .educational planning and management, teaching and learning that is enhanced through the use of cost effective ICT. (Samoa Ministry of Education, Sports and Culture, 2006a, p.42).

\section{FORMAL EDUCATION IN SAMOA}

Formal schooling in Samoa consists of 8 years of primary schooling, and 5 years of secondary schooling. Children start school when they are five and they may or may not have attended a pre-school. According to 2001 figures, $40 \%$ of children aged 3-5 were enrolled in one of the many pre-schools run by village community members or pastors wives (Afamasaga, 2006, p.81). The number of children attending primary schools in 2005 comprised about $96 \%$ of the total number of primary-age children in Samoa, and this represents a relatively high participation rate for primary education. The situation is less positive for secondary schools, as the participation rate for 2005 was about 50\%; which was hardly an improvement from about 42\% in 1994 (Samoa MESC, 2004a). 
There are 159 primary schools and 44 secondary schools in Samoa; in 2005 the student to teacher ratio was 31.8 for primary schools and 21.8 for secondary schools (MESC, 2005). These figures hide discrepancies between schools as urban schools tend to have a much higher student to teacher ratio than rural schools, which are as low as 10 students per teacher (Afamasaga, 2006, p.84).

The secondary school curriculum has recently undergone substantial revision to better meet the needs of Samoan students. Prior to this review, the Samoa secondary curriculum followed the New Zealand curriculum with few adaptations. With recent revision, it is now more appropriate to the Samoa context while retaining its global relevancy. Student achievement in formal schooling is measured at Years 4 and 6 in the form of Samoa Primary Educational Literacy Level (SPELL) tests; at the end of Year 8 by the Year 8 National Examinations; at the end of year 12 in the form of the Samoa School Certificate (SSC) Examinations and at the end of year 13 by the Pacific Senior Secondary School Certificate (PSSC) Examinations. While the majority of these assessments used to be predominantly in the form of formal written examinations, the secondary assessments have undergone revision to include other assessment instruments.

\section{INFORMATION AND COMMUNICATION TECHNOLOGIES POLICY AND PLANNING IN SAMOA}

The development of the ICT policy in Samoa seems to have followed a clearly discernible pattern since 1999. In 1999, Communications Ministers of the Pacific Forum countries, which includes Samoa, convened to discuss matters of importance to communications in the Pacific Forum countries. They agreed upon the consequent 1999 Forum Communications Action Plan. In April 2002, this plan was reviewed at the second Forum Communication Policy ministerial gathering (Pacific Islands Forum Secretariat, 2002a). This 2002 meeting of Forum Communications Ministers is to be credited with the visionary Forum 
Communications Action Plan which had the progressive theme of Information and Communication Technologies for every Pacific Islander. (PIFS, 2002a, p.1). The Pacific Islands ICT Strategic Policy and Plan was another product of this 2002 ministerial meeting; it had the broad aim of providing guidance for ICT policy development and cooperation for the Pacific Islands Countries and Territories (PICTs) (Pacific Islands Forum Secretariat, 2002b, p.2). The Samoa government department responsible for ICT wasted no time in responding with a policy for Samoa and in June of the same year (2002), the Samoa Information and Communication Technologies Policy and Strategic Plan was drawn up and approved. This policy document adopted the same guiding principles and strategies as that of the Pacific Islands Strategic Policy and Plan (Government of Samoa, 2002).

The policy developments in the area of Information and Communication Technologies in the Pacific region speeded up at the same time as the rest of the world focused on the use of ICTs for development. The 2003 World Summit on the Information Society held in Geneva agreed to promote and encourage the use of ICTs to increase global participation in the global information infrastructure. (Pacific Islands Forum Secretariat, 2004a, p.4). Following the Geneva Summit in late 2003, the place of ICTs in education appeared as Item 8 on the agenda of the 2004 gathering of Pacific Forum Ministers of Education. This was the first time the issue of ICT in education was raised in a meeting of Education stakeholders, and the ministerial discussion of Item 8 centred on the proposals put forward at the Geneva Summit on the Information Society, particularly where they related to education.

However, it seemed that the development of ICT in the Pacific region was not as rapid as hoped for and this was officially noted at the December 2004 Subregional Symposium on ICTs for Development in Pacific Islands Developing Countries, held in Suva, Fiji. The Symposium held the view that the execution of the Pacific Islands ICT Policy and Strategy Plan was advancing slowly (Pacific 
Islands Forum Secretariat, 2004b, p.3). One of the key factors affecting continuity of the Plan's implementation was the fact that national representation at regional conferences was not guaranteed and tended to change with every meeting.

Nevertheless, there seemed to be gradual progress in the Education sector as, following the Forum Education Ministers' 2004 meeting which highlighted ICT in Education, an 'ICT in Education' regional conference was held in 2005 in Suva, Fiji. The objectives of this workshop were:

1. To share the results of a JICA-funded research project which carried out an 'Evaluation of the Computer Science (CS) Curriculum in Fiji Secondary Schools'

2. To review the existing status of ICT Education in the region and explore pathways to enhance the quality of ICT Education

3. To determine a systematic approach at the regional level in order to achieve educational goals in ICT

ICT Capacity Building at USP Project, 2005, p.10.

It seemed that Pacific nations were seriously considering how to improve the usage of ICTs in education in their local contexts. Samoa's Country Status Report at this workshop was the first step in identifying a number of issues facing ICTs in education in Samoa. The report pointed out that in order to plan for effective provision of computers in education, Samoa would need to work on:

1. The existence of clearly defined and understood outcomes

2. The professional development of teachers

3. The processes of provision

4. The model of provision

Roebeck-Tuala \& Esera, 2005, p.50.

The report also recommended that the following goals be set for the integration of ICT in education in Samoa: 
1. The provision of access and training to the community as a whole, to promote lifelong learning and economic/vocational success

2. The provision of access and training to students and teachers, to provide both groups with the skills necessary to use ICT effectively

3. The integration of ICT into the curriculum, resulting in changes to teaching and learning, i.e. a shift to learning with and through technology

Roebeck-Tuala \& Esera, 2005, p.50.

In June of 2006, 7 years after the issue of ICT became an item in the development of the Pacific region, and 2 years from when it was specifically considered in the area of education, Samoa's Ministry of Education, Sports and Culture Strategic Policies and Plan for the next ten years was finalised with a separate section for Information and Communication Technologies. This can be seen as the continuation of steps in the right direction for development in Samoan education. While a limitation exists in the emphasis of ICT for structural management and administration, in addition to negligible direction for the provision of computers and the effective integration of ICTs in education, it is still a positive inclusion in planning for development in Samoan education.

\section{ICT IN THE CURRICULUM}

The Samoa National Curriculum Policy Framework lists Information and Communication Technologies as a study option in Years 9 to 11 (Samoa MESC, 2006a, p.16). However, a national curriculum statement has not yet been developed for these levels. In addition, Computer Studies appears as an optional subject for Years 12-13, and a curriculum statement has recently been approved for this course of study (Samoa Ministry of Education, Sports and Culture, 2004b). This curriculum is assessed at Year 13 level by the South Pacific Board 
of Educational Assessment via the Pacific Senior Secondary School Certificate examination at the end of Year 13. MESC is currently working on its Year 12 assessment program for Computer Studies (MESC, 2004b, p.7).

It is interesting to note that, national representatives to a regional conference on ICT in Education made the observation that the inclusion of a Computer Studies curriculum seems to have been driven by the provision of computers in several schools, taught by Peace Corps volunteers in the absence of qualified/sufficiently skilled teachers (Roebeck-Tuala \& Esera, 2005, p.53). Nevertheless, the Year 12-13 Computer Studies Curriculum as it exists has taken into account the local context and constraints on student and teacher access to computers. For instance, the Year 12-13 Computer Studies Curriculum Document has been developed with the following factors in mind:

- Integration of technology is still in its early stages in Samoa and the emphasis is on promoting computer literacy and skills

- Most students do not have computers at home and exposure and contact with computers is limited to time within the Computer Studies scheduled hours

- Flexibility in the curriculum at Year 13 is provided by the inclusion of optional strands to cater for the diverse skills and backgrounds of teachers and students alike

- It is expected that as the baseline skills of students develop, the focus of the curriculum will be on the promotion of problem solving and critical thinking

MESC, 2004b, p.9.

According to Roebeck-Tuala and Esera (2005, p.49), a 2003 survey ascertained that 15 out of the 43 secondary schools in the nation offered Computer Studies. However, this number may have increased given the implementation of the SchoolNet Project in 5 schools in Samoa in 2006-2007. 


\section{SCHOOL ACCESS TO ICT}

There is an identifiable lack of concrete information regarding the number of computers and other ICTs available to schools, however, conclusions can be drawn from the information that is available. In 2003, relatively few schools in Samoa could boast of computers that were accessed by students as well as staff; these few schools were predominantly located around the urban spread of Apia (Vaa, 2003, p.209). The majority of these computers had been donated by donor organizations, enterprise and other institutions; they were for the most part located in secondary schools. A 2005 report by the Ministry of Education Sports and Culture indicated that the number of computers available in schools increased by $20 \%$ in 2004, but it is unclear from the report how the increase in the number of computers eventuated, or was quantified (Roebeck-Tuala \& Esera, 2005, p.50).

Regardless of the actual numbers however, school access to computers and other ICTs increased with the implementation of the SchoolNet project, which saw 5 schools that did not previously have computers being outfitted with a Computer Learning Centre. "On average, each CLC was equipped with 10 internet-ready networked computers... two PC servers, a video camera, a data projector, two printers, a fax-scanner, a photocopier, and uninterruptible power supply (UPS) devices for the servers" (Strigel, Chan Mow \& Vaa, 2007, p.116). Given that the number of secondary schools outfitted with this equipment under the SchoolNet project represents about $10 \%$ of the total number of secondary schools in the country, this is a sizeable improvement in the relative number of schools with access to ICTs.

Other information and communications technologies that are more or less available in schools for preparation and implementation of lessons include telephones, facsimile machines, digital cameras, cassette recorders, radio/CD 
players, TV sets and VCRs. Of the total number of schools however, less than $25 \%$ of secondary schools and a negligible number of primary schools have access to the internet (Pacific Islands Forum Secretariat, 2002c, p.5).

Equally important, an educational radio broadcast prepared by the Educational Broadcast Unit has been in place for several years and this has been successful according to Ministry report, although explanation of its success is limited (Samoa MESC, 2006a, p.42). This educational broadcast is primarily targeted at primary school students and provides a teacher resource for the teaching of English and other key learning areas.

\section{THE SCHOOLNET INITIATIVE}

The SchoolNet initiative was set in motion by the government of Samoa and funded by the Asian Development Bank. The goal of the initiative was to .pilot an appropriate model for introducing Information and Communication Technology (ICT) in schools and their respective communities. (Samoa SchoolNet Portal, http://www.samoaschoolnet.edu.ws/). In doing so it aimed to support the Samoa National ICT Policy of .ICTs for every Samoan. (Government of Samoa, 2002). The SchoolNet model has been trialed in countries such as Nigeria and the U.S. and basically consists of a network of schools connected to each other via the SchoolNet portal which also serves as a virtual resource centre. Internet access is available within a learning centre located inside the school grounds, used as a school facility during school hours, and which becomes available for community use outside school hours.

Samoa is the first country in the Pacific to establish an initiative of this kind, and to date, five schools have been set up with learning centers connected as SchoolNet schools. The SchoolNet schools consist of four secondary schools and a single primary school. Each computer learning centre consists of a room 
that is fully equipped with 10-12 networked computers and various ICTs such as a DVD player, TV, printer, scanner, multimedia projector and fax machine. Internet connection is through a mixture of dial-up and wireless connections. At the moment, wireless connectivity seems to be more suitable given Samoa's geographic characteristics and available infrastructure. Training for community and school representatives in the maintenance and use of the ICT facilities have been included as part of the SchoolNet project.

When the computer learning centres were first set up, internet connection was free for the school and the funding also provided for staff training and computer maintenance. However, the computer learning centres were set up with the goal of self-sustainability in mind; accordingly, workshops were carried out with nominated administrators from each school to help them run a facility that would meet its own costs. The computer learning centres thus started charging fees for internet access, printing and other usage when the government funding ended. As the centres opened to the community after school hours, this was the main source of revenue to meet the costs of maintaining the computer learning centre.

While the long term goal of the government remains the extension of the SchoolNet pilot model to other schools in the country, future provision of ICTs in schools in the absence of a reliable national infrastructure seem to be reliant on "upcoming donor-aided projects" (Roebeck-Tuala and Esera, 2005, p.55).

\section{RESEARCH FOCUS}

The Samoa Ministry of Education is currently grappling with the issue of how to successfully integrate Information and Communications Technology in education. A Ministry report to a regional conference on the status of ICT in secondary schools highlighted this issue when it stated that, .the government has only limited expertise with which to be effective in formulating and implementing 
national ICT policies, and the education sector is without the resources and knowledge base to integrate ICT into schools. (Roebeck-Tuala \& Esera, 2005, p.49).

ICT integration into education in Samoa started with the existence of computer resources for students in some schools, which necessitated the arrival of Peace Corps Volunteers to teach student Computer Studies. This seems to have developed sporadically over the years since the establishment of the first secondary school in 1957 and it followed no discernible guidelines. Evidence for this statement can be seen in the current Samoa National Curriculum Policy Framework which lists no national curriculum for Computer Studies for all levels to Year 11 (Samoa MESC, 2006a, p.16). The existing curriculum for Year 12 was developed as recently as 2005 , while the curriculum for Year 13 is determined by an external assessment authority - the South Pacific Board of Educational Assessment (SPBEA). Yet, Computer Studies has been taught in schools since computers were first brought into schools and continues to be taught in Years 911 despite the lack of national curriculum guidelines. As Roebeck-Tuala and Esera note (2005, p.53), the development of Computer Studies as a subject in schools seems to have been determined by the donor provision of computer resources in several schools, and the presence of Peace Corps volunteers to teach the subject.

The issue of erratic development of the computer studies curriculum was further exacerbated by that fact that curriculum development in the area of ICT was not accompanied by a systematic teacher training program. (Samoa MESC, 2006a, p.43). Nevertheless, the Ministry of Education has formulated a policy which states that "provision of professional development for teachers to use ICT in classroom learning will be supported through pre-service and in-service training." (Samoa MESC, 2006a, p.44). At this point in time, it is unclear who will provide the ICT professional development for teachers that the MESC will support through pre-service and in-service training. 
A statement of the problem requires at least an outline of the competing approaches to the integration of ICT in education. Spitzer, Eisenberg and Lowe (1998) have written extensively on the subject and outline two major approaches to the question of ICT in education. The first is the traditional approach, which sees ICTs included in the curriculum as a separate subject either called computer studies or technology studies, and concentrates on the transfer of skills and knowledge regarding the technology (Spitzer, Eisenberg \& Lowe, 1998). The second approach regards technology as tools to be used in the learning process, and focuses on teaching students problem-solving skills through the use of technology. To put it simply, the traditional approach, that of ICT as a separate subject, involves students learning about technology; the second approach involves students learning through technology and therefore aims for across the board integration in all subject areas. The latter approach is supported by findings that "ICT alone does not enhance learning; rather it is the way in which ICT is incorporated into the various learning activities that is of fundamental importance. (John \& Sutherland, 2004, p.102; cited in Pachler, 2005, p.192). The realization that there are two possible approaches to the integration of ICT in education; and that one is superior to the other given the goal of education to create lifelong learners, alerts one to the fact that what teachers think and do with regards to ICTs in teaching and learning is of vital importance.

A growing body of research indicates that teacher perspectives influence how and to what extent ICT is integrated in education (Albirini, 2004; Baylor \& Ritchie, 2002; Czerniak, Lumpe, Haney \& Beck, 1999; Hennessey, Ruthven \& Brindley, 2005; Niederhauser \& Stoddart, 2001; Olson, 2000; Sugar, Crawley \& Fine, 2004; US Department of Education, 2000; Veen, 1993; Wabuyele, 2003).

Equally important, research recommends that professional development for teachers in the area of ICT should be informed by teacher perspectives (Ertmer, Addison, Lane, Ross \& Woods, 1999; Lumpe \& Chambers, 2001; Olson, 2000). 
No one has perhaps put the reason as well as Fullan, well known researcher of educational change processes, who stated that "educational change depends on what teachers do and think - it's as simple and as complex as that" (1982, p.107).

The recent SchoolNet initiative placed computers and an assortment of other ICTs in 5 schools in Samoa which previously did not have these resources. This initiative had the aim of piloting a particular model of ICT integration in schools, with the view to extending this to other schools in Samoa over a period of time. It is within this setting that this research took place, at one school chosen as a case study.

This study obtained insight into the perspectives of teachers and administrators in Samoa regarding Information and Communications Technologies in education. These perspectives are very much needed in light of the fact that no such research has been carried out among Samoan teachers. As outlined above, research indicates that teacher perspectives on ICT affect how ICT is integrated in teachers' professional practice, and should therefore inform teacher training and professional development. It is hoped that the result of this research will assist in informing decision-making regarding the integration of ICTs in schools in Samoa. Similarly, it is hoped that perspectives gained from this study will be of some assistance in the future development of technology training opportunities for teachers, outlined as a priority area in policy documents (Samoa MESC, 2006a).

\section{RESEARCH QUESTIONS}

\section{Question One}

How do teachers in Samoa perceive the use of information and communications technology in education? 


\section{Sub-questions}

a) How do teachers in Samoa perceive government policy regarding ICT in education?

b) How do teachers in Samoa perceive government initiatives to integrate ICT in education?

c) How do teachers in Samoa perceive the role that ICT plays in student learning?

d) How do teachers in Samoa perceive the role that ICT plays in teacher practice?

\section{Question Two}

What are Samoan teachers' perceptions about how they manage factors that encourage or inhibit use of ICT to enhance student learning?

\section{Sub-questions}

a) What are Samoan teachers' perceptions about how they manage perceived obstacles to the use of ICT to enhance student learning?

b) What are Samoan teachers' perceptions about how they manage factors that encourage the use of ICT to enhance student learning? 


\section{SIGNIFICANCE OF THE STUDY}

The integration of information and communications technologies in education occupies a growing body of research in the field of education. However, to date there has only been a handful of research studies conducted in Samoa within this area, and these were mostly at the instigation of an institution outside Samoa with vested interest in Samoa's development.

This research is significant for the following reasons. Firstly, the findings of this study will have implications for staff professional development programs in schools that already have ICT resources as well as those that will be equipped with such in the near future. Secondly, while the emergent issue of ICT integration in Samoan schools already has implications for teacher training programs, the results of this study will provide relevant case study background information for the designers of such programs. In addition, this study collected and synthesised a considerable body of literature regarding ICT integration in schools, which may be useful in helping school administrators and teachers determine their response to the government drive to integrate ICTs in schools.

This research is equally important for the reason that very little literature exists regarding the integration of ICT in developing countries in the Pacific, with their unique resources and constraints. This study will therefore contribute to knowledge and research in this field. Finally, this study bears significance for its relevance at a time when the aim of technology integration is aggressively pursued as a government aim, and when the implementation of the SchoolNet project in five pilot schools in Samoa is finally completed. 


\section{LIMITATIONS OF THE STUDY}

This research focused on the perspectives of teachers in Samoa regarding the integration of Information and Communication Technologies in schools using a case study of one secondary school. There is a limitation in that the study did not account for the perspective of teachers from primary schools or tertiary institutions. In addition, the participants were from a school in the urban area, which negates the perspective of teachers from a rural school. Furthermore, the study may have benefited from a consideration of student perspectives of the integration of ICT, but this was not included as it was considered outside the scope of the study. This being the case, an analysis of student perspectives may have helped in developing a well-rounded consideration of the issue.

\section{DEFINITION OF TERMS}

The definition of Information and Communication Technologies used in this study is that used by Farell (2003, p. 5) which covers "not only the newer digital technologies of computers, Internet, e-mail, World Wide Web, wireless, etc, but also the older technologies of print, radio and television that have been used extensively in both distance education and classroom instruction".

The term 'teachers' refers to teaching staff, and the term 'administrator' within this study refers to the school principal.

In addition, the following acronyms are in use throughout the study.

ACOT: Apple Classrooms of Tomorrow

ADB: Asian Development Bank

AUSAID: Australian Agency for International Development

CROP: Council of Regional Organizations in the PACIFIC 
ICT: Information and Communication Technologies

MESC: Ministry of Education, Sports and Culture

NUS: National University of Samoa

NZAID: New Zealand Agency for International Development

PCV: Peace Corps Volunteer

PIFS: Pacific Islands Forum Secretariat

PITA: Pacific Islands Technology Association

PSSC: Pacific Senior School Certificate

SPBEA: South Pacific Board of Educational Assessment

SSC: Samoa School Certificate

USP: University of the South Pacific

\section{ORGANISATION OF STUDY}

This report is organized into six chapters: introduction; literature review; research methodology; description of findings; analysis and interpretation of findings and the final chapter will outline implications and areas for future research. Chapter One includes a background of the education system in Samoa, the current status of ICT integration in the curriculum and access, and a description of the SchoolNet initiative. It also contains the statement of the problem, the significance and limitations of the study. Chapter Two provides a review of the existing literature on the integration of ICTs in schools, and Chapter Three focuses on the research methodology, framework and design, as well as a description of the site of research. Chapter Four describes the findings obtained and Chapter Five is an analysis and interpretation of the research findings. The final chapter outlines the implications of the research findings for policy, practice and research which emerged from the study. 


\section{CHAPTER TWO \\ LITERATURE REVIEW}

\section{INTRODUCTION}

The literature on the integration of Information and Communications Technology in teaching and learning has proliferated corresponding with increased concern among educators that this educational innovation needed extensive research basis to support its implementation. As this research project concentrated on the perspectives of teachers on the integration of ICT in a particular setting, the literature review leans towards, but is not limited to, research carried out on teachers and their interaction with ICT in teaching and learning.

This literature review is divided into six themes as follows: ICT in education; background and outcomes; the interaction of ICT and teaching and learning, which is in itself subdivided into three sub-themes; the teacher and integration of ICT in teaching and learning; other factors (apart from the teacher) influencing the integration of ICT in teaching and learning; teacher professional development for integration of ICT in teaching and learning, and ICT and pre-service teacher training.

\section{INFORMATION AND COMMUNICATION TECHNOLOGY IN EDUCATION: BACKGROUND AND OUTCOMES.}

It is generally acknowledged that integrating Information and Communication Technologies in education has not resulted in the great reform of education that many expected would take place (Cuban, 1986; Cuban, 2001; Geoghegan, 1994, 
Watson, 1998; Pelgrum, 2001). Cuban's (1986) research in the 1980s on U.S. teacher use of instructional technologies including the use of film, radio and instructional television concluded that while many millions of dollars had been spent on placing these technologies in the classroom, teacher use of these technologies for student learning was far from being commonplace in schools. In addition, Cohen (1987, p.153) made the statement in 1987 that "new technology is an old educational enchantment" and noted that new technologies had failed to revolutionise education contrary to expectations. Researchers such as Geoghegan also lent support to Cuban's (1986) and Cohen's (1987) observations on development of technology use in education. At an address in front of the $22^{\text {nd }}$ Annual Conference of the International Business Schools Computing Association, held in Baltimore, Maryland, Geoghegan (1994) made the observation that instructional technology had failed to deliver the revolution in teaching and learning that its proponents claimed would happen, and that technology had not been integrated into education past its use as basic tools.

As the years progressed, so did the number of researchers speaking out about the perceived failure of Information and Communication Technologies to deliver on its promise to transform education. Editors of the highly regarded academic publication, the British Journal of Educational Technology, observed that the billions of dollars spent by Britain since the 1970s to place ICTs in schools had brought little return in terms of educational achievement or innovation (Nichol \& Watson, 2003). They also noted that although this had been the feedback consensus of academic researchers in Britain since the 1980s, political optimism regarding the potential of ICT to transform education prevailed and continued to direct spending and policy in this area. Conlon and Simpson (2003) had concluded in their analysis of two schools considered to have high access to information and communication technologies that, while instructional technologies were an everyday feature of classroom teaching and learning, their role was still separate, and not integrated into the teaching and learning process. 
However, the feedback concerning technology integration into teaching and learning has not been completely negative. A project by the title of 'Apple Classrooms of Tomorrow (ACOT)' (Dwyer, 1994) observed over a period of 8 years the changes in classroom teaching and learning that occurred in U.S. schools where computers had been provided for home and class use for both students and teachers. According to their findings, the way teaching and learning occurred in the classroom underwent a dramatic transformation in that time period. Students became highly adept at manipulating computers in order to solve problems and produce projects, individually and in groups, and therefore displayed development of higher order thinking skills. Teachers as well started taking on the role of facilitator and became proficient at using the technology for personal use, teacher preparation and classroom learning. In the ACOT classrooms therefore, the integration of technology experiment was highly successful.

Nevertheless, the ACOT report (Dwyer, 1994) seemed to be the exception, not the rule, in the attempt to reform education through the integration of information and communication technologies. It was only inevitable then, that educational researchers would query why technology had made so little impact on teaching and learning. Cohen (1987) discussed the perceived failure of technology integration by way of examining the usual explanations for it. He convincingly rebuffed the explanations that sought to pin the blame on school organization, flaws in the reform itself (such as insufficient resources) and lack of incentives for innovation in teaching. Instead, he offered explanations for the continued dominance of traditional modes and methods of teaching which make minimum use of technology.

Firstly Cohen (1987) explained that it is difficult to sustain innovation in a profession where there is an age-old tradition of teaching as the 'telling' of objective truth. In addition, community and social practices depend on the same 
methods to pass knowledge; community and social practices therefore support traditional methods of teaching and learning. Finally, the reform effort is negated by the fact that .many changes in practice require new knowledge. (Cohen, 1987, p.163). However, the institutions responsible for creating and disseminating this new knowledge, (universities in particular), are either not interested or are not able to communicate the necessary knowledge to schools and related organizations. In fact, many of them follow the same traditional teaching practices that the integration of technology seeks to modify.

Cohen (1987) therefore suggested a historical perspective in any analysis of educational innovation. He also made the comment that policies "are interventions into established patterns of social relations", and urged policywriters and analysts towards a multi-disciplinary perspective in order .to enrich our understanding of how innovative policies and programs work. (Cohen, 1987, p.169).

Watson (1998) also raised the question of the perceived failure of the technology integration reform, and proposed answers that deviated from those proposed by Cohen (1987). Watson suggested that "one major factor has been the confusion of purpose about the role of IT in schools, and how best that might be addressed" (Watson, 1998, p.187). Watson's (1998) research indicated that teachers were reluctant to adopt ICTs, partly in objection to the widespread notion that technology should be in schools in the midst of insufficient evidence to support its usefulness in education.

In addition according to Watson, teacher rejection of the idea of technology integration was in itself due to "a complex intertwining of the technocentric focus, real barriers to change and professional unease. (Watson, 1998, p.187). Watson concluded that the current deficit model of teachers was behind the failure of technology integration. She suggested that the focus ought to be taken off the technology and placed on pedagogy; professional reflection would then identify 
strategies for capacity building and areas where support ought to be concentrated. The last crucial factor was an understanding of the needs of teachers, in order to plan for effective technology integration (Watson, 1998).

Other researchers have carried out medium scale studies in schools that shed light on the inadequate results of placing technologies in classrooms. Cuban, Kirkpatrick and Peck (2001), conducted a research study in two American schools to examine why a pattern of low usage of ICTs seemed to persist in schools considered to have high access to ICTs. They offered two explanations which have policy implications. Firstly, they proposed that technological integration in schools was a 'slow revolution' that took time to gather momentum after invention of the technology. In this case policy should aim to speed up the process. The second explanation for the discrepancy of high access with low use of ICTs was that the organisation of schools themselves presented rigid barriers to the integration of ICTs. They pointed out that the historical development of high schools as institutions which employed specialists in discrete subject areas to teach students during segmented portions of the school day, have established inherent barriers to the integration of technology. In this case, "fundamental changes would need to be made in how schools are organized, how time is allocated, and how teachers are prepared" (Cuban, Kirkpatrick \& Peck, 2001, p.830).

While Cuban, Kirkpatrick and Peck (2001) entertained the theory of the slow revolution (2001), Cuban (2001) in his landmark publication 'Oversold and Underused: Computers in the Classroom' discarded the 'slow revolution' explanation for the lack of educational reform resulting from technological integration in schools. Cuban (2001) pointed out that the 'slow revolution' explanation is not sufficient to explain why teachers use their home computers to a far greater degree than in school, and why they persisted with traditional modes of teaching even after becoming very skilled in the use of computers and other technologies. Alternatively, Cuban (2001) suggested that a combination of 
historical factors and current constraints pose an effective barrier to the widespread integration of ICTs in teaching and learning. Historical factors included parent and community beliefs about what constitutes education, as well as policies that govern the allocation of funding in schools, whereas constraints on teachers include class length and timetabling, subject demarcation and curriculum requirements (Cuban, 2001). As it is, Cuban's discussion of the issue mentions factors that more or less agree with Cohen's (1987) earlier analysis of the status of ICT integration in schools.

Another important study was carried out by Conlon and Simpson (2003), who carried out a comparative analysis of two studies aimed at assessing the impact of information and communication technologies on teaching and learning in schools in the US (Cuban, 2001) and Scotland (Condie et al, 2002). They found out that, although information and communications technologies may have been in adequate quantities in some schools, there was evidence to show that their use was limited to reinforcing instead of reforming existing pedagogies (Conlon \& Simpson, 2003). They went further to look for explanations and identified several factors.

From the Scotland study, the analysis identified: unrealistic demands on teachers time and energy; insufficient and inappropriate infrastructure; inadequate skills and a deficiency of motivating examples of pedagogy and teaching aids. From the U.S. study, it was apparent that inbuilt obstacles such as the separate and independent classroom, beliefs about what teacher work involves, school timetables and infrastructure constraints guarantee that ICT integration will not effect more than basic changes in patterns of teaching and learning in schools.

A study conducted by Tearle (2003) in a different school submitted findings similar to Conlon and Simpson (2003) and Cuban, Kirkpatrick and Peck (2001). Tearle (2003, p.579) noted that "although ICT use had permeated the curriculum, there were few signs of radical alteration to existing structures and working 
practices, or even evidence of particularly innovative application of ICT to enhance and extend learning opportunities". Tearle's (2003) report therefore raises the question of whether this is a necessary stage in a school's adoption of ICT towards fully integrated ICT where presumably teaching and learning practices would be radically altered. Such a question is not unlike Cuban, Kirkpatrick and Peck's (2001) proposal that technological innovation in schools was similar to a slow revolution that took its time but would eventually come to pass.

At the same time as researchers noted the lack of meaningful integration of technology in schools, policymakers and government spokespersons continued to extol the virtues of technology in schools. For instance, the Scottish Department of Education had this to say for a multi-million dollar project called the National Grid for Learning aimed at upgrading the status of technology in UK schools.

The NGfL will change the face of education in Scotland by integrating the new information and communications technologies into the process of teaching and learning (Scottish Office, 1998).

Cited in Conlon \& Simpson, 2003, p.144.

The Asian Development Bank (ADB) which sources much of the funding for the development of education in the Pacific has the following perspective.

...the need to improve the intergenerational and international transfer of knowledge and skills to the more than one billion young people between 5 and 24 years of age in the Asia-Pacific region requires the adoption of the new learning technologies that are already widely used in developed countries.

Loxley \& Julien, 2004, p.v.

Kerr (2005) provides a refreshing viewpoint in the literature with his exploration of why people are so enamoured of technology in education. He used the metaphor 
of a 'meme' which originated in Richard Dawkins' (1976) book entitled 'The Selfish Gene' to discuss how the idea that technology is highly beneficial in schools develops and disseminates among people. A 'meme' refers to "a cultural unit that individuals rapidly take up and pass along to others" (Kerr, 2005, p.1007). This cultural unit "is simply an idea, perspective or image" (Kerr, 2005, p.1008). He suggests that the integration of technology in education is a 'meme', a catchy and appealing idea that has so inspired people that they endeavour to pass it on to anyone within their sphere of influence. Such an understanding holds the implication for educators that, instead of looking at the best way to integrate ICT in education because of notions about the benefits of ICT, educators should consider the purpose of education first before considering how to use ICT to support this purpose.

This is not to say that Information and Communication Technologies do not enhance the teaching and learning experience for students as well as teachers; in fact quite the contrary as outlined in the research perspectives that follow.

\section{THE INTERACTION OF ICT AND TEACHING AND LEARNING}

\section{ICT use and the link to Constructivist Teaching}

Constructivism is based on the assumption that people create knowledge as a result of interaction between existing knowledge or beliefs and new knowledge.

Rakes, Flower, Casey \& Santana, 1999.

Rakes et al (1999) propose that a constructivist approach to teaching and learning is more compatible with the use of Information and Communications Technologies than other teaching approaches because ICTs can be the medium through which students interact with new knowledge. Students can locate, organise, synthesise and present knowledge using a variety of technology, with 
the teacher present to guide and provide assistance in this learning process. Rakes et al (1999) further advocate that successful integration of technology in teaching and learning presupposes a constructivist ethic, which provides room for the varied utilisation of such tools.

Nowhere did this notion receive more support than in the ACOT (Dwyer, 1999) experiment, which examined the behaviour of teachers and students in classrooms across the United States after they were provided with computers for home and school use. Dwyer's (1999) report was replete with examples of how teachers' pedagogies altered over time to incorporate more student-centred strategies, as teachers learnt to be flexible and allowed students to interact with new knowledge through the medium of the computer. Teachers thus developed in their roles as facilitators as students developed skills in problem solving and critical thinking, Such a transformation describes a development toward a more constructivist way of thinking, teaching and learning, and this is what some researchers argue occurs when technologies are placed in the teaching and learning process.

Becker and Ravitz (1999) also acknowledged the strong positive correlation between effective use of computers and the development of a constructivist orientation to teaching and learning. In a study aimed at explaining this relationship, Becker and Ravitz (1999) found that while teacher use of technology depends upon particular teacher perceptions regarding technology in education, these teacher perceptions were not static and in fact changed over time. Even more significant was the fact that,

Those teachers who use computer technology regularly with students, over many years, and with student productivity goals (rather than knowledge-absorption or skills-mastery goals) in mind, and who exploit new technological resources such as the Internet, are the same teachers who report having made important changes in their teaching practice and who report changes in the students they work with.

Becker \& Ravitz, 1999. p.376. 
As the first explanation of why teachers' behaviour and beliefs changed when using technology over time, Becker and Ravitz (1999) suggested that teachers learn from experiments with technology, and when they see effective learning taking place, they adopt the behaviour and their beliefs change regarding the usefulness of technology, giving rise to a "theory of technology-induced belief change" (pp.376).

They also made the suggestion that, teachers who reported changes in their practices may already have had constructivist-oriented beliefs but may not have been able to act on these beliefs due to limitations beyond their control, such as inadequate access to technology, giving rise to a "theory of facilitating conditions" (pp.376). Or, as they suggest, it may be due simply to the fact that teachers who are more prone to experiment with their teaching style are also more open to experimenting with new technology, and are therefore more likely to make changes in their teaching practice.

\section{ICT in Teaching and Learning}

A widely publicised report on experimental classrooms where teachers and students had been provided with a computer for home and another one for school use (Dwyer, 1994), demonstrated the changes in teaching, learning and school culture when computers were provided to teachers and students in adequate quantities. It found that over time, both teachers and students became proficient at using computers to solve problems and address tasks and started to interact with each other differently. As teachers started taking on the role of guide rather than always being the source of information, they started trying out different modes of teaching and learning and assessment. Students in turn started exhibiting highly developed skills of collaboration, problem solving, organisation, understanding of complex systems and manipulation of technology. While achievement scores on standardised tests did not change significantly, the 
changes were noted in the kinds of skills acquired by students and teachers. At the completion of the research project, most teachers displayed a constructivist orientation to their practice. While the study also boasts that technology "engages students systematically in higher-order cognitive tasks", (Dwyer, 1994, p.9), perhaps this attributes to technology agency it does not possess and which should be credited to the teacher, as the facilitator of this learning experience.

While Dwyer (1994) outlined the dramatic changes that occurred in the teaching and learning setting with the provision of technology, Cuban, Kirkpatrick and Peck (2001) found that less had changed in other settings with high access to technology. A study of the patterns and form of computer usage by teachers at two schools in the U.S. with high level access to information and communications technologies by Cuban, Kirkpatrick and Peck (2001) found that for the majority of teachers, the availability of technologies had modified their teaching in terms of efficiency, modes of communication and sources of information. However, of this number, less than a third had changed their pedagogy in fundamental ways such as adopting a more student-centred approach. The findings from this study reflected national findings in the U.S. - that increased availability of ICTs did not necessarily result in a pedagogical shift towards student-centred learning.

Gallini and Baron (2001) also noted in their study of a course that had incorporated web elements in its structure that contrary to expectations, the inclusion of web aspects did not result in changes to the course structure, but instead became an addition to it. From the same study they reported that instructors and students were more interested in their web courses than their non-web courses.

Bottino (2004) also examined one aspect of technology integration, that of educational software, which is different from web-integration as discussed by Gallini and Baron (2001). In an analysis of the various forms educational software has taken over the years, Bottino (2004) noted that this developed in 
three stages. The first forms of educational software developed as the transmission model, then as a learner-centred model, and lastly as the participative model (Bottino, 2004, p.555). Bottino explained that ICT integration in the transmission model used ICTs to develop and reinforce student skills, which also makes up the majority of educational software in retail. As this developed into learner-centred forms, discovery and problem-solving became features of educational software. However, the latest trend has been to consider the teaching and learning process from the teacher's perspective, taking into account the social, organisational and curriculum context (Bottino, 2004). Bottino's discussion may also have implications for research into constructivist teaching and technology (Rakes, Flower, Casey \& Santana, 1999; Becker and Ravitz, 1999) given its stance on the development of software integration models in the form of learner centred and participatory frameworks.

Whereas the previous literature examined all forms of available ICTs within the school setting, the discussion that follows is focused on one type of ICT, specifically the PowerPoint presentation tool.

Adams (2006) analysed the phenomenon of PowerPoint, the habits of mind it engenders and its relationship with classroom culture. She drew attention to the fact that PowerPoint presented information via a medium that reduced this information to a set of bulleted points, and presented students with information that has already been selected as important. In doing so, Adams argued that the use of PowerPoint encouraged linear and reductionist thinking amongst students, at the cost of the development of multi-directional and analytical thinking skills which are seen as one of the main aims of the educational experience. In support of this theory, she presented extracts from dialogue with students which, as examples, imply that students consider information not contained in the PowerPoint presentation to be irrelevant, and that students sometimes felt constrained by it because it proceeds in only one direction and does not facilitate discussion. 
However, Adams (2006) urged that the technological possibilities of PowerPoint can be utilized by the reflective practitioner to stimulate higher level thinking, as long as he/she moves beyond the default templates to mold PowerPoint to the learning objectives that he/she wants to achieve. Not only that, but the reflective practitioner must be prepared to diverge from the PowerPoint, for moments will present themselves in a lecture or class when it will be better to address students' questions at the cost of following the PowerPoint slide sequence. Underpinning Adams analysis is the idea that; "each new technology embodies a form of thinking that orients a person to approach the world in a particular way" (Adams, 2005, p.390 following Apple, 1991, p.75).

Vallance and Towndrow (2007) perceived Adams' (2006) analysis to be overly pessimistic and argued that PowerPoint or any other technology can be consistently used to enhance learning than would otherwise be possible without the use of technology. They explained that this is done by 'informed use' of the technology by teachers and practitioners. 'Informed use' involves self-reflection upon the part of the teacher/lecturer and prompts them to ask questions such as - 'Why am I using this particular technology in this way in this part of the lesson?' In addition, 'informed use' prompts teachers and lecturers to reflect on the perceived usefulness of each type of technology and how to use it most effectively to achieve set learning goals for each activity. In this way, Vallance and Towndrow contend that "it is possible for teachers to elevate content above form, develop higher intellectual thinking skills and positive habits of mind, respond positively to the unexpected and allow significance to be highlighted in information-gathering and knowledge-construction" (p.226) even when using technology such as PowerPoint.

Adams' (2007) subsequent response to Vallance and Towndrow (2007) suggested that their perspectives were not at all in conflict. She explained that teachers should be cognizant of the little understood power of technology and 
structures to mediate, determine and perpetuate particular frames of thinking. She gives an example of how the blackboard at the front of the classroom encourages a different pedagogy compared to the colourful desks of an art classroom, the stainless steel tables in a science lab and the tiered seats in a lecture auditorium. All lend themselves to define how teachers and students see themselves and the learning process. Adams' (2007) encouraged research of the relationship between humans and technology pointing out that it is little understood. Her concern was that "teacher education and professional development programs tend to treat ICT merely as tools that, when deployed effectively and with sufficient saturation, promise to enhance pedagogy, student ICT literacy and academic success" (p.230). Furthermore, Adams (2007) pointed out that while ICT may not and should not determine how we teach' it has already influenced how we think about teaching before we consider activities and lessons - and it is this pervasiveness that she urges educators to keep in mind. Thus Adams' successfully restores balance to the argument for using technology in teaching and learning, using the example of the PowerPoint presentation technology.

There has also been discussion on technology integration that is of a different nature from that previously mentioned, which focuses on the actual process of technology integration and how it occurs over time. Following Rogers (1983) and Moore (1991), Geoghegan (1994) explained that the dissemination of technology through a society occurs over time with the number of people adopting the technology showing up like a normal distribution curve; it begins with a few Innovators, increases with early Adopters, then decreases with Later Adopters before tapering off with Laggards. Geoghegan claims that the market of innovators and early adopters has been saturated, but no inroads have been made in convincing the later adopters and laggards to take up instructional technology. He lists the reasons for this which are: ignorance that a gap exists between the early adopters of instructional technology and mainstream practitioners; the one-size-fits- all approach by all involved in promoting 
instructional technology does not address needs of mainstream instructional faculty; mainstream faculty have been alienated due to their reluctance to take up instructional technology and teachers are not sufficiently convinced of the benefits of software or different instructional technology. Geoghegan subsequently recommends a solution which involves: recognition of mainstream faculty needs and voices, an approach that includes the notion of peer support; provision of a compelling reason to buy and use instructional technology and institutional commitment to integration of instructional technology.

\section{Teacher and Instructor Perceptions of ICT in Teaching and Learning}

A number of research initiatives have been carried out recently which focused on teachers' and instructors' perceptions of technology use in education. Some of the notable ones are outlined below.

Research carried out in the United States by Brill and Galloway (2007) to examine lecturer use of instructional technology and their perceptions of such technology found that instructors perceived technology to have had beneficial impacts on the instructional setting. Within the context of a public university, instructional technology,

...facilitates the clear and elaborate presentation of information to students; enables the showing of numerous and complex examples; enhances the engagement/attention of students; encourages student-student and student-instructor interaction; and provides structure and support to the in-classroom experience.

Brill \& Galloway, 2007, p.100.

Instructors also discussed barriers to their use of instructional technology and these consisted of incompatible classroom environments and insufficient equipment to cater for needs of instructors. Levin and Wadmany's (2006) research into teacher beliefs and how they affect teacher practice within a 
technology-rich classroom environment has also added valuable knowledge in this area. They carried out a qualitative study of teachers within a school in central Israel that had recently implemented major changes in order to have technology-based teaching and learning. They found that teachers' beliefs regarding teaching and learning changed over three years within a technologyrich environment, and these changes had manifested in modified classroom behaviour.

Equally important, they found that as teachers' beliefs changed, so did their perceptions of how technology fit into the process of teaching and learning. For instance, the teacher belief that education was for the purpose of transmitting knowledge to passive learners in order to fulfil curriculum and policy requirements corresponded with views of technology merely as a support to that process. On the other hand, as this belief changed to a more constructivist orientation, teachers became more reflective of how technology could be used to enhance student engagement in the learning culture. Furthermore, Levin and Wadmany (2006) pointed out that teachers react in varied ways to new ideas regarding the use of ICTs in teaching and learning, and may hold multiple views at once, which can and do change under the right circumstances. For some teachers in the study, their beliefs changed from a behaviourist orientation to a constructivist orientation.

Nevertheless, there were many supporting factors that may have made the difference in the development of teacher beliefs. As already mentioned, the environment was already well equipped with the necessary technology in adequate quantities. In addition, the school developed a professional development strategy including mentoring of teachers which included: the provision of the requisite support materials; demonstrations of learning activities and research tools were carried out for teachers, and university personnel with expertise in educational technology and subject areas were available to mentor and assist teachers in implementing the reform (Levin \& Wadmany, 2006, p.163). 
The above findings should therefore be considered in conjunction with the support factors listed above, as evident in Levin and Wadmany's research (2006).

The theme of change in teacher beliefs highlighted by Levin and Wadmany (2006) is also apparent in a study by Hennessy, Ruthven and Brindley (2005) of subject faculties of four English secondary schools with average access to technologies compared to national levels. The study aimed to find out how English teachers in secondary schools were going about the process of integrating information and communications technologies in education. Although the research concentrated on English teachers' perspectives, it also included findings on the perspectives of Math and Science teachers. The research found that teachers were generally committed to using ICT in the classroom although this was tempered by structural constraints such as the availability of ICTs, as well as curriculum pressures embodied in examinations for which they had to prepare their students, as well as assessment regulations. Secondly, "while there was a feeling of inevitability and acceptance of the role of technology, the teachers simultaneously portrayed a reflective and critical outlook" (p.185). That is, they expressed caution regarding the use of technology, in terms of undiscerning use, the need to keep learning goals uppermost, and the possible repercussions for subject cultures.

An equally significant finding from the study was that the theme of 'change' was highlighted in teachers' discussions. Teachers were reflective of the changing context of teaching and learning and were responding with changes in pedagogy and thinking. The study therefore concluded that English, Math and Science teachers were reflecting on the place of technology in their subject areas, and were trying out new ways of teaching and learning that included technology. Just as important, Henessy, Ruthven and Brindley (2005) recommended that teacher involvement should be at the centre of technology integration in teaching and learning rather than the technology itself. 
Albirini (2004) provided a developing country perspective in his study of Syrian teacher attitudes toward ICT. Albirini argued that, while teachers have mostly positive attitudes regarding the integration of technology in schools, merely providing schools with technology will not achieve the changes mandated by government policy (2004, p.386). He maintained that policy makers must be cognizant of the fact that educational reform will only happen if teachers have positive attitudes towards such a process. In doing so, Albirini implied that plans for the integration of ICTs in schools should take into account teacher perspectives regarding such reform.

\section{THE TEACHER AND INTEGRATION OF INFORMATION AND COMMUNICATION TECHNOLOGIES IN TEACHING AND LEARNING}

Recent research into the relationship between teacher and technology reflects recognition of the fact that the teacher has an important role in the integration of technology in teaching and learning. This facet of the technology integration reform is increasingly under scrutiny, resulting in numerous research reports from educational researchers all over the world. There is even a quantitative instrument for the measurement of teacher attitudes towards computers called the TAC (Teacher Attitudes towards Computers) survey, developed by Knezek and Christensen (2002), the existence of which reflects growing discourse in the area.

Albion and Ertmer (2002) outlined research on the significance of beliefs for human behaviour, which has implications for understanding teacher behaviour and integration of ICT in teaching and learning. Building upon Pajares' (1992) position that human behaviour is more likely to be determined by belief than knowledge, they observed that beliefs lie at the core of teacher behaviour, have been formed through personal experience and are remarkably resistant to 
change. However, while beliefs determine behaviour for the most part, they also noted that changes in beliefs may occur during, and after changes in behaviour.

Regarding the integration of technology in teaching and learning, Albion and Ertmer (2002) suggest that teacher beliefs and therefore behaviour regarding technology integration can be changed if teachers' levels of self-efficacy can be made to increase. Broadly speaking, self-efficacy refers to individual beliefs about the ability to perform a particular task according to prescribed standards. In other words, if teachers' beliefs about what they can and cannot do with technology becomes progressively positive, they will attempt novel ways to utilise technology in their teaching and learning. As an example, Albion and Ertmer (2002) outlined a successful effort to boost self-efficacy levels of pre-service teachers by modeling exemplars of a technology integrated classroom using multimedia applications.

Research by Hadley and Sheingold (1993) in the U.S. found that teachers who extensively integrated technology into their teaching practices experienced changes in their pedagogy as well as in their students' learning. They found that 'the teachers' motivation and commitment to their students' learning and to their own development as teachers" was a key factor in their success with the integration of technology (Hadley \& Sheingold, 1993, p.298).

Hadley and Sheingold (1993) aimed to comprehensively summarise what teachers who used technology were doing as well as how they felt about it. Results showed segmentation into five types with shared characteristics from 'enthusiastic beginners' to 'struggling aspirers'. The study identified three key reasons behind teacher success with technology integration. These were: teacher motivation and dedication to achievement of goals; support from colleagues with integration and satisfactory access to technology in adequate numbers. 
Veen and Sleegers (2006) conducted a study on teacher emotions during times of reform that has relevance to this research. They chose six teachers from a larger sample that had participated in a previous study to explore the ways in which teachers emotionally construed their situation. Veen and Sleegers (2006) adopted a social-psychological approach to examine how teachers experienced the current reforms and how this relationship led to different emotions. The study was carried out in the context of Dutch reforms which asked teachers to: shift from traditional teacher-directed learning to more student-centred learning; take on more responsibility in the school organization via collaboration and participation; and reemphasise the moral dimension in education. The study participants were chosen from the two groups identified as being extremes in orientation to teaching. Three of the participants were from the group identified as having a student-centred learning orientation, and the other three were from the group identified as having a content/teacher-centred learning orientation.

The Veen and Sleeger (2006) study found dramatic differences in the way the teachers from the two groups viewed the reforms and their place within the reforms, as well as differences in range of emotions experienced as a result of the reforms. The teachers with student-centred learning orientation viewed the reforms positively, felt good about the reforms, felt it was more congruent with their own teaching styles and therefore were more committed to its implementation, and felt empowered as a result of the reform. In contrast, the teachers with content/teacher-directed learning orientation were disappointed and angry with the reforms, did not see the relevance for themselves and they way they viewed teaching, were less committed to its implementation and in fact felt disempowered by the reforms (Veen \& Sleegers, 2006).

This study shows that teachers respond differently and will have different perspectives of a reform according to what they consider to be teaching and learning. In turn such perspectives will determine how they react or cope with the reform, and whether they engage in the reform or decide against it. These 
findings have bearing on the context of educational reform in integrating ICTs in education. The implication of Veen and Sleegers. (2006) findings for the integration of ICT in schools is that teachers will respond differently to and have different perspectives of ICT integration according to what they perceive teaching and learning to be. Such perspectives will determine whether they participate in ICT integration or not.

In a three year Canadian study conducted by Goodson and Mangan (1995), teachers readily admitted that "their teaching styles derived directly from their concept of education and its intersection with their personal lifestyles" (1995, p.621). Goodson and Mangan's conclusions therefore support Veen and Sleegers' findings regarding the importance of teacher beliefs for teacher behaviour.

Churchill (2006) conducted a slightly different study to those mentioned above, but his findings echo notions suggested by other researchers. Churchill (2006) researched how teacher beliefs related to their design of instructional materials. He bases his belief in the primacy of teachers' private theories in influencing the way they teach on research carried out in Singapore with teachers considered to be exemplary users of technology. He found that the type of instructional material developed by teachers closely matched their personal beliefs regarding teaching and learning and the place of technology in this process.

Similar to Churchill (2006), a study by Niederhauser and Stoddart (2001) to explore the connection between teacher use of technology software in teaching and learning and their instructional beliefs found that there was a strong correlation between teacher instructional perspective and the type of software used. Niederhauser and Stoddart (2001) surveyed elementary teachers in one state in the U.S. to gather data on their use of educational software and their perspectives of what constituted effective instructional use of technology. They noted that technology in itself does not suggest a particular teaching philosophy, 
but the way it is used as well as the software that accompanies it is directly related to teacher beliefs regarding teaching and learning. What this implies for educational reform is that policymakers should be aware of the influence of teacher beliefs on teacher behaviour. In addition, educators should be aware that educational software is created from a certain perspective of teaching and learning that may not necessarily match teachers' instructional perspectives.

Another study by Czerniak, Lumpe, Haney and Beck (1999) investigated the effect of teacher beliefs on usage of technology in the classroom. The findings of their research supported the view that positive teacher attitude towards any kind of reform was necessary in order for that reform to occur. By implication, teachers will limit the use of instructional technology if they are not convinced of its usefulness in teaching and learning.

Bitner and Bitner (2002) also agree that the teacher is perhaps the most important factor in the process of technology integration in the classroom, but add that they are also perhaps the most disregarded.

Findings by Baylor and Ritchie (2002) support that of Albion and Ertmer (2002) in a study of factors that assisted teachers and student learning in technology integrated classrooms. Baylor and Ritchie found that teacher adoption of technologies in their daily practice was significantly influenced by their level of willingness to change. According to them, "teachers who are open to change, whether this change is imposed by administrators or as a result of selfexploration, appear to easily adopt technologies to help students learn content and increase their higher-level thinking skills" (Baylor \& Ritchie, 2002, p.412). While other factors contributed to student success in content acquisition and development of higher order thinking skills, teacher openness was found to be the all-important determinant of such outcomes. 
Furthermore, Dexter, Anderson and Becker (1999) proposed that the teacher was the most important factor in planning reform in teaching and learning, and not the technology itself. In this way, it adds to Henessy, Ruthven and Brindley (2005) who recommended that teacher participation in the change process, and not technology, be the focal point of ICT integration. Dexter, Anderson and Becker (1999) interviewed 47 teachers regarding their use of computers and their perceptions of the role of computers in the changes they made in their pedagogies. In doing so they examined the assumption that computers are catalysts for change. However, they found the strongest agent of change to be the teachers' reflection upon their own practice and re-consideration of their beliefs about effective teaching. In addition, teachers acknowledged that formal learning experiences were one of the main reasons for their change toward more constructivist practice.

The final main catalyst of change in these teachers' pedagogy was a school culture that emphasized and valued student-centred learning. Dexter, Anderson and Becker therefore argued that teachers must be given time to interact with the technology and develop their own understanding of where it fits in with the process of teaching and learning.

Another research study by Ertmer, Addison, Lane, Ross and Woods (1999) obtained data from surveys, observations and interviews of seven participant teachers to find out their perceptions of how and why they use technology. Underpinning their research were assumptions on the existence of first-order and second-order barriers to change, which was in this case the integration of technology in teaching and learning. First-order barriers are "described as being extrinsic to teachers and include lack of access to computers and software, insufficient time to plan instruction, and inadequate technical and administrative support" (p.54). Second-order barriers are "intrinsic to teachers and include beliefs about teaching, beliefs about computers, established classroom practices, and unwillingness to change" (p.54). The study found that: the 7 teachers used 
technology at different levels of frequency which seemed to relate to how they structured their classrooms; the most common context for technology use was as a learning station located at the rear of the room and technology was used primarily as a supplement to the existing curriculum. Technology was also viewed as a support to the curriculum with the potential of extending the curriculum, but this occurred to a lesser extent.

Teachers also perceived student interest and motivation as an incentive for using technology. They identified the existence of barriers to technology integration in the form of: insufficient equipment, time and technical support, in addition to second order barriers such as irrelevance; lack of confidence and unsuitability for classroom management. These barriers influenced teachers differently although they were commonly experienced. Ertmer et al (1999) concluded that first order barriers and second order barriers interacted and affected teachers differently to limit technology use, although second-order barriers, or those barriers intrinsic to teachers, are more resistant to change.

Other researchers offer additional perspectives on teachers and their role in technology integration. For instance, Sugar, Crawley and Fine (2004) conducted a study of teachers from four selected schools in the south-eastern United States to find out the factors behind teachers' decisions to integrate technology in their classroom practice. They found that the decision to integrate technology was predominantly personal, and influenced by thoughts of students future career and interest. Another publication by the same authors (Sugar, Crawley \& Fine, 2005) observed that since teacher attitude is closely linked to pedagogy, it is therefore desirable to bring about positive teacher attitudes towards the incorporation of technology in teaching and learning. They also noted the necessity of finding out existing teacher attitudes in order to facilitate effective integration of technology in the teaching and learning experience. 
Recent research by Forgasz (2006) in Australia to identify factors that limited and encouraged the use of computers by math teachers in secondary schools supports the notion that favourable teacher attitudes and perceptions are conducive to the use of information and communication technologies to support teaching and learning.

Kian-Sam Hong of Otago University and Chee-Kiat Koh of Serian Secondary School in Malaysia conducted a survey among 200 teachers from rural schools in Malaysia to ascertain their levels of computer anxiety and attitudes toward computers (Hong \& Koh, 2002). They used a quantitative survey instrument to obtain their data. Based on their collected data, they concluded that the majority of teacher surveyed had low levels of computer anxiety - which correlated with positive attitudes towards computers. A key finding from their research is that there was no significant difference in attitudes between teachers who had access to school computers and teachers who did not have access, although it was the opposite for teachers who owned/did not own a computer. Positive attitudes to computers also seemed to be independent of perceived available support from school administrators. A final conclusion from their research is the positive relationship between experience with computers and affirmative attitudes towards computers in education.

Similarly, Kersaint, Horton, Stohl and Garofalo (2003) in a study of mathematics teachers found that teachers needed to feel comfortable with technology before they integrate it into their teaching and learning. This is supported by Bullock (2004) who found out that certain factors enabled or disabled teacher use of technology in teaching and learning, and one of these factors was the way teachers felt about using technology.

Equally important, Dr S.E. Aduwa Ogiegbaen of Southern Nigeria undertook to research teacher perception and attitudes toward technology among College of Education staff from 12 Colleges of Education in Southern Nigeria. He 
recognized that positive teacher attitude was essential for successful implementation of the newly-introduced guidelines for technology integration in Nigeria (Ogiegbaen, 2006).

Pelgrum (2001) adds to this discussion knowledge from a worldwide survey of schools from 26 countries where he identified that among the main factors inhibiting the incorporation of technology in teaching and learning was the lack of knowledge among teachers.

Marcinkiewicz may have touched upon the central issue in this debate with his statement that "...to understand how to use computers, we need to study teachers and what makes them use computers..." (1993, p.9). His research focused on the relationship between teachers' computer use and variables extracted from major themes in the theory on human motivation and decisionmaking (Marcinkiewicz, 1993). Data was collected from a survey of 170 teachers in 4 elementary schools across a state in the eastern U.S. The schools were selected on the basis of their having high access to technology, implying that teachers have had contact with the computers. A quantitative analysis of the results showed that perceived levels of self-competence, willingness to change and motivation were significant on the levels of technology use by teachers. The evidence therefore seems to point toward the importance of understanding teacher behaviour regarding technology before planning for better implementation of technology integration programs.

\section{OTHER FACTORS (APART FROM THE TEACHER) INFLUENCING THE INTEGRATION OF TECHNOLOGY INTO TEACHING AND LEARNING}

Data from a U.S. national probability sample survey (Becker, 1994) of both computer using and non-computer using teachers was analysed to separate exemplary computer using teachers in order to examine how they differed from 
other computer using teachers. Exemplary teachers were differentiated according to whether computers were a significant feature of the student environment and whether these computers were used to achieve higher level learning. It was found that exemplary computer users were more likely to be in: an environment with a high level of collegiality and computer use among staff; a school with highly integrated technology for practical use e.g. printing press; a school that devoted resources to staff and professional development in technology as well as the provision of support for teachers; a school with smaller class sizes.

Becker (2000) analysed the results from a national survey of over 4,000 teachers in the U.S. to examine patterns of computer use and factors impacting on this computer use. Becker (2000) found that the survey results more or less agreed with Cuban that "intractable workplace conditions" were still an obstacle to the productive integration of computers in teaching and learning. In addition, the majority of computer use occurred in computer class or business studies lessons. Becker's (2000) analysis suggested that infrequent use of computers in other subjects were due to: inflexible scheduling in classes of less than an hour; demands on teachers to cover an extensive curriculum; and classroom access to computers. It was found that 5-8 computers in the classroom encouraged more computer use than their centralization in a computer lab with scheduled access that did not consider teacher or curriculum needs. Becker (2000) therefore suggested (amongst other things) that the construction of centralized access to computers is not a productive investment.

Becker also found that teacher limitations in terms of skills and knowledge in the use of computers hindered integration of computers. Teachers with highly developed skills tended to use ICTs more and in varied formats than teachers with less developed skills. Furthermore, teacher philosophy regarding appropriate teaching methods determined whether and how they used computers. While ICTs were used by both constructivist and transmission 
oriented teachers, constructivist oriented teachers were more likely to use them in varied forms, in order to accomplish deeper learning objectives than curriculum coverage. The study therefore concluded that computers and other ICTs are enabling educational tools under the right conditions which are:

...where teachers are personally comfortable and at least moderately skilled in using computers themselves, where the school's daily class schedule permits allocating time for students to use computers as part of class assignments, where enough equipment is available and convenient to permit computer activities to flow seamlessly alongside other learning tasks, and where teachers' personal philosophies support a student-centred, constructivist pedagogy that incorporates collaborative projects defined partly by student interest.

Becker, 2000.

Cuban, Kirkpatrick and Peck's (2001) research into low-level use of ICTs within a high-level access environment identified reasons discussed by teachers themselves for their limited use of ICTs. These included insufficient time to preview and evaluate software, discuss collaborative technology-integrated learning with colleagues, and carry out technology-integrated lessons. Secondly, the training and professional development offered to teachers in the area of ICT was deemed unsuitable for teachers' timetables and context.

Czerniak, Lumpe, Haney and Beck (1999) also argued that support structures in the areas of resources, classroom structures, staff development opportunities and collegial community were essential to the effective implementation of a reform such as the integration of technology in teaching and learning.

Ertmer, Addison, Lane, Ross and Woods (1999) differentiated between first-order barriers and second-order barriers to technology integration, with first-order barriers being those obstacles that are external to the teacher; second-order barriers have already been mentioned in a previous section. External obstacles 
to the integration of ICTs in schools included problems with accessing computers, software and technical support and lack of preparation time to plan lessons.

Geoghegan (1994) also explained several factors that account for the lack of integration of instructional technology. According to Geoghegan, these are: shortage of appropriate equipment and facilities that an instructor may want students to use; flawed expectations of what teachers were supposed to do and accomplish with technology; as well as a disregard for the social and psychological aspects of such a reform on individual teachers.

The importance of technology access in sufficient quantities has been underscored by Henessy and Deaney (2005) who reported on the findings of an interview survey of 16 teachers involved in the TiPS Project in England. The study explored "the extent to which these teachers had, or had not, sustained, developed and disseminated their innovative practices over time and to identify factors that had supported or constrained them" (p.6). Henessy and Deaney (2005) found that the sustainability, development and dissemination of ICTsupported practice was most influenced by whole-school or organisational factors, of which the most important was ease of access to technology resources. Other key factors were organization change and prioritization of ICT by the school, technical confidence and teachers' confidence in the teaching approach encouraged by the use of ICT. Success and learning also stood out as an important motivating factor for teachers in the use of ICT to support teaching and learning.

Another research initiative by Hennessy, Ruthven and Brindley (2005) found that teachers were generally committed to using ICT in the classroom although this was tempered by structural constraints such as the availability of ICTs, as well as curriculum pressures embodied in examinations for which they had to prepare their students, in addition to constraints in the form of assessment regulations. 
Tearle (2003) highly insightful case study of a school considered to have high access to ICT, and where ICT was used regularly in all school subjects identified additional significant factors in the integration of ICTs. The study sought to find out why this particular school had 'risen to the challenge' of integrating ICT, as opposed to many schools which had not done so, despite extensive resource provision. Data was collected using interviews, questionnaires, observations and document analysis. Tearle (2003) found that one of the strongest emergent factors was the way the school responded to external influences. The school's positive attitude towards external influences was enabled by its strong leadership, high expected standards of staff and students, high levels of motivation and positive outlook towards change. An equally important factor was the existence of a model/procedure for school adoption of innovation/change. This factor seems to be the differentiating aspect from other case studies for it provided the school with an actual mechanism for evaluating and adopting change.

Other key events which facilitated school wide integration of ICT were: the construction of modern facilities to house the equipment; the existence of separate funds for technical procurement and maintenance; the establishment of a specific position of ICT co-coordinator and manager and an effective training programme for teachers in the use of ICT (Tearle, 2003). These factors alone are insufficient however; the explanation for this school.s success with technology integration can be seen in the combination of these factors with excellent management and leadership. Furthermore, technology adoption had occurred in stages, so that the ICT coordinator could spend time in each department identifying needs and placing them on the track to ICT adoption. In conclusion, Tearle suggested a model for ICT adoption that involves the vision, culture and organisation of the school as a whole. 


\section{TEACHER PROFESSIONAL DEVELOPMENT FOR INTEGRATION OF ICT IN TEACHING AND LEARNING}

Given that the research literature on integration of technology in education only started attracting widespread attention in the 1980s, the literature on professional development to accompany such initiatives is understandably modest (Lawless \& Pellegrino, 2007). However, the available research on professional development for the integration of ICTs in teaching and learning has yielded some significant findings as apparent in the literature that follows.

Coupal (2004) provides a case study analysis of how politics and power influence educational frameworks for teacher professional development in the area of ICT. It describes two differing approaches to teachers' ICT professional development, which were determined by the political ideology of the party in power in British Columbia (Canada). It is a convincing argument that "the influence of politics produces shifts in educational policy" (p.588). The report describes that when a democratic socialist party was in power, their emphasis on the social and individual needs of people was reflected in a constructivist focus in educational policy and processes. This was in turn reflected in a professional development program that consisted of a research-based mentorship program funded by the government and the materials were developed by teachers. In contrast, the neoliberal party that replaced the democratic socialist party emphasized building a workforce that would meet the needs of industry, which was reflected in a behaviourist focus in their educational policy. The ICT professional development program was altered to consist of ICT- standards that must be used in schools, and professional development was placed in the responsibility of private licensors.

The focus of Haydn and Barton's (2007) research was on an actual professional development program for ICT integration. They trialed an innovative approach to 
ICT professional development which adopted an action research framework that allocated time for teachers to reflect on their own practice in using ICT. In doing so, Haydn and Barton (2007) sought to examine "whether a bottom-up approach based on enabling teachers to develop their own interests in the ICT might be more productive" than the top-down ICT professional development programs currently available in the UK and which were notably unsuccessful. Teachers were given time to work on their own or with others on problems that were directly related to their current practice. While the resulting use of ICT differed between departments, teachers appreciated the programme structure because it gave them time to construct knowledge of a new pedagogy which included ICTs. This resulted in major changes for some teachers and modest changes for others. A significant aspect of this undertaking is that it did not appear to have had any negative feedback from staff. Haydn and Barton (2007) therefore recommended this model for all ICT teacher professional development programs.

A number of researchers have focused on mentoring as one of the factors that contribute to a successful professional development for ICT-integration. Jamissen and Phelps (2006) are two such researchers and their collaboration resulted in a report from the perspective of two teachers who had been involved in ICT teacher professional development initiatives in their respective countries, Australia and Norway. From their critical discussion of the similarities and differences in those initiatives, they are able to make concrete recommendations for other ICT teacher professional development programmes. They identified the critical role of reflection in implementing fully-integrated school-wide change. This "meta-cognitive approach to ICT learning... is founded on the premise that adoption and integration of ICT by teachers is influenced by their attitudes, beliefs, motivation, confidence and learning strategies" (p.296). Secondly, Jamissen and Phelps advocate that mentoring is essential to ICT professional development, with the "mentoring activities... focused on metacognitive support (values, attitudes, beliefs and learning strategies) and not just skill development" (p.303). According to the researchers, these two ideas underpinned the success 
of the projects, with the following as important components of a successful ICT professional development program: school-wide participation and development; scaffolding of teachers at different levels of understanding; mentorship; action research; teacher reflection on teaching and learning; the setting of concrete objectives to achieve and a constructivist perspective.

Swan and Dixon (2006) also conducted research to explore the impact of a mentor-supported technology professional development program on the attitudes and performance of mathematics teachers in south-eastern United States. They used multiple methods of data collection consisting of the TAS Scale, focus groups, technology log books and teacher evaluations. Four things were apparent in their findings. Firstly, contrary to the researchers' assumptions, barriers related to the availability of technology were perceived by teachers as significant barriers. Secondly teachers considered the provided model of professional development useful and expressed intentions to use technology more frequently as a result. Thirdly, teachers acknowledged the need for continued training in technology but evidence pointed to the fact that they wouldn't attend such training if it was seen as irrelevant, or not meeting teacher needs. Finally the research found that teachers were not provided with sufficient release time for planning, training and collaboration. In conclusion, the report pointed out that mentoring and collegial support prior to, during and following the professional development program.

A successful program of professional development for the integration of ICT therefore should include action research (Haydn \& Barton, 2007; Jamissen \& Phelps, 2006) as well as mentoring (Jamissen \& Phelps, 2006; Swan \& Dixon, 2006; Levin \& Wadmany, 2006).

On the usefulness of professional development specifically for the integration of 
ICT, research by Baylor and Ritchie (2002) indicated that professional development made a difference in teacher morale and therefore teacher willingness to embrace innovation in their classroom practice. For this reason, Baylor and Ritchie recommend that professional development initiatives gear towards the needs of teachers, and include exemplars and continuing assistance to support teacher development. Lumpe and Chambers (2001) add that providers of professional development should take note of teacher beliefs in all areas of teaching and learning, in order to plan for effective professional development.

\section{ICT AND PRE-SERVICE TEACHER TRAINING}

Research by Albion (2003) concluded in his proposition that pre-service teachers were strategically placed to bring to fruition the potential of ICT for teaching and learning, as ICTs should be a normal feature of their teacher training program. He carried out a research study conducted among final year Bachelor of Education students to examine how their dispositions towards the integration of ICTs compared with findings from other studies (Albion, 2003). The research participants consisted of half the graduating class and were therefore considered to be representative of the whole class. From questionnaires distributed during tutorials, he extrapolated that the graduating class had considerably better access to ICTs than in previous years and were therefore more comfortable with ICTs. In addition, he found that the student teachers were more positive towards the use of ICTs in teaching compared to student teachers in previous studies and were possibly developing more constructivist orientations to teaching and learning. This led him to the conclusion that due to the above factors, the graduating class of 2002 was better placed than previous years to successfully integrate ICTs into their teaching and learning.

Another research project carried out with pre-service teachers trialed a new technology integrated design for an elementary teacher training program within 
one university (Clift, Mullen, Levin \& Larson, 2001), and arrived at a proposition that supported Albion's (2003) suggestion in the previous paragraph. The aim of the study was to examine the impacts of technology on student teachers and the context in which they worked. Using a qualitative framework over a period of four years among student teachers that utilised multiple data sources such as a survey, interviews, email messages and case studies, Clift et al (2001) arrived at the following conclusions. Firstly, integration of information and communication technologies in the teacher education courses themselves was more productive than having courses in ICTs for student teachers and secondly, they found that the degree of support to teacher education faculty impacted upon student teachers' use of technology. Clift et al (2001) therefore recommended that the role of pre-service teacher education in facilitating change should be maximised in terms of technology integration, and that designers of teacher education programs should deliberately build opportunities for student teachers to share expertise into the program, as this does not automatically occur in reality.

\section{SUMMARY}

This chapter reviewed some of the research literature on selected themes in the ICT in education discourse. The themes were: ICT in education - background and outcomes; the interaction of ICT and teaching and learning - subdivided into three sub-themes: ICT use and the link to constructivism, ICT in teaching and learning and teacher perceptions. The third theme was the role of the teacher and integration of ICT in teaching and learning followed by other factors (apart from the teacher) influencing the integration of ICT in teaching and learning. The fifth theme was teacher professional development for integration of ICT in teaching and learning, and finally ICT and pre-service teacher training. 


\section{CHAPTER THREE \\ THE RESEARCH METHODOLOGY}

\section{INTRODUCTION}

This research explored the perspectives of teachers and administrators in Samoa regarding the integration of information and communication technologies in education. The study places itself within the sphere of qualitative research, within the subset of phenomenological research, while adopting a case-study approach.

\section{CONCEPTUAL FOUNDATION}

\section{Phenomenology}

Phenomenology is one facet of qualitative or interpretive research in which there is "generally an emphasis on consciousness, subjective understanding, or psychological understanding" (Willis, 2007, p.173). Phenomenology reasons that in order to arrive closer to knowing what is real, one needs to find out how humans perceive themselves and the world around them (Willis, 2007).

According to Grbich (2007), the development of phenomenology as a research methodology seems to have progressed in three directions resulting in three types of phenomenology. Transcendental phenomenology, also known as pure phenomenology, is ascribed to Edmund Husserl (Moustakas, 1994; Bogdan \& Biklen, 2007), philosophical (Holstein \& Gubrium, 1998), and focuses on describing the essence of something through phenomenological reduction (Moustakas, 1994). This is phenomenology in its original form which has also been called the European branch of phenomenology (Denscombe, 2007). The second type, existential phenomenology, is ascribed to Martin Heidegger (Willis, 
2007) a student of Husserl, and focuses on the subjective perceptions of human experience (Grbich, 2007). The third type of phenomenology is differentiated from the aforementioned two due to its inclusion of hermeneutic principles and analysis (Denscombe, 2007; Grbich, 2007).

This research falls solidly within the domain of existential phenomenology because it concentrates on individual teachers' perceptions of an experiencenamely, the integration of information and communications in teaching and learning. The phenomenological research paradigm is deemed appropriate to the focus of this research in that it provides the framework for an in-depth exploration of how teachers view themselves within the newly implemented integration of ICTs in Samoa.

\section{Key Assumptions}

According to Willis (2007), the dominant research paradigms in the world today differ according to their foundational assumptions regarding: the nature of reality; what constitutes knowledge; the purpose for carrying out research; beliefs about the type of data that is worthwhile collecting; the approach to data analysis and the relationship between research and practice. The foundational assumptions of phenomenological research are those of qualitative research, which are also the assumptions underpinning this study.

The first and perhaps most important assumption for placing this research within the broad research paradigms is that reality is socially constructed; what is known is shaped by the worldview of the knower and collaboratively negotiated with other individuals (Willis, 2007). Equally important, knowledge is understood within a specific context and may not apply to a different context. As Hoepfl (1997, p.47) explained, phenomenological enquiry "uses a naturalistic approach that seeks to understand phenomena in context-specific settings". 
Consequently, the purpose of research within this paradigm is to achieve understanding (verstehen) of a specific situation or context (Willis, 2007). As Bogdan and Biklen (2007, p.25) elucidate, the purpose of phenomenological research is to "attempt to understand the meaning of events and interactions to ordinary people in particular situations".

This research was designed as an exploration of the perspectives of teachers in Samoa regarding the integration of information and communications technologies in education. While such insight has intrinsic value, the agenda behind such an exploration was a better understanding of the integration of ICTs in schools in Samoa. In this case, the context is a secondary school in Samoa, and the situation for which understanding is sought is the integration of information and communication technologies in teaching and learning.

Appreciation of context is central to carrying out and understanding phenomenological research (Willis, 2007). For this reason, the preferred sources of data in phenomenological research are close to if not within the situation itself. Willis (2007, p.111) has phrased it thus:

For those two reasons - the abandonment of the quest for objectivity and emphasis on the importance of context professional practice knowledge is elevated to a position that is often considered superior to knowledge based on out-of-context empirical research.

In other words, the sources of data for a phenomenological investigation will be participant perceptions of the situation as evident in their own words, and perhaps manifested in their behaviour within the situation. This view is congruent with the phenomenological standpoint which .takes human interpretation as the starting point for developing knowledge about the social world. (Prasad, 2005, p.13). 
In this research, the participants in the phenomenon of technology integration are students, teachers, parents and administration. However, this research has chosen to limit its scope to the perceptions of teachers. In seeking understanding and clarification of teacher perspectives on the issue of ICT in education in Samoa, the study aspired to an exploration of the perceptions of those intimately involved with the issue, as explained in their own words. A bigger scale research over a longer time period would do well to explore the experience and perceptions of all participants in the integration of information and communication technologies in teaching and learning.

Regarding data analysis, Willis (2007) makes the point that understanding the pivotal role of context in phenomenological research data is crucial to the analysis of such data. The findings of qualitative data need not, and in fact does not, seek to be applied to contexts different from where the research took place. However, as Willis (2007) suggests, application of research findings is a reflective process, whereby the choice of how far to appropriate resultant knowledge is the individual's considered decision.

While this research was conducted within the paradigm of, and adopted the tenets of phenomenological research, a case study approach was used in selecting the researching site and in the presentation of research findings.

\section{Case Study}

According to Stake (1998), there seems to be three different ways to conduct a case study due to the differing purposes for carrying out such investigations. An 'intrinsic case study' is one where research is for the purpose of gaining insight into a case with unique characteristics (Stake, 1998). The second type, an 'instrumental case study', is one where a case comes under scrutiny for knowledge it may yield regarding a matter of concern to the researcher (Stake, 1998). In this instance, the case is important because it may assist in 
understanding an issue or application of theory. The last type according to Stake (1998) is the 'collective case study' which utilises multiple cases for examination

of an issue or phenomenon. Finally, Stake (1998) acknowledges that case study research may be conducted within a qualitative or quantitative framework, but that it is essential to define the boundaries of the case as well as the phenomenon being investigated. This study chose a case for research because of insight it may yield on the integration of ICTs in schools in Samoa.

An understandable criticism of case study research regards the generalisability of its findings. However, the aim of this study is to "illuminate the general by looking at the particular" (Denscombe, 2007, p.36). In addition, Stake (1998, p.104) summarised the objective of case study research thus: "the purpose of case study is not to represent the world, but to represent the case". The final report will therefore incorporate enough detail and description regarding the case study to enable the reader to make an informed decision about how far he/she may apply the findings to similar cases (Denscombe, 2007, p.44).

\section{SELECTION OF SITE}

The site for this research was selected using purposeful sampling. Purposeful sampling applies to the selection of "information-rich cases... from which one can learn a great deal about issues of central importance to the purpose of the inquiry", (Patton, 2002, p.230). This school satisfied the criteria of there being .a "high probability that a rich mix of the processes, people, programs, interactions, and structures of interest are present" (Marshall \& Rossman, 1999, p.69). In other words, this school is known for having relatively high access to information and communication technologies, having recently integrated it in teaching and learning. Other criteria for selection recommended by Marshall and Rossman (1999, p.69) and fulfilled at this site included where: there is ease of entry, the 
phenomenon to be investigated is present and the researcher will be able to build rapport with research participants.

\section{SITE OF RESEARCH}

Samoa comprises of 7 islands in the South Pacific, located to the northeast of New Zealand. Its location within the tropical zone means that its temperature averages at 29 degrees Celsius all year round. Schools in Samoa therefore have an early start to the day at $8 \mathrm{am}$ and finish at $2 \mathrm{pm}$ during the hottest time of the day.

Samoa was colonised by Germany prior to 1914, after which they were replaced by New Zealand as trustees of Samoa as a British territory. While there is little remaining evidence of the German colonial influence, New Zealand influence was pivotal in shaping the early years of Samoa's educational development. Education sector reforms from 2000 onwards have resulted in streamlined curriculum that is more appropriate to Samoa's context, decentralised management of schools and upgraded school facilities across the country.

Manuao College (a pseudonym) is located on the smaller of the two main islands of Samoa, on the north-eastern side of the island of Upolu. It was founded as a secondary school in 1954 to serve the district of Vaimauga beginning with Forms 1 and 2 (Years $7 \&$ 8). Manuao Secondary School as it was then called added subsequent levels in the following years but did not offer the senior graduating year; this was only offered at colleges in the country. The school did not offer the School Certificate qualification until 1996, and the PSSC qualification was offered in 2001 after the addition of a 6th Form level. With the addition of the 6th Form level, Manuao Secondary School became Manuao College during the Education sector reforms of 2001. At the present time, Manuao College offers students 17 subjects up to Year 12 level, with 10 offered at Year 13 level. 
The students enrolled at Manuao College are predominantly from the surrounding district, with students enrolling in Year 9 when they leave the primary feeder schools in the district. Prior to the addition of Year 13 or 6th Form, the school roll tended to fluctuate around 300 students. However, since the addition

\section{MAP OF SAMOA}

Source: http://www.lib.utexas.edu/maps/australia/samoa_rel98.jpg

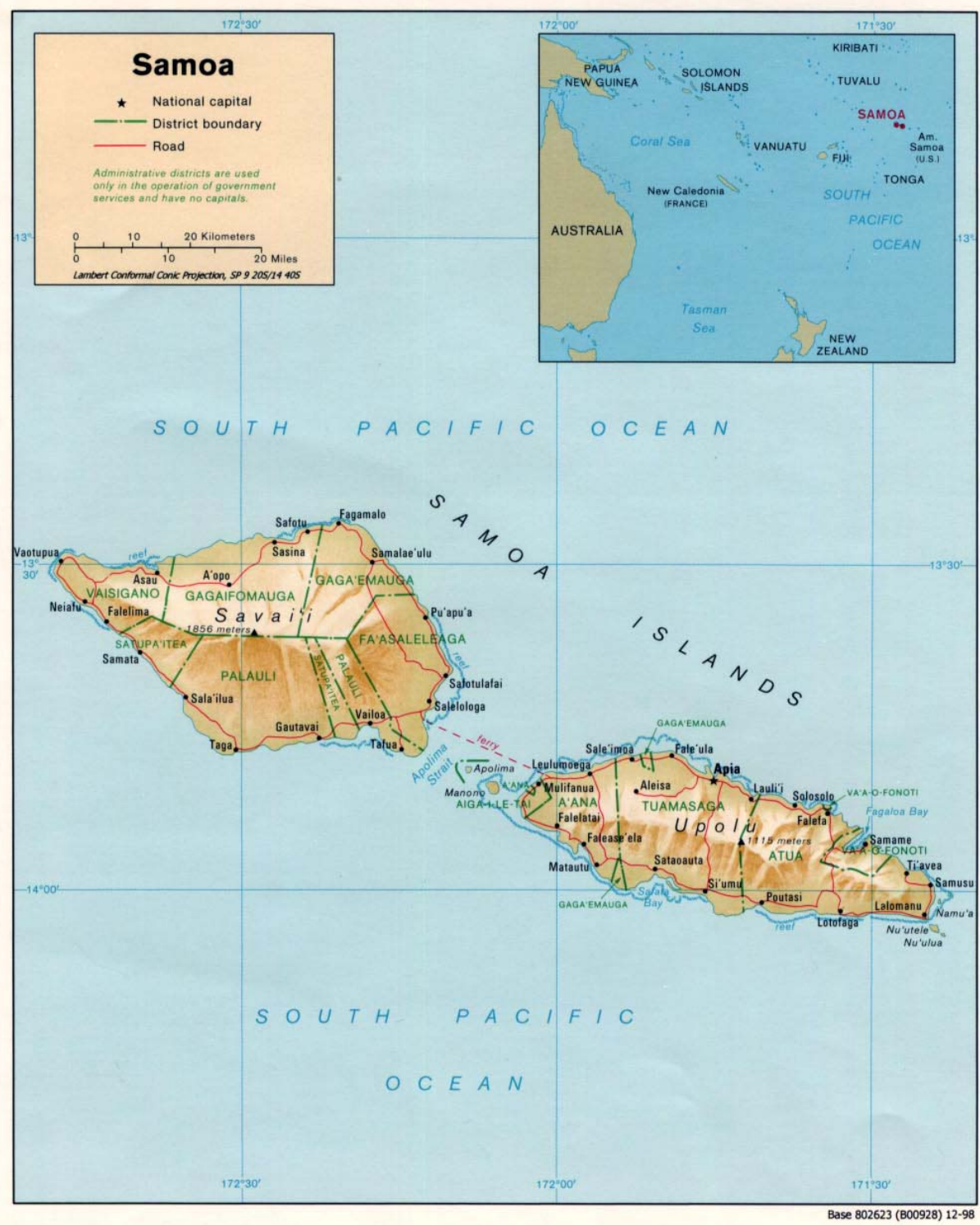


of Year 13 and its subsequent recognition as a college, Manuao College's enrolment increased to an average of 450 since 2001. While the majority of Manuao College students are still from the district, an increasing number are from outlying villages in other districts of Upolu as well as the island of Savaii. This implies that a number of students leave their parents and travel to Upolu to live with relatives and attend the college. During the time of fieldwork for this research, there were 547 enrolled students in the school.

The staff at Manuao College number 34; this figure puts the school within the recommended Ministry of Education guidelines for teacher: student ratio. However, as they only offer 10 subjects at Year 13 level, there is a desire for teachers who can teach subjects that are not yet offered. Nevertheless, Manuao College is well equipped to offer what are known as vocational courses such as Food and Textiles, Visual Arts, and Design and Technology.

Manuao College is to an extent funded by the government. The recent reforms by the ADB-funded Education Sector Project saw strengthened partnerships between schools and their community which limited government financial responsibility to the provision of teachers, curriculum and stationery for students. However, Manuao College continues to receive assistance from the government in the form of course materials and equipment such as cooking equipment and rolls of fabric for the Food and Textiles course and carpentry tools for the Design and Technology classes. However, it is expected that most of the school running costs with the exception of teacher salaries are to be met by school fees and fundraising carried out by the school and its partners. Student stationery is provided by the Ministry of Education according to estimated enrolment from the previous year, but students are expected to provide their own textbooks.

Manuao College follows the common practice of all schools in Samoa in terms of assessment. The entire school has an exam period halfway through the year and at the end of the year, while Years 12 and 13 (Forms 5 and 6) have additional 
external national examinations in November. The school examinations are the basis of reporting and reward for students in the form of prizes presented at the annual school prize-giving ceremony.

\section{SCHOOL ACCESS TO INFORMATION AND COMMUNICATION TECHNOLOGY}

Manuao College was the last school to become part of SchoolNet in Samoa in 2007. Prior to this, they had 6 computers for staff and student use which they received from the Ministry of Education. In 2007, they received 10 additional computers and related technology as part of the SchoolNet project. They are now connected to the internet and have their own web page. The school computers are housed in a computer lab which is used for computer studies classes by all levels from Year 9 to Year 12. A teacher at the school acts as the computer coordinator and teaches Computer Studies classes for all levels, as well as supervising community access to the computer lab after school hours. Every Computer Studies class is allocated two hours per week but due to insufficient computers, each class is divided into two groups which take turns in the computer lab. Consequently, students' contact with computers may be limited to one hour per week of class time, although they may use the computers after school or during lunch time. Computer maintenance and technical assistance is carried out by a service provider in the business community.

\section{MANUAO COLLEGE SCHOOLNET}

The SchoolNet project was implemented in Samoa with the objective of enhancing communication between schools in Samoa, as well as providing online resources that would be accessible to all SchoolNet schools. As part of 
SchoolNet funding, Manuao College received computers, a printer and fax and internet dial-up connection in 2007.

\section{GAINING ENTRY AND SELECTION OF PARTICIPANTS}

Following established practice, I sought and obtained permission from the Samoa Ministry of Education Sports and Culture prior to conducting the research at Manuao College. I then met with the principal of the school and discussed the best way to carry out the research. The principal was most helpful and offered constructive suggestions which facilitated the research process. I went along with his suggestion to address the teaching staff at the next staff meeting in order to explain the purpose and details of my research.

The fact that I was acquainted with many members of staff from previous inservice training facilitated entry and acceptance into the research site. In a short verbal presentation during the staff meeting, I explained the reasons for my research, and invited staff to participate. As agreed with the principal, voluntary and confidential participation was sought from all teachers and the burden of taking the initiative to respond was placed on the teachers themselves if they so wished. Teachers then individually approached me on subsequent days for interviews which were recorded and later transcribed. Out of a total staff of 33 teachers, 11 agreed to participate in the research and gave their consent for interviews.

\section{COLLECTION OF DATA}

Typically in the phenomenological investigation, the long interview is the method through which data is collected on the topic and question. The phenomenological interview involves an informal, 
interactive process and utilizes open-ended comments and questions.

Semi structured interviews were the single source of data for this research as befitting its phenomenological orientation. There are four reasons for the suitability of interviewing as a data collection method for a phenomenological study (Denscombe, 2007, p.82). Firstly, interviewing is conducive to in-depth exploration of issues and perspectives. Secondly, it is open-ended enough to encourage the interviewee to discuss matters he/she considers important. Thirdly, it enables interviewees to describe and interpret their own experiences. Finally, there is provision for checking that the interviewer has accurately understood the interviewee. Furthermore, in light of this research, interviewing allowed clarification of questions and ideas when needed especially given the fact that the potential interviewees do not have English as their first language.

Interviews were carried out during the school day as this was more convenient for participants, in an empty classroom. As interviewer I attempted as much as possible to place the interviewee at ease and interviewees were carried out in both English and Samoan as most interviewees were more comfortable conversing in Samoa. While I had a list of questions that were based on the key questions of the research, the flexibility of the interview structure allowed us to pursue lines of thought that may have been different from the planned questions but were nevertheless significant to the research.

As explained to the research participants, I transcribed each interview and returned the English transcript to each interviewee for checking. I then sought permission from the participants to use the English translation of the interview, if they were satisfied with the transcript. While two participants made changes to the transcripts that were noted and utilised, all interview transcripts met with approval; the participants signed their consent to use this data in my research. 


\section{OTHER GUIDELINES}

In order to successfully carry out research in Samoa, researchers should respect and follow Samoan cultural etiquette. Such guidelines are similar to those outlined by Smith (1999, p.120), who pointed out that researchers of indigenous communities should:

1. Have and demonstrate love and respect for people

2. Present yourself to people face to face

3. Look and listen before speaking

4. Be generous, host and share with people

5. Be cautious

6. Be careful and not trample over the mana of people

7. Be humble and refrain from flaunting knowledge

\section{THE RESEARCHER}

Morse $(1998, p .66)$ encapsulated the importance of the researcher in qualitative research when she pointed out that "qualitative research is only as good as the investigator". She continued to explain that "it is the researcher who through skill, patience and wisdom, obtains the information necessary during data collection and fieldwork to produce a rich qualitative study" (1998, p.66).

It would be presumptuous, not to mention academically tenuous, to declare that I was the perfect researcher during this first attempt at academic phenomenological research. In hindsight, there are things that perhaps should have been done differently. However, I attempted as much as possible to 'bracket out' my own knowledge and assumptions; a process that Grbich (2007) explains is vital in phenomenological research. It is not necessary for the 
qualitative researcher to be seen to attempt a completely objective stance in research; qualitative researchers argue that such is not possible. However, it is necessary to acknowledge and pinpoint understanding that the researcher takes for granted, in order to better 'hear' what participants are saying in their dialogue.

I entered fieldwork with assumptions that may have influenced how I gathered and analysed data during this research. Prior to the fieldwork taking place, I was of the impression that the integration of information and communication technologies in education in Samoa was being conducted in a haphazard fashion, with little guidance for schools and teachers. I was also under the impression that teachers received very little curriculum and pedagogical guidance in technology integration, and were not aware of the different models of technology integration in schools and their research basis. In addition, while the

government understandably pursued their development aims in education with the procurement and installation of information and communication technologies in schools, their policy aims and rationale might often be lost on teachers who are at the implementation end of the technology integration issue. Awareness of these assumptions helped me 'bracket out' such understanding in order to better 'hear' what research participants were saying.

\section{DATA ANALYSIS}

Different researchers have suggested guidelines for the analysis of qualitative data (Bogdan \& Biklen, 2007; Miles \& Huberman, 1994; Wolcott, 1994) with some specifically for phenomenological research (Polyzoi, 1982; Grbich, 2007; Moustakas, 1994). Wolcott (1994) suggests that when researchers code data and classify it into categories, such activity is more appropriately termed 'data processing', and uses the phrase 'transformation of data' to refer to the entire process of description, analysis and interpretation of data. Miles and Huberman 
(1994) agree that data processing is what happens before data analysis takes place although they reiterate that the coding process is data analysis.

Analysis of interview data in this study followed the guidelines suggested by Bogdan and Biklen (2007, p.159) which is summarised as "working with the data, organising them, breaking them into manageable units, coding them, synthesizing them and searching for patterns". This process has been expanded elsewhere by Miles and Huberman (1994) and Wolcott (1994).

After transcription of recorded interviews and translation into English, the transcripts were returned to research participants for member checking. The approved set of data was then ready for processing and analysis. After reading through the entire interview data several times in order to get a 'feel' for it, I went through the data with a pencil and marked in the margins a phrase that summarised what the participant was talking about every paragraph. At the end of this process, I listed these marked phrases on paper as this would form the initial list of codes. This list of 44 codes was used to code the entire data set; some codes had to be modified in order to more accurately reflect the data, and some were removed. The data was then broken into categories according to their codes - it was very clear that some categories were closely interrelated - they were therefore placed together under a heading that summarised their relationship.

Chapter 4 describes the final classes of data according to identified themes. Chapter 5 analyses and interprets the data gathered to answer the initial research questions. 


\section{RESEARCH VALIDITYI TRUSTWORTHINESS}

Wolcott's (1994, p.343) early discussion of qualitative research validity commenced with an explanation of the term 'validity', which focuses on "whether one is measuring whatever it is that is supposed to be measured". Accurate measurement is of utmost importance and this was achieved by using the correct methods in the correct way. As Smith (1990, p.168) pointed out, "valid research was distinguished from invalid research in terms of the extent to which the proper procedures were properly applied". However, this might seem more applicable for quantitative research than for qualitative research.

Take this study for instance, which stated its purpose as: To explore the perspectives of secondary teachers regarding information and communication technology in a secondary school in Samoa. If the purpose of this research was to explore teacher perspectives, then questions of its 'goodness' (Smith, 1990; Marshall, 1990; Heshusius, 1990) should regard the issue of whether the research adequately carried out such exploration, and whether the reported findings of the said exploration can be trusted. What some literature on qualitative research referred to as 'goodness' (Smith, 1990; Marshall, 1990; Heshusius, 1990) seems to have been replaced by Lincoln and Guba's (1985) notion of trustworthiness, comprised of four aspects: credibility, confirmability, dependability and transferability (Lincoln, 1990).

Lincoln and Guba (1985) proposed that the best way to ensure credibility of qualitative research is to conduct member checking. As mentioned elsewhere in this report, member checking refers to the process of allowing research participants to check transcripts of data to ensure that obtained data does not misrepresent what happened/what participants thought happened.

The confirmability of qualitative research depends on whether the processes of data collection and data analysis have been sufficiently described (Wolcott, 
2001). Seale (2003, p.172) adds that this "involves the provision of a methodologically self-critical account of how the research was done", also referred to as auditing.

The notion of dependability is directly related to research design flexibility in order to allow for changes in the research context (Toma, 2006). Such changes and their justification are acceptable, only that they must be recorded in detail for readers and future researchers with similar aims.

The question of transferability comes into play when considering whether the findings of a certain research report can be applied elsewhere. It would be naïve to expect readers to take a report at face value without considering its usefulness to other settings, other cases. Lincoln and Guba (1985) therefore advocate that researchers should provide thick description of their case/s to facilitate comparison to another site/setting. However, the burden of proving transferability is shared between the researcher and the reader.

That is to say, an investigator can make no statements about transferability for his or her findings based solely on data from the studied context alone. At best the investigator can supply only that information about the studied site that may make possible a judgement of transferability to some other site; the final judgement on that matter is, however, vested in the person seeking to make the transfer, who must be in possession of similar data for the receiving context.

Lincoln, Y.S. \& Guba, E.G. 1985, p.217.

In light of the above criteria, I have endeavoured to provide sufficient description of the entire research process as well as the obtained data in order to, as much as possible, approach trustworthiness. 


\section{SUMMARY}

This chapter provided an outline of the conceptual underpinnings of the methodology used in the study. These underpinnings were drawn predominantly from phenomenological research with contributions from case study research. It also included background information of the research site in particular the introduction of ICTs. In addition, processes of data collection and analysis have been described in detail, with a discussion of the place of the researcher in the research process. Discussion of methodology in a phenomenological study is incomplete without discussion of research trustworthiness and this completes the current chapter. 


\section{CHAPTER 4 \\ DESCRIPTION OF DATA}

\section{INTRODUCTION}

The previous chapter discussed the research methodology employed in this study. As stated elsewhere, the phenomenon with which this study was concerned is integration of information and communication technologies in a secondary school in Samoa. As well, as already explained, I chose to explore this phenomenon through the perspectives of those who teach at the school.

This chapter describes the data gathered from in-depth interviews with the research participants. I have chosen to let the data describe itself; although as the researcher, I have grouped the data into categories directly determined by their content with explanations where necessary. What follows will hopefully give the reader insight into what teachers thought of the recent incorporation of information and communication technologies in the case study.

\section{HOW MANUAO COLLEGE CAME TO BE PART OF SAMOA SCHOOLNET}

Two weeks before the school year started for Manuao College in 2006, the principal received an unexpected but important phone call from the Samoa Ministry of Education Sports and Culture. It was a phone call that seemed to herald a season of development in information and communication technologies for the college. The principal had already heard of the SchoolNet project being implemented in other schools in the country, but this was the first he had heard of his school's involvement in the project. In his words: 
Our school was not one of the schools originally selected for the SchoolNet project. I was rung in 2006 at the beginning of the year, 2 weeks before school was due to start, and they asked me if I wanted this project in the school.

The principal was given an offer that no self-respecting school administrator in his/her right mind would turn down. The MESC spokesperson on the other end of the line asked him if he wanted Manuao College to be part of the SchoolNet project, and he replied in the affirmative. The principal knows that his school was not the original intended recipient of the technical assistance, and he has speculated about the identity of the original receiver.

Perhaps the original school was Samoa College, but they already have ICT equipment so that's why I was approached.

The MESC spokesperson subsequently directed the principal to set aside a room for the installation of a community learning centre as required by the SchoolNet setup plan. The principal has commented that other schools in SchoolNet had had ample time to prepare a physical facility for the installation of the facility, compared to the preparation time for Manuao College. Nevertheless, he immediately went about the process of organising where the community learning centre would be set up.

When they told me, I had to decide what to do - I approached the committee, and I thought perhaps the two new rooms on the other side of the campus, but they were too far from here - so I decided upstairs would be better.

The principal understandably wanted the computer learning centre to be located where he could monitor its use with ease; in other words, not too far from the administration block. It was therefore allocated a room almost directly upstairs from the principal's office. He approached the school committee before he could make this decision, as there was also the question of installing air conditioning in 
the unit before the equipment arrived. Money would be needed to install air conditioning, and this is the perceived responsibility of the school committee.

There were many issues pertaining to administration and shipping that had to be resolved before the community learning centre could be set up. Approximately five months after the first communication between the school and MESC regarding the installation of a community learning centre, it was finally carried out in June 2006. There is at present no air conditioning in the Manuao College community learning centre. In the words of the school principal:

Some time elapsed while other things had to be sorted out and it was about June when the computers arrived. The room had to be wired, however there is no air conditioning...

\section{THE COMMUNITY LEARNING CENTRE}

2007 opened with a new study option for Manuao College students - that of Computer Studies. Computer Studies was offered as an option at every level up to Year12 (Fifth Form), and many students eagerly listed it as their study choice of optional subject. The computer lab is almost fully booked with computer studies classes and there are few, if any, vacant periods during the day. There are however, not enough computers for the number of students listed in every option. There are 11 computers in the learning centre, in addition to a printer and photocopier, and this does not meet the current needs of the school. The principal exaggerated only slightly when he commented on the mismatch.

If only we had enough computers... right now one student may be seated at the computer but 6 may be crowded around that student. Then they may take turns operating the computer... 
Manuao College registered the first community users of its community learning centre when it opened its doors to the public on the 11th of April 2007. As of the end of 2007, there were 20 registered users from the community, who were able to use the community learning centre facilities after hours. Included in this number are student users who attend other schools in the district. The costs of registration are $\$ 5$ for a student and $\$ 10$ for an adult, respectively equivalent to about \$2.50NZD and \$5NZD. The fee for using the internet for an hour is \$2 (\$1NZD) - a very low cost in Samoa even for a dialup internet connection.

\section{UNDERSTANDING OF MESC ICT POLICY AND RATIONALE}

It has already been established that the integration of technology in teaching and learning at Manuao College came about when the school became part of SchoolNet. However, SchoolNet itself is part of the Samoa government's plan to fulfil its policy of 'ICTs for every Samoan'. Teachers were asked whether they were aware of the Samoa government (MESC) policy on ICT in education and why it was introduced. The following sums up their individual responses.

Sina: I have heard of it on TV. I have seen a program on TV and they were talking about ICT.

Fomai: No. All I know is that we have received this assistance.

Sarona: Well...I think so - you know because once you are a public servant you should be aware of all the policies- you have to follow it, so especially if you don't follow the policy then they can automatically cease your salary - or they can punish you... like transfer you from one place to another.

Finau: Well... I don't know... but I suppose the reason is... maybe one of the goals is for the schools to be able to communicate with one another. 
Mareta: The idea seems to be to get the students to use computers as well as the community; I guess that's why the computers were brought here to help the students...

Risati: I saw on TV the Ministry of Education program that aimed to put computer labs in every school... to make it easier for teachers... I think that was the main goal.

Moana: what l've heard is that it was to help the students of this community to have access to the computers, to improve students' access...

Timoteo: There haven't been any clear and detailed explanations; the only thing that I heard was that... I'm sure the principal is very clear of that... but the only thing I know is that it was to help the students of College, not just the school but all the students of the community, to help them learn how to use the internet and computers... for general knowledge and for improving their learning.

Monalisa: ...The reason why these developments have been carried out in the school... the Ministry is looking at some of the ways in which teaching and learning could be improved...

\section{ICT AND THE STUDENT's LEARNING PROCESS}

Teachers were asked what they thought of the usefulness of information and communication technologies to students' learning. Most of them referred to how ICT seemed to boost student motivation to learn new things. 


\section{ICT and Student Motivation/Interest}

Sarona: You can tell them to do their work and you can find them not doing their work but they are playing or talking to their friends... Most of them want to come to the computers.

Mareta: ... when the bell rings for the Computer Studies option, they run to class, they have a race to see who gets there first because... the previous teacher always gives them a chance to do their typing test... to do games like spelling... the word appears and the student has to type it... at the same time the students are so interested in the use of the computers.

Fomai: they like to get on the computer and do different things... but if you give them something in class from an activity that you want them to do... you go and check on them and they'd still be sitting at it... and you're thinking... the mentality of the student is that the lesson from the board is boring.. But when they get to the computer lab it's more interesting for them...

Timoteo: when the students are using these machines - some students only come alive then... they find it interesting and enjoyable, it's like a game, and that's where the student is motivated to learn more about the subject.

Moana: what I mean is, whenever I do this in class, I can tell that they are bored, I try different things but they don't... are not interested in the subject... but when they are on the computers... they have learnt a lot... I saw that they were very into it... It seems that the computers have increased their motivation to study math...

Risati: if students see that it is writing on the board every day, they are bound to get tired of it and lose interest in copying notes all the time. But if you use different technologies, it will pick up students' interest... 
The interviewees also described examples where the use of the computer helped students to learn what might have been more difficult to understand without the use of the computer and/or the internet.

Mareta: They give me their original drafts to view... then I tell them to go and type it up... and sometimes when they give it back, they have reworded some sections... and sometimes where they tended to beat around the bush and waffle, they have shortened it... so they have improved. I can say that for my Year 12 students...

Monalisa: I have already taken them upstairs and taught them how to look for information on the net... we used the topic of mangroves... they found the information on mangroves then they compared it with our field study on the mangroves of Samoa. That's... that's how they were using the net... for their literature study.

Risati: It is easier to get information... easier to do student research... the students used to go use other schools... computers... now they just come here.

Vaega: All I do is observe, but the importance is that students can carry out searches for information for their assignments.

One teacher described her amazement at the speed with which senior students grasped mathematical concepts when on the computer compared to their struggles with the same concepts in the classroom.

Moana: some students are still struggling with it... but some students... especially the girls... I am so amazed at the girls... especially with the 12._... maybe because the girls are fast anyway. I don't know... but with the girls... when they know they like to show me. I just stand there and ask them to do it 
again... and this female student did the whole exercise on the computer. I was happy because I saw that they had learnt something in a different... so downstairs in the classroom I changed the exercise around to reinforce what they have learnt... made it a little more challenging for the 12._, and I saw that the results were good. Some made mistakes but for the majority of students especially among the girls, the results amazed me...

A couple of teachers did not agree that the use of computers and other ICTs had any significant process on the students' learning processes.

Sina: I don't really know how there can be a difference when they are merely typing up what they drafted manually.

Finau: Well to me... there is no difference... no difference... it is the same when using this technology and when using other methods.

For a few teachers, the capacity of students to produce well-presented work when using the computer is enough incentive to encourage and even require students to produce word-processed assignments.

Mareta: ... during research for my Year 12 class, I don't accept any more written work; it has to be nice and typed...

Sina: ... we have a research project that the students must do... so I tell them... go and do it... and you are not allowed to handwrite your essays... that will be too much to try and read your handwriting.

Fomai: But I know that quality (has improved) in terms of spacing, paragraphing... with help from the teacher... but I write it on the board... because I seldom go to the computers... but I write on the board what's needed, the kind of formatting needed... 


\section{Perceptions of Student Attitudes toward ICT}

Teachers talked about their observations of student interaction with computers, noting that for the most part, students had positive attitudes toward using computers.

Sarona: I think they want to explore, they want to know what it is... they are happy about it; they want to see it, touch...

Sina: ... it's not just educational but they are also entertained by it...

Mareta: ...the students are so interested in the use of the computers... as proof, the students don't leave for the next class when the bell rings until the teacher for that class comes looking for them.

Fomai: ...most of the students like practical work... after they are shown what to do... they like to get on the computer and do different things...

Rosa: I suppose the students feel differently about it... they like it...because it's new... instead of staring at the board... and writing... so it's a change and they feel differently about it... and that's how it is when they use computers...

Timoteo: ... and this is a different kind of learning, the learning that happens when the students are using these machines, and some students only come alive then ... they find it interesting and enjoyable...

Moana: ... but when they are on the computers... they have learnt a lot... I saw that they were very into it... 
Risati: if students see that it is writing on the board every day, they are bound to get tired of it and lose interest in copying notes all the time. But if you use different technologies, it will pick up students' interest...

\section{Perceptions of Student Ability}

The topic of student ability often came up as teachers reflected on teaching and learning at the college. Approximately half of the teachers interviewed perceived Manuao College students as 'weaker' students.

Sarona: ... most of the students are not up to the standards that you expected according to the name of the school because it's called a college. But to the standard... the majority of the students are the weaker ones...

Moana: ...but because our school has weaker students... some students attend for one month then don't attend the next month... so its hard to do anything.

Risati: ... with a school like you have to offer Vocational subjects, because most of the good students go to College. With these students, you must have practical work, not a lot of writing work...

Monalisa: ... you have to keep in mind a school like this, these are the schools that don't get the cream, the cream goes to College, College. I'm not saying these kids are dumb or what, but I'm just saying it's the quality; it's just the level where they are at...

As well as reflecting on student ability at Manuao College, the following two interviewees went further to explain why the introduction of computers would be useful to their students. 
Timoteo: Most students at our school are not very bright, they are of medium ability and some are very weak, but these computers are very useful in that it helps the learning of the weak students... because the students have different learning abilities...

Fomai: ... especially the students we have here... very weak... and the teacher can be talking and talking and all the students do is stare at the teacher... but once you put them in front of the computer, then away they go...

\section{ICT and Future Student Employment}

As teachers talked about the usefulness of ICT on student learning, several comments linked computer or ICT literacy to success in looking for employment.

Mareta: ... it seems that the jobs advertised nowadays always require one to be computer literate so I guess that's why they are making it imperative that the students use computers in schools...

Sina: If this is the way the world is going, and the students don't know about it, then... If they go to jobs and technology is everywhere then that will not be good for them...

Fomai: ... without technology, well the students' learning would be limited... especially this time where there is wide use of computers, most of the working environment use computers...

Rosa: ... it's getting to the stage where jobs will be hard to find... and then it will be up to the student... how good they will be at using the new technologies... unless it's a job where you don't need it... 
Timoteo: ...students should enter work knowing how to use the computer, but right now students enter work and further education not knowing...

Vaega: I know that students like to get on the computers and it is useful for communications with overseas. Students can also learn skills that they can take with them when they leave school and/or go overseas...

\section{ICT AND TEACHERS' WORK}

The research participants were asked about how the introduction of ICTs impacted teacher work. Their perspectives are highlighted in the excerpts that follow.

Monalisa: When they use it... for the individual teacher to type up their exam... to type up their tables... tasks... things like that... it has speeded up their work... things like photocopying tasks...

Vaega: ...the equipment is vital for overseas communications with Fiji ... we used to have to find a fax but now it is very fast and efficient to send the communications via email...

Moana: When I first came to teach and there were no machines... no computers, photocopier... writing notes on the board was too time-consuming, when I turn around to teach, there would be maybe 10 minutes left... I can't meet the objectives of the lesson for that period... but with these machines, I am able to prepare my own notes... then use the other machine to make copies... it has made teacher preparation easier...

Timoteo: For teachers ...it is very useful for teachers especially ... it is useful in preparing for classes, especially when teachers are looking for information that 
cannot be found in the textbook. Especially in preparing notes, teachers can type them up and hand out to students instead of having to write them on the board and having students copy it... so you use the printer and the copier...there is internet here at the lab, and I have been able to get other information regarding the topic that I am teaching the students... that is not in the textbook from the Ministry... it provides wider background for the students...

Rosa: Well... it's useful to the teacher as a resource... to help with preparation... and to make it faster and easier.

Finau: ...especially when we send our IA marks to Fiji, the communication is now very easy... instead of our teachers running to look for a fax... to send their marks... and when it comes to changes that have to be made... now it's very easy through email.

Mareta: Yes... well it saves time... we don't have enough textbooks so if I type things up on the computer, make copies, and then give it out... and we have a class discussion... so I'm happy...

Sina: if there is anything I need for my subject, then I go upstairs and use the computers and the internet... it has been a great help for my classes... from my perspective as a teacher... It's one of the biggest sources of help for me...

Sarona: ... when the typists are very busy we can use the computer to type our exams and print documents... It's the quickest way of sending our tasks, we send our programs to Fiji to be approved. We use the internet as our correspondence overseas instead of the faxes... 


\section{Examples of ICT Use in Teaching and Learning}

Teachers also referred to examples of how information and communication technologies were utilised in teaching and learning on a day to day basis.

Sina: ... we have a research project that the students must do... so I tell them... go and do it... and you are not allowed to handwrite your essays... that will be too much to try and read your handwriting.

... even though I didn't have enough knowledge... I know I have this source of information that I can ask anything... I don't know about other subjects like Math and ...But as for me... anything I want... It's all there...

Mareta: ...during research for my Year 12 class, I don't accept any more written work; it has to be nice and typed...

...we don't have enough textbooks so if I type things up on the computer, make copies, and then give it out... then we have a class discussion... so l'm happy...

Well the only thing they used the computers for was in their research... and they had this assignment where they had to look for... information... the internet is really useful for when they have to look for information...

... When we have oral instruction, then we used the tape recorder...

Fomai: Well yes... to type up their assignments, I send them to the Computer Studies teacher to show them what they need to do...

I do a lot of my work on the board... but there are times when I photocopy... or print a chart to use... 
Rosa: ... especially with the preparation of exams... because when I first got here... we had the manual copier...

Timoteo: I have used them many times especially when I need to things like get on the internet, and to type things that needed typing... but my class has not used it... I have not used it for my class; it's just for me...

Moana: ...there were students that did their projects... Year 12 and 13 students... they had to do graphs and such... and I came to the lab once and saw the students working on graphs on the computer I make notes and then make copies, and give it to students...

Risati: ... last year I used a video of a house being built, and I showed that to the students...

Monalisa: I take my Geography class... we have our lesson, and we use the computer to look for maps, information for researches...

There are teachers that use our video... they get a video on these topics... conflicts of the world... they get that and show the students...

\section{Teacher Knowledge and Motivation to Learn About ICTs}

Whilst discussing the impact of ICT on teacher work, individual teachers described their own knowledge of computers and those of their peers in different ways; several expressed the desire to learn more.

Sina: I can't say that I learnt of the internet here at school... because I have my own computer at home, that's how I learnt to use it, pressing the keys... 
Mareta: ...I'm the same as the students; this is the first year I have come into contact with a computer... Well I want to learn more!! (Laughs) I wish I had one at home... then it would be fast...

Fomai: Yes... most of the teachers were not computer literate but now they can go and type up their own exams... there were also teachers that did not know how to type... but now they go and do their thing...

I have a desire to improve my use of computers though...

Finau: I know a good number of teachers use computers... but maybe just to type their assignments... do their work... and only a few teachers use the internet to look for information... because not a great number of teachers know how to use the internet to do any work...

Timoteo: ... we don't have enough understanding... like me... in using it, I don't know enough, because I didn't take computers before... I just come and ask the teachers who take this subject and I learn a little... when I get the chance... Moana: ...none of us have had computer classes... what I know I have learnt by just getting on the computers and teaching myself...

Risati: ...we should have someone come in to train all teachers to use computers because all teachers should learn to use it... and also not all teachers know how to use them...

Vaega: The teachers also want to learn and use computers and sometimes they should be at their classes, but instead they are upstairs using the computers...

Monalisa: There was training... training for teachers... to be able to use the equipment but only a few teachers used it... In my opinion the teachers are not confident in this area... 
In addition, several teachers described learning experiences with the use of computers and/or the internet that stood out for them since the college became part of SchoolNet.

Moana: ...there were a lot of things I didn't know how to do... all I knew was how to type in numbers... even fractions I didn't know how to type on the computer... but I asked... him to help me... and he gave me a lot of help... and now... no Math teacher wants to do their own papers (exam)... they prepare it then they pass it on to me... and I have to do it all...

Mareta: There was this question on the previous paper for English, and the question was who the former president of ITO was... so I went to the computer lab... and the computer studies teacher helped me get on the internet and she told me that all you have to do is type the question and press search... and I found the answer! And that was the first time...

Sina: ... I make my own notes then I go and give it to the class...for example like umm doing expository writing... there's a lot of guidance given in there of how to do one...

Timoteo: It is useful because I can get...for example the internet, there is internet here at the lab, and I have been able to get other information regarding the topic that I am teaching the students... that is not in the textbook from the Ministry...it provides wider background for the students... and for me as well...

\section{ICT TRAINING FOR TEACHERS}

Computer training for staff from SchoolNet schools was carried out during the school holidays as well as after hours, before and during the installation of the 
computer learning facilities. This training was available to all staff but the majority of teaching staff at Manuao College did not attend this training. There was also training for school computer coordinators, and four teachers from Manuao College were selected to attend this training. Much of the training for staff at Manuao College seemed to have concentrated on the basics; this is understandable given that many may have not used computers before. Different teachers had different perspectives of this training.

Was the training useful for you?

Sina: Yes of course, because there were some applications that I didn't know how to use like the PowerPoint, and another one that I can't remember...and functions like...copying and pasting... and now I know about it.

Finau: It was useful to some...but not to some... because some people didn't even make it to the training...they were busy...most of the teachers I know...haven't been on a computer yet...

Monalisa: My knowledge of what I learnt at the training ended when the training ended. But with that training, after the training we went (on holiday), and we forgot all about what we learnt...

One teacher said the training had been useful for her, but when asked whether there had been any difference in her teaching before and after the training, she gave this answer.

Sarona: before the training I know how to use the computer and after the training...there was no difference, and the training wasn't deep...it was only the basics and some of the programs on the computer but not all like...the PowerPoint. 
Other participants had not been involved in the training sessions and had the following views.

Timoteo: There were workshops, and there were teachers selected to go to these workshops... but it stopped there...There hasn't been another workshop/training... where these teachers that went to the workshop could show us who didn't go to the workshop... what they learnt...

Mareta: ...there were others involved in that, but then I went and learnt from the trainees... well...I think that particular training should have been open...available to anyone...

A couple of teachers had additional views regarding the timing and structure of the training in ICT.

Sina: The rule at our school is that teachers cannot use the computers or the internet during school hours... until school finishes (at 2.15)... but remember by then teachers are tired and want to go home...so there is no time for the teacher to practice the knowledge they have gained from the training until it just goes away/dies... and then its like we have to learn all over again...because going through the training is different, from practicing it...

Monalisa: ...we need to observe, and practice, observe and practice...but when this training finished... many people were still unclear about many things...it was demonstrated to us, we observed, practiced a bit...and then it stopped... and everything we knew disappeared. It should be ongoing... 


\section{OBSTACLES TO EFFECTIVE USE OF ICTS TO ENHANCE TEACHING AND LEARNING}

Teachers were asked what they thought were obstacles to effectively integrating ICTs in teaching and learning at Manuao College. Every teacher had something to say on this topic, and their responses can be grouped into different categories as shown in the sections that follow.

\section{Insufficient Access to Computers}

Sarona: I think the lab is quite small you can't fit all the 30 students we only have about 10...Yes because the room is... we only have one lab for the whole school...not all kids have the chance to touch the computer only the computer classes students...

Sina: because there are so many students and not enough computers as well...

Finau: Resources... at this point in time...there are not enough computers for students in the school. So when they come to the lab, they are crowded...

Rosa: ...there are no periods allocated... for subject classes...like just for my Science class to go use the computer lab....if it was possible for the teachers during any period to take their subject classes there to go use the computers...I'm sure that would present great opportunities for learning...

Vaega: With all things there are always problems...the most important one I can say is the insufficient number of computers...

Monalisa: ... if I have a class of 25, they cannot all fit into the lab if I wanted to use it...that's another difficulty, it's a barrier to improvement... and to the intention 
of the Ministry. In my opinion, there should be enough for a single class. If one class is $30-35$, then there should be enough to have a whole class in there...enough for one class.

\section{Running Costs}

Fomai: Here there is a committee... that pays the bills... and sometimes they are slack... and the bills are not paid...

Finau: If there hasn't been any community use or student use to bring in money, then the equipment stays there, unused, until we get some money...

Vaega: The other thing that I think of is the cost when the bill arrives. Right now we have a contract for a $\$ 100$ a month. But one of the most important things is the cost- there are times when you have to pay the bill, there are times when you have to pay the labour for those who fix the machines and you always need funds...

...there is no one that is able to fix the machines so that we can keep using them. If something is broken, its use stops and we can't do anything about it. But the thing is- to get a skilled person costs money as well.

Monalisa: If only there was enough as was needed, as well as funds for maintenance... because sometimes it breaks down...sometimes our internet is disconnected because they say we haven't paid the bills.

...financial matters are the major factor... the economic factor...we cannot maintain it... us teachers, we are here to carry out the work... the school committee collects all the students' fees... and then they allocate those 
funds... and that's why its slow... that's why our internet gets disconnected because of things like that... our power was disconnected, as was our water...

\section{Teacher Access to ICTs}

Sarona: ...we need resources, because we only have a few ones and we can only use them after school, because during school times it's just for students, but we only use them after school, and only if the school committee is here with the key to the facilities...

Sina: ... the rule at our school is that teachers cannot use the computers or the internet during school hours... until school finishes - but remember by then teachers are tired and want to go home...

Mareta: ... as for staff we don't really have time to get on it unless you stay behind after school because we can't use it during school hours...

Fomai: ...I mean teachers... there is no time for us to go and use the computer except the computer studies teachers...

Rosa: ...If I only get to the computers once a week - then my interest starts to wane because I seldom- maybe once a month. Some don't get to use it for months because they don't come into contact with it everyday. Maybe if every teacher had a computer then they would be interested in using it to help their work as a teacher. But the way it is now you only see it once a week, but it seems that the focus is on the student. Teachers are allowed to use it but - only when the lab is free - then there is opportunity for the teacher during a period when there is no class. But if I don't get to use it for a while then I lose interest in it. There's no reason to go use it if I don't know how to use it. 
...secondly there is no time given to use it.

Vaega: Right now teachers can only access the computers after 2.30, but if they have free periods, you will find them in the computer room. But I tell them that they can go use the computer room after 2.30 and whatever they need to let me know.

\section{User Pays System}

It was apparent that a user-pays system was in place for the use of computers, printing and the internet. As apparent in the following comments, teachers' views diverged regarding this issue.

Sarona: .all the financial responsibilities are on the school so it's very hard to get that money. So now if the students want to print something on the computer they have to pay about 10 sene...

Rosa: ...you have to pay to use the internet...you can only use it when you put money into your account, and that's new as of halfway through the year. But when it was first introduced, it was free...

Moana: ... and we work on it for free...I don't know where the money comes from to pay SchoolNet...I wanted to use the computer but couldn't open anything because I didn't have any credit in the system, so then the CS teacher put in some credit for me...l put in money... and she was able to open it up for me to use. I think that's a good system if it was extended to all the students...

Monalisa: That becomes my concern, even with the teachers- even if its work that we do for the students, we pay, because if we do not pay, the program cannot be maintained. So it's an economic factor - but it really matters, it really 
matters. That's why I said, it defeats the purpose of the program. Sometimes we face disagreements with the ones who run the program - we are arguing that the work we're doing is for the students, we don't need to pay for that, it's for the students, but they argue that if we don't pay, then we cannot maintain the program for the school.

\section{Disadvantages of Using the Internet}

Mareta: As I have already stated... on the internet when going to the wrong sites...but now that I know to use it...

Rosa: ... The students are depending on it, they just - like the internet - they can just look for the information, and if they have a printer, they can print out what they have found and hand it in as an IA (Internal Assessment) - and for a student that's not very able, they can just look for the information, print out how many pages for this IA, then hand it in - but they haven't read what's on it at all.

Timoteo: But there are drawbacks when the equipment is used inappropriately, using the programs that are - we all know - although it cannot be opened on the internet at the moment, but it can be a distraction for some students...

\section{Teachers Do Not Know How to Use ICTs}

Several teachers pointed out that they did not know how use ICTs in their lessons.

Rosa: That's the other thing - not knowing how to use it and if I ask someone who knows - sometimes they don't want to help - or I am disturbing them with my 
questions - you'd be interested in using it if you knew how to use it - but if you don't know - then you just leave it.

Well, in my opinion the blame is on the teacher...they don't know how to use it...

Timoteo: The first reason is that I don't have any understanding of how to do this... of using computers to carry out a lesson for my class - my understanding doesn't extend to that...

Sina: I would like to use it but well - there's no time - it never crossed my mind and also because l'm not used to it - and I forget - and also I'm so used to talking in class.

Finau: ...not a great number of teachers know how to use the internet to do any work - that's why there not a great deal of interest in using - because of insufficient knowledge...

Slightly different from the previous comments, the following gives insight into the perspectives of two teachers who thought that some of their peers could be more willing to try something new, such as using ICTs in their classes.

Timoteo: ...but teachers should be urged...to have the skill... to have a desire to learn...because there is no use doing it and teachers have no desire to learn about it...

Monalisa: Some have the knowledge, they have everything... but that is what is lacking... commitment... There is no desire to do their job well... and there are a lot of teachers affected by that...affected by no desire to do their job with excellence... 


\section{SOME NEGATIVE IMPACTS OF ICT INTEGRATION}

Teachers were also asked what they thought of the impacts of introducing ICT into teaching and learning at Manuao College. The positive impacts have already been illustrated under headings such as 'Benefit of ICT on Teachers' Work'. However, some teachers also mentioned what they regarded as negative impacts; while their views might not have been shared or mentioned by other interviewees, they are nevertheless included here.

\section{Inappropriate Student Use of ICTs}

Moana: Some students were watching an inappropriate DVD on those computers, we found out because they must have gone and left the DVD in the computer. But the blame for that is on whoever assisted the students, they should have supervised the students, and they would have realized what was happening.

\section{Non-productive Use by Teachers}

Fomai: ... but sometimes... the teachers don't use the facilities productively... and some don't use it at all...but when I get up there I want to use it to do this and that... but I get there and some are playing solitaire- cards - on the computer...

Moana: There are teachers who do not use the machines appropriately. Sometimes they type up their raffles - you know things that are not to do with school. I don't know but I think the internet is locked unless you request to use it. I have only started using it recently for email and such but some don't use it appropriately - and some teachers type up their court statements here... 


\section{Increased Workload for Computer Coordinator}

Finau: It has a negative impact on my work...in the beginning, the community could come in...so when the community members come in the evening, that's an extra hour for the person working in the lab (computer lab)... to work all day and continue on into the evening...

Vaega: ... if teachers are stuck, they can refer to the Computer Studies teacher for assistance and the CS teacher will help them. So the CS teacher is still carrying out that work so it seems like the CS teacher has a large workload which includes assisting other teachers with the use of computers.

\section{Gap between Students}

Monalisa: I also understand...the reason why these developments have been carried out in the school...the Ministry is looking at some of the ways in which teaching and learning could be improved...and I agree... I agree that this will improve teaching and learning, but this purpose is defeated...because we don't have enough. It also widens that gap...not only between the schools, but also between and amongst the students themselves. There are times that the people in the - in our development there - they ask the students to pay when they use the internet. They ask the students to pay for the copies that they produce for their work.

\section{MANAGEMENT OF OBSTACLES}

Faced with the problem of too many students in each computer studies option class, and not enough computers, the teachers have decided to split each option 
class into two groups. If there are two computers studies periods per week for each class, the groups take turns going to the computer lab, and the group not in the lab stays in the classroom for independent study.

Sarona: Its not enough for the whole class., so that's why we have options so ...we have a quite big number of students, so they have two turns. They have another half on another day and another half on another day they don't come in all at one time, the teacher takes the class but...

Other comments regarding how to manage obstacles to effective use of ICTS were given as suggestions.

\section{TEACHER SUGGESTIONS FOR IMPROVEMENT OF ICT INTEGRATION AT MANUAO COLLEGE}

The research participants were given the opportunity to express their thoughts on what needed to be done to improve the integration of ICTS in teaching and learning at the school. The extracts below illuminate their perspectives regarding further development of ICT integration at Manuao College.

Sarona: We need a bigger room and enough resources and we need teachers to have enough knowledge for the computers..

Sina: What needs to be done is that teachers need to be brought in who are trained in using computers, and to have computers that are working well and in sufficient quantities...

I think that there should be periods set aside where teachers and their subject classes can go use the computers... to practice... instead of just writing... 
Mareta: Well there should be enough time for the students to access the technology, as I told you they have 4 hours a week on it... 4 periods, but to me we really need more time upstairs for the students as well as the teachers... for me as the teacher, if I wanted my students to use the computers for something, I should understand how to do it first... but there is no use going in and I don't know and the students are asking me what to do... so we need more time for the teachers to use the computers because most of the teachers don't have much experience with it... so we need more hours...

The teachers need to know how to use the computers before they give work to the students that involves computers. So for me I think there should be a day set aside in the week for the teachers to do their training - for me, I learn really fast if there is someone who is teaching me...

Fomai: And. Workshops...there should be training...to support teachers in their use of the technology...because it's only the teachers that went to the training provided by the Ministry that know... but training is needed especially how to treat the computers... and appropriate use as well (laughs)... because there are a lot of programs that the teachers don't know how to use...

Finau: There should be training for teachers so that if one leaves, another can take their place easily... another thing is the treatment of equipment in the lab...everyone should know how to treat them...and there should be a fund for maintenance of the equipment in the lab... and the lab itself should be improved...should have air conditioning... there should be those things to keep the equipment...

About 20 computers in one room... so that they can use it in pairs... and if there are more than 2 students to a computer...that's really not enough... 
... and that's one of the main ideas... is to make it possible for any subject class to go use the lab for their own subject...so they can do their own typing for their own Internal Assessments and all that...

Well... that's the other use...to get other students and teachers to use the lab themselves... they can use the projector....for their classes... they can go and do things like learn to type.

Timoteo: Further workshops and training are needed to improve teachers' knowledge and skills in the use of these ICTs. Because only a few teachers have knowledge regarding this... as there is a teacher who specializes in Computer Studies...but all teachers should know how to use all programs in the computers...for their preparation, but also for the students' sake. That needs to improve. In addition, students need to have ability in the area... and the other thing is the maintenance of the equipment, we should have air conditioning to keep the machines in good condition, so they will last a while...

...it shouldn't be just computer studies where computers are used... it should be any subject...but I know the number one difficulty is the insufficient numbers of computers...

Moana: Well, with students, the teacher who is supervising must be aware and diligent to supervise the students when they are using the computers. They should have a look at all the material that students bring inside and keep an eye on the students and assess how the students are using the computers; they should have rules for the computer lab

Vaega: At the moment during every option, the class is divided and some students remain in the room for reading or remedial work and the rest go to the computer room, then the next Computer Studies period they switch so that they both have the opportunity to use the computers every week. 
Well I think there should be rooms allocated for the computers... rooms that are set aside specially for the computers. There should also be enough teachers sufficiently skilled to teach the subject, as well as to take care of the maintenance of the computers. The Ministry of Education should have a weekly visit of the computer rooms to discuss any problems and to check if all is going well. Then our role will be to help and assist in whatever way possible. There should be teachers to teach the subject and people to maintain the equipment, in order that the work is not stopped when machines break down so there is no disruption to the classes...by unpaid power bills or non-working machines...so there is no disruption to the education of the young people.

\section{SUMMARY}

This chapter described the data gathered from in-depth interviews with the participants in the study. After the coding process, the different data segments were gathered into themes according to their content. As described in this chapter, the identified themes within the research data are: teacher understanding of MESC ICT policy and rationale; ICT and the student's learning process; ICT and teachers' work; ICT training for teachers; obstacles to effective use of ICTs to enhance teaching and learning and teacher suggestions to overcome those obstacles. The next chapter will present an analysis and interpretation of the research data. 


\section{CHAPTER FIVE}

ANALYSIS AND INTERPRETATION OF FINDINGS

\section{INTRODUCTION}

This chapter synthesises the data obtained during fieldwork into themes in teachers' perceptions of technology integration at Manuao College. A total of six themes in teacher perceptions have been identified: perceptions of the rationale for school integration of ICT; perceptions of the relationship between ICT and student learning; perceptions of the relationship between ICT and teaching; perceptions of ICT training for teachers; perceptions of obstacles to effective use of ICT in teaching and learning and perceptions of measures to improve the use of ICT in teaching and learning at the school. These themes have been identified as a natural 'umbrella' for data categories from the previous chapter that were deemed to be closely interrelated. It would be erroneous to perceive of each theme as independent of the rest; in research participants' perceptions of ICT in schools, each theme influences and is influenced by the others.

I have also attempted to interpret this data with reference to research carried out elsewhere while keeping uppermost the situated nature of the insights gained from this study.

\section{PERCEPTIONS OF THE RATIONALE FOR SCHOOL INTEGRATION OF ICT}

The MESC (2006) Strategic Policies and Plan document governing the present period lists ICT in education as one of the areas for which policies and strategies have been developed for implementation. As of the time of this study, most research participants were not aware of any government policy regarding either the introduction or the integration of information and communication technologies 
in schools. Their awareness of such a policy was limited to awareness of the SchoolNet program that was carried out with 7 schools in Samoa; however, two teachers involved in the research knew of government intentions from watching a TV presentation regarding ICT in schools. For the rest of the research participants, while they did not know of the specific government intention to place computers and other ICTs in schools in Samoa, they verbalised their understanding of reasons for such an objective.

The research participants mainly perceived that the government wanted to integrate computers and other ICTs in schools in order to improve student access to computers, with particular reference to students from the community, as well as to improve teaching and learning. They also perceived student competency in computers and other ICTs to be directly related to their chances of future employment. One research participant speculated that the project was perhaps carried out in order to facilitate communication between schools.

It is evident that teachers are unclear as to the specific policies the government have in place for ICTs in education, never mind how such policies are being implemented. Their statements as described in the previous chapter attest to the lack of clarity regarding government policy. Nevertheless, the introduction of SchoolNet to Manuao College brought teachers face to face with government intentions which they may have previously thought excluded their school. In response to such an experience, teachers had developed their own answers to justify why this program was brought to their school.

Lack of clarity about the purpose of ICT in schools is nothing new as Watson (1998) observed of schools that have chosen to integrate technology in teaching and learning. However, in the absence of clarified aims and guidelines regarding the placing of computers and other technologies in their school, Manuao College teachers have already reflected on the potential use of such technology, and have begun to use ICTs in their daily teaching and learning. 
Moreover, the phenomenon of technology integration in schools perhaps offers less certainty about what works compared to other issues in education. The emerging literature on ICT in education indicates that educators are increasingly concerned with the place of information and communication technologies in schools, and is still far from offering definitive answers. Therefore, that teachers are uncertain of government aims regarding technology in education need not be an issue, as long as teachers themselves reflect on why it should be done, and how it should be done for the purpose of assisting student learning.

\section{PERCEPTIONS OF THE RELATIONSHIP BETWEEN ICT AND STUDENT LEARNING}

The teachers involved in the research observed that students seemed to find working on various activities on the computer more interesting than their lessons in the classroom. Certainly it seemed to teachers to elicit high levels of engagement from students compared to their engagement in class lessons. One teacher observed that students rush to their Computer Studies periods as soon as the bell rings, and delay their departure when the bell rings for the next class.

In addition, teachers perceived that students had positive attitudes towards the use of computers and other ICTs. Teachers also reflected on why students had positive attitudes toward computers and they thought it was because: computers offer a change from their daily routine in the classroom; computers involve hands on learning; computers have entertainment value for students and because they are still considered a novelty, computers are therefore inherently interesting.

High levels of student interest and motivation to learn using computers have also been observed by teachers in other countries with a longer history of technology integration (Rakes, Flower, Casey \& Santana, 1999; Dwyer, 1999). Such 
increased engagement has been observed in primary classrooms all the way to tertiary lecture theatres (Dwyer, 1999; Rakes et al, 1999; Brill \& Galloway, 2007). The perceptions of Manuao College teachers are therefore consistent with perceptions of teachers elsewhere regarding student interest in learning using computers and other ICTs. In addition, research suggests that student interest and motivation has been perceived by teachers to be sufficient incentive to integrate technology in their daily learning experience (Ertmer, Addison, Lane, Ross \& Woods, 1999).

Teacher perceptions of students' interaction with computers were not limited to observations of increased interest. Teachers also noted that students like to pursue their own learning while using computers; several teachers described instances where students constructed new knowledge while working with technology. One teacher described how her mathematics students worked out the logic of statistical concepts on the computer, while another described improvements in the content and form of written work after it was word processed. That these incidents were described in detail points to their significance in these teachers minds in terms of the learning that took place in the mind of the student.

However, other teachers pointed out that they did not think the use of computers and other ICTs resulted in beneficial differences in student learning. It thus seems that while teachers agree that using computers and other ICTs boosts student motivation, their opinions differ regarding the actual impact on student learning processes. This difference in perception regarding ICT and student learning processes seems to be directly related to student learning experiences they have been able to observe taking place.

On the subject of student learning involving the use of computers, the teachers in the study have differing perceptions; some perceive it conducive to learning and some perceive it to have no impact on student learning. In fact, such differing 
perceptions may be an accurate snapshot of what has been documented worldwide. Dwyer (1999) reported that the integration of ICT in primary classrooms facilitated a major transformation in teaching and learning in one particular school. As well, other researchers propose that the potential of using ICT to enhance student learning is realised when ICT is used in its capacity as a student centred medium for learning (Rakes et al, 1999; Becker \& Ravitz, 1999).

However, other reports paint a conservative picture of the impact of such integration, suggesting that the current forms of technology integration has not impacted teaching and learning in any significant way (Cohen, 1987; Conlon \& Simpson, 2003; Cuban, 2001; Cuban, Kirkpatrick \& Peck, 2001). Nevertheless, such reports do not necessarily contradict overseas findings described in the previous paragraph as well as at Manuao College. It might be that the usefulness of ICT to assist student learning depends on how it is used in the teaching and learning process.

It was also significant that teachers chose to discuss student ability in relation to interest in computers. Approximately half of the teachers interviewed mentioned their perception of students at Manuao College as being 'weaker' students. Two teachers noted the significance of increased student interest and rapid acquisition of skills on the computer compared to what they perceived to be weaker abilities in all other subject areas. Equally important, Manuao College teachers perceived students' future career and employment to be sufficient reason to develop their ICT skills in schools. This concern is shared by teachers elsewhere, and provides some with the impetus to start using ICT in their classrooms (Sugar, Crawley \& Fine, 2004). 


\section{PERCEPTIONS OF THE RELATIONSHIP BETWEEN ICT AND TEACHING}

The teachers involved in the research were given the opportunity to share how the introduction of ICTs had impacted their work. For many of them, the introduction of ICTs such as computers, internet connections, printer, photocopier and fax made teacher preparation faster and easier. For example, the ICTs enabled better and faster communication with the overseas examining authority; this was considered especially important as the Year 13 qualification was administered by SPBEA in Fiji. Outlines of teacher set assessment tasks as well as each subject assessment program had to be approved by SBPEA before they could be given to students. This had been a time-consuming task since Year 13 was added at Manuao College in 2001 because the nearest usable fax machine was at the MESC headquarters, 15 minutes away by car. However, with the installation of networked computers and a fax machine, teachers could send their task outlines and assessment programs to Fiji and have it approved or returned for changes in a single day, without leaving the school grounds.

Other aspects of teacher preparation that were now conducted more efficiently as a result of available ICTs were the preparation of student notes and exams, as well as searching for information on any given topic. However, the introduction of newer ICTs to Manuao College had been detrimental for one teacher. For this teacher, the introduction of ICTs resulted in a much increased workload as, not only was she teaching a full load throughout the day, she was also in charge of the after hours community learning centre in addition to assisting students and staff on computers when needed.

Teachers also provided descriptions of how they used ICTs in teaching and learning. Most teachers instructed their students to word-process assignments before submitting them for marking. As well, several teachers liked to prepare student notes on the computer usually with the aid of information from the internet, before printing and photocopying these notes for their classes. This is 
perceived by teachers as one of the ways in which ICT has eased their workload in light of insufficient or even non-existent textbooks for students as well as teachers. Other teachers have used videos in class as well as the tape recorder for exercises in oral and aural skills. One teacher described a lesson which involved the use of the internet to look for information they later compared with information collected on a field trip.

It is apparent that much of the teaching and learning that takes place at Manuao College is in teacher-centred mode. With a few exceptions, much of the ICT use that teachers have described involves its use to support existing teaching practice which is mostly teacher-centred. Again, this has been observed in other schools which have introduced computers and other ICTs into their classrooms (Cohen, 1987; Conlon \& Simpson, 2003; Cuban, Kirkpatrick \& Peck, 2001; Cuban, 2001). Even in schools that are rich in resources and have high access to technologies, ICTs are used predominantly to reinforce and support teacher centred pedagogies (Conlon \& Simpson, 2003; Cuban, Kirkpatrick \& Peck, 2001, Tearle, 2003).

Whilst discussing the uses and impacts of ICTs on teacher work, it became apparent that teachers had positive views of computers and other ICTs; several expressed the desire for more understanding of how to use ICTs to support teaching and learning. For a few of the research participants, the installation of the community learning centre at Manuao College was also a new beginning for them in learning how to use the computer to carry out daily teacher tasks. This is significant for research shows that teacher attitudes towards ICT influence the effectiveness of technology integration (Albirini, 2004; Czerniak, Lumpe, Haney \& Beck, 1999; Kersaint, Horton, Stohl \& Garofalo, 2003; Sugar, Crawley \& Fine, 2005; Forgasz, 2006; Ogiegbaen, 2006; Jamissen \& Phelps, 2006).

It is regrettable that I did not delve deeper into teachers' beliefs regarding teaching and learning; while evidence pointing to teacher beliefs did not come up 
in the interview data, I am certain that such beliefs exist. Teacher beliefs are at the core of much that teachers do, and therefore influence how they respond to the introduction of technology (Albion \& Ertmer, 2002; Churchill, 2006; Niederhauser \& Stoddart, 2001; Veen \& Sleegers, 2006). As identified in other research, teacher beliefs influence the amount of effort teachers will expend to meaningfully incorporate ICT into their lessons (Jamissen \& Phelps, 2006; Lumpe \& Chambers, 2001; Ertmer et al, 1999; Cuban, 2001). It is also worth mentioning that while such beliefs are central to teacher behaviour, they can and do change (Albion \& Ertmer, 2002; Becker \& Ravitz, 1999; Levin \& Wadmany, 2006).

\section{PERCEPTIONS OF ICT TRAINING FOR TEACHERS}

The teachers who participated in the study had definite perceptions about the inservice training in ICT that had been carried out at various instances during the year. As can be seen in their comments in their previous chapter, some teachers perceived the training opportunities as useful, and some considered it irrelevant. For teachers who perceived the training instances as useful, they explained that this was because they learnt new skills from the training, such as how to use the cut and paste functions in the Microsoft Office applications. Other teachers did not perceive it to be useful because it covered skills in which they were already proficient and they subsequently did not learn anything from the training. There were also comments made about the availability of the training to a few selected staff when it could have been made available to all. However, these comments may have been referring to training for computer coordinators from SchoolNet schools, and four teachers were selected from Manuao College staff to attend this training.

Teachers also had perceptions of the timing and structure of the training in ICT. 
Some perceived the training to have limited usefulness because it did not allow time or opportunity for teachers to practice what they learnt during the training. For instance, one teacher commented that it would have been useful to have the training continuously throughout the year instead of during the long holidays as they tended to forget what they had learnt during the holiday period. Another commented that what she learnt was quickly forgotten because there was no opportunity during the day to practice her skills and she was occupied with other tasks when school was over for the day. Yet another teacher pointed out that their newly-obtained knowledge from the training was easily forgotten because it wasn't sufficiently established and they needed more time to practice such skills with experts present before trying it on their own. Through these examples, it is clear that teachers perceive training opportunities in terms of their practical application to their daily activities, and consider it important to have sufficient time to practice and reinforce their skills.

Research on the preparation of teachers for the integration of ICTs in teaching and learning argues for the development of meaningful and relevant ICT professional development for teachers. Jamissen and Phelps (2006) advocate that teacher preparation should involve more than skills training in the use of computers and other technologies; it should include support in developing learning strategies, opportunity for teacher reflection on teaching and learning; mentoring and action research. Other findings highlight the need for professional development in ICT to include sufficient release time for teachers to plan, mentor and collaborate on ICT integration. Furthermore, other researchers recommend that professional development planning should take into account the needs of teachers and offer modeling and exemplars to support teacher learning (Baylor \& Ritchie, 2002). 


\section{TEACHER ATTITUDES TOWARDS ICT}

The literature on ICT integration and teachers often discuss teacher attitudes towards ICTs and how this impacts on the success of the technology integration process (Albirini, 2004; Bullock, 2004; Lumpe \& Chambers, 2001). It is apparent from statements made by the research participants that they were willing to learn new skills and some had actually demonstrated initiative in kick-starting their own learning. Several teachers explained that they developed most of their skills from getting on the computer and trying it out, and asking for assistance from more knowledgeable colleagues when necessary.

\section{PERCEPTIONS OF OBSTACLES TO EFFECTIVE USE OF ICT IN TEACHING AND LEARNING}

Teachers noted several existing obstacles which prevented the effective use of computers and other ICTs in teaching and learning at Manuao College. Most teachers perceived the insufficient numbers of computers a limitation as there are not enough to cater for a single class - 10 computers compared to students twice or three times that number. In addition, running costs and maintenance for computers and other equipment meant the need for a constant supply of funds which was often insufficient despite the existence of a user-pays system. There was also an issue with what was perceived as a limitation on teachers, who were allowed to use the computers after school hours only. Several teachers saw the existing arrangement as inhibiting because they were usually too drained of energy to stay after hours to use the computers when needed. In addition, it was not possible to take an entire subject class to the computer lab as it was usually booked for Computer Studies classes.

Equally important, while some teachers understood the need for a user-pays system for the computer lab, others perceived this to be a limitation as it asked 
students and teachers for funds they may not have, thereby negating the objective of improved equity for all technology users. Teachers perceived their lack of knowledge as a limitation; they would not use ICTs in their lessons if they lacked the knowledge to do so. There was also a perception among two teachers that their peers were not sufficiently desirous to learn about and attempt novel ways of teaching. Another aspect perceived by some teachers as an obstacle was unproductive use of computers by their peers, defined as use of computers for matters other than communication or teacher preparation. Teachers also mentioned disadvantages with the use of the internet in terms of access to restricted sites and students plagiarising material off the web.

The obstacles perceived by teachers in this study correspond to those listed by teachers in research settings elsewhere (Conlon \& Simpson, 2003; Ertmer et al, 1999; Pelgrum, 2001). In addition, Ertmer et al (1999) have classed such obstacles into first order and second order barriers to successful integration of ICT in schools. First order barriers are external to the teacher and include such things as: insufficient numbers of computers for student use; insufficient hours for students and teachers to access the technology; timetabling restrictions and technical and maintenance difficulties. Second order barriers are those barriers intrinsic to the teacher and include teacher beliefs and attitudes towards ICTs, as well as teacher skills and knowledge of ICT. Ertmer et al (1999) found that all factors interacted to limit successful integration of technology in schools although measures to do so might differ between first order and second order barriers.

\section{TEACHER SOLUTIONS TO MANAGE PERCEIVED OBSTACLES}

As outlined in the preceding section, the research participants identified many aspects of current practice they considered to be obstacles to effectively using ICT to enhance teaching and learning. However, it was clear from their 
responses that with the exception of a few, most obstacles seemed to be beyond their control.

It has already been stated that teachers considered the insufficient number of computers a hindrance to effective inclusion in the classroom. However, they had already implemented a solution of sorts, in the form of dividing each computer studies option class into two groups. Each group took turns in the computer lab at every computer studies period; the group that was not in the lab were in a room next door for independent study or to complete work set by other teachers. In this way, the problem of insufficient computers was resolved for the computer studies classes at least.

Some teachers had also taken the initiative to overcome their own inadequacies in computer skills by attempting to teach themselves with assistance from other colleagues. As apparent in their statements, although such assistance was sometimes not forthcoming, it did not dampen their enthusiasm and willingness to learn.

It is significant that of all the obstacles mentioned by teachers, only a few had been resolved, which left the great majority unresolved from the teachers' perspective. It may be that many of these perceived obstacles are beyond the immediate control of individual teachers, or equally important, may be perceived as being beyond their control. However, as evident from the data, there was no shortage of teacher suggestions about how such obstacles should be overcome.

One of the more common teacher suggestions for improvement of ICT use to enhance teaching and learning was the provision of relevant professional development for teachers in the use of ICTs. Teachers emphasised the need for skills in operating the technology as well as pedagogical understanding of how to use it effectively in teaching and learning. Teachers also suggested that there should be teacher access to computers during school hours, which is a response 
to the current (unwritten) school policy of after-hours access for teachers. As well, a request was made for the learning centre to be available to other classes and not just the computer studies class. However, the implementation of such a solution would necessitate timetabling changes as the computer lab is at present almost fully booked with computer studies classes from all levels across the school.

Additional suggestions consisted of: having more computers in a bigger airconditioned room; more funds for maintenance of ICTs; more skilled personnel to be capable of teaching Computer Studies as well as being responsible for maintenance and support, and MESC to be responsible for upkeep of the computer facilities.

\section{SUMMARY}

This chapter has presented an analytical discussion of the data described in the previous chapter, with references to relevant research literature. The major themes emerging from the data as discussed in this chapter are: teacher perceptions of the rationale for school integration of ICT; teacher perceptions of the relationship between ICT and student learning; teacher perceptions of the relationship between ICT and teaching; teacher perceptions of ICT training for teachers; perceptions of obstacles to effective use of ICT in teaching and learning and teacher solutions to manage perceived obstacles. The next chapter summarises the findings of the study and discusses implications for policy, research and practice. 


\section{CHAPTER SIX \\ SUMMARY OF FINDINGS, IMPLICATIONS AND REFLECTIONS}

\section{INTRODUCTION}

This chapter summarises the findings of the study in answer to the research questions which guided the study. These findings have implications for policy, practice and research and these are discussed here. Researcher reflections on the study are also included.

\section{SUMMARY OF FINDINGS}

Research Question One: How do teachers in Samoa perceive the use of information and communication technologies in education?

a) How do teachers in Samoa perceive government policy regarding ICT in education?

It is apparent from the interview data that most research participants were unclear regarding the specific MESC policies that were in place for the integration of computers and other ICTs in teaching and learning in Samoan schools. These policies are outlined in the MESC 2006 Strategic Policies and Plan document which went into effect the previous year. Two teachers had become aware that such a policy existed because of a MESC broadcast they had viewed on national television. However, the other research participants did not share the same awareness.

b) How do teachers in Samoa perceive government initiatives to integrate ICT in education? 
It is interesting that although most research participants were unaware of ministry policy to integrate ICTs in teaching and learning, they were cognizant of the reasons behind the SchoolNet initiative. They recognised the installation of the community learning centre at the school as a positive contribution to teaching and learning at the school. In the absence of clear ministry and school policy regarding the inclusion of ICTs, teachers perceived that the government initiative to provide schools with ICTs was in order to: a) improve student and community access to ICTs; b) improve teaching and learning; c) ensure students are ICTliterate when they enter the job market.

c) How do teachers in Samoa perceive the role that ICT plays in student learning?

The research participants perceived that the use of computers and other ICTs engaged student interest more than the use of conventional methods of teaching and learning. They perceived several reasons for this: a) computers offered a change from classroom teaching and learning; b) using computers and other ICTs involve hands on learning for students; c) computers and other technology can be entertaining and d) technology is a novelty and is therefore interesting.

Also, while teachers agreed that teaching and learning involving computers and other ICTs raised student engagement levels, they disagreed on the question of whether it actually enhanced student learning. Some teachers perceived that using computers allowed students to work independently and facilitated their learning while others perceived that it did not make any difference in how or what students learnt.

Moreover, several teachers perceived computers and other ICTs to be especially useful for students that were characterised as having 'weaker' ability, because they nevertheless became speedily proficient at using such technology. 
d) How do teachers in Samoa perceive the role that ICT plays in teacher practice?

The research participants perceived computers and other ICTs to be of great assistance in raising the efficiency of teacher preparation. According to the interview data, ICTs facilitated teacher preparation in three main ways: a) faster communication; b) faster and better preparation of student notes and exam papers and c) provision of a ready source of information on any given topic. It was also apparent that ICTs were used predominantly to support existing teacher-centred pedagogies.

Teachers also had positive views of computers and other ICTs and expressed the desire to increase their understanding of how to use technology in their classroom learning situations. Several indicated that they had initiated their own learning on ICTs with assistance from more skilled colleagues.

The research participants also had definite ideas about the usefulness of previous staff training in ICTs; they perceived these training opportunities differently depending on how relevant it was to their learning needs. Perceptions of the usefulness of ICT training were dependent on whether the training provided the teachers with new skills and understanding; these differed between teachers because they were at different levels of ICT literacy. Nevertheless, the majority of teachers expressed the need for more knowledge and understanding of how to use ICTs, particularly their meaningful integration in the process of teaching and learning.

Research Question Two: What are Samoan teachers' perceptions about how they manage factors that encourage of inhibit use of ICT to enhance student learning? 
a) What are Samoan teachers' perceptions about how they manage perceived obstacles to the use of ICT to enhance student learning?

The research participants perceived certain obstacles to be in the way of effectively using ICTs in teaching and learning. These were: a) computers are mostly accessed by Computer Studies classes and are not available to subject classes; b) teachers do not have the knowledge and therefore the confidence to successfully integrate ICTs in teaching and learning; c) inadequate numbers of computers are not conducive to whole class lessons; d) teachers do not have enough time and opportunity to develop ICT skills; e) the user pays system disadvantaged some students as well as some teachers; f) operating and maintenance costs were sometimes unmet resulting in ICTs being unavailable until bills were paid.

It seems that three limitations stand out for teachers in terms of disabling conditions for effective ICT use. The first is that the school's ICTs are concentrated in the computer lab, which is the domain of the computer studies classes. With the exception of one senior class lesson, no subject classes have been carried out in the computer lab. Secondly, although teachers have expressed the desire to increase their knowledge of how to use ICTs for their lessons, they do not have the knowledge, and therefore lack the confidence to do this. Thirdly, the ICTs may be available but not in sufficient quantities and not enough time to facilitate a whole class learning experience.

As outlined in the preceding chapter, teachers have managed the obstacle of insufficient numbers of computers by splitting each computer studies class in two groups which take turns in the computer lab. However, this does not address the need for other subject classes to use the computer lab. Secondly, some teachers have taken the initiative to improve their understanding of ICTs by attempting to teach themselves while asking for help when available. However, it seems that 
the majority of obstacles are unresolved and are beyond teacher control such as: timetabling of the computer lab for computer studies classes only and technical and maintenance issues. As Becker and Ravitz (1999) suggested, factors beyond teacher control often stop teachers from implementing innovative ideas they may have for teaching and learning.

b) What are Samoan teachers' perceptions about how they manage factors that encourage the use of ICT to enhance student learning?

As teachers saw it, there were few enabling factors for the effective use of ICT to enhance student learning. One can be seen in the presence and willingness of the CS teacher to assist students whenever necessary. Some teachers have stated that although they do not have the time to take their students to the computer lab, they send their students to the CS teacher for assistance in carrying out research and word-processing their assignments. The presence of the CS teacher also makes a difference to teachers. learning when she is present to give assistance - but as one teacher commented, sometimes this assistance is not forthcoming. This is understandable given that the CS teacher acts as facilities manager, CS teacher for the entire school as well as after-hours community learning centre manager.

Another enabling factor can be seen in student willingness to use ICTs; teachers capitalise on this by setting requirements for word-processed assignments and encourage students to carry out research on the internet for such tasks. Although teachers cannot carry out such activities as part of the class lesson, they encourage the students to do this in their own time. 


\section{IMPLICATIONS OF FINDINGS}

The findings outlined in this research hold certain implications for policy, practice and research in education.

\section{Policy Implications}

It would seem that even within the short period since implementation of the SchoolNet initiative, the experience in this case of teachers, might be useful for informing ministry policies. As already outlined, teachers were unaware of the specific government policies regarding Information and Communication Technologies in schools. MESC might want to consider how to more effectively communicate its aims to those who have the task of implementing these policies at the ground level; specifically principals and teachers.

In addition, the policies and strategies that exist are unclear about how teachers should go about the process of meaningfully integrating ICTs in teaching and learning. While a school policy for ICT use exists at Manuao College, this is specifically for administration and user care of equipment. It is advisable that teacher feedback be incorporated in the formulation of policies for timetabling computer use and the resolution of other perceived obstacles.

\section{Implications for Teacher Practice}

It is heartening to observe that teachers at Manuao College are already reflecting on the usefulness of ICTs in teaching and learning in addition to learning how to use it for various tasks. However, teaching and learning will be greatly enhanced if teachers understood how to meaningfully integrate ICTS in their classrooms. It would seem that while the technology has been introduced into the classroom, its 
usage by teachers appeared not to have been systematically integrated into their teaching practice; nor its impact on improving student learning identified and informing their own teaching practice. It is advisable that someone/some people must take the initiative to experiment with different ways of utilising ICTs to better enhance student learning; secondly, the obstacles that teacher perceive to be in the way of effective integration must be somehow removed. As already outlined, teachers have suggestions as to how this can be done. It is also noted that improved teacher practice cannot happen without a whole-school approach to problem solving and improvement. Without appropriate mechanisms for the implementation of feedback from teachers, those suggestions are unlikely to be institutionally captured towards improving teacher practice.

\section{Implications for Research}

This study was an initial foray into the phenomenon of ICT integration in education in Samoa. It has resulted in insights into teacher perceptions regarding this phenomenon that although far from definitive, does help set direction for further research. It would be beneficial to explore whether these perspectives are shared by other teachers in other schools with access to ICTs. Further research on the perceptions of students at the school or in other pilot schools on the research questions of this study would be informative. Additionally, research on the actual measures of learning, use and impacts of ICT at the case study school and/or other pilot schools will extend this study further.

Moreover, it would be useful to trial different models of technological integration in Samoa to find out what is most appropriate given Samoa's context, while bearing in mind that there are different teaching and learning contexts within Samoa itself. Finally, additional areas for research include the levels of competencies of all teachers, the nature of and needs for teacher professional development and more. 


\section{REFLECTIONS ON THIS STUDY}

This research has been a steep learning curve for me as a beginning researcher and educator. The study started with the formulation of specific research questions for which answers were sought throughout the research process. As I near the completion of this journey, more questions than answers arise in my mind.

The objective of my research was to explore perspectives of teachers at Manuao College regarding the place of Information and Communication Technologies in teaching and learning. On reflection, I am unsure if I had fully explored the perspectives of teachers and sufficiently carried out the research. One of the questions I now ask myself is how much my data has been affected by the process of translation from Samoan into English, for the purpose of data analysis and reporting in the English language. While all transcripts were checked by interviewees for consistency in translation and subsequently approved, I wonder whether I have lost elements of data quality, as the research participants may not have noticed discrepancies for the same reason they preferred our interviews to be conducted in Samoan. A future similar study in a Samoan context may need to utilise the skills of another translator, thereby minimising the concern raised above.

Another question that I also ask is whether my being a female affected the interview data I obtained during in-depth interviews with male participants. This is given the fact that this research was conducted in Samoa, a somewhat patrilineal society where most positions of authority are held by males. While I hope that my data was not in anyway lessened because of this, I acknowledge that the possibility existed. A future similar study may benefit from a cluster group meeting instead of a one-on-one interview. 
I also wonder at the information I had obtained, because of the questions I did not ask. In hindsight, there are other questions I could have asked of teachers in the study, but did not, and therefore did not know their perceptions of. Likewise, I am aware that the questions I did ask during the course of the interview, as sincerely designed as they were, directed participants. answers and might have narrowed the data generated somewhat. Again, a similar future study might benefit from a combination of data gathering techniques including cluster group meetings, journal entries, open ended reflection notes by the teachers and more.

Finally, in writing this research report, I am aware that research by its very nature benefits some people at the expense of others. I am conscious that it is possible to unconsciously write in a way that exploits and undermines the .researched.. It is my ultimate hope that this piece of research benefits the researched. as much as it has benefited me.

One of such benefits is my own heightened awareness of the unintended effects of the research endeavour; and my renewed commitment to ensure that in future research projects, care is taken to maximise the positive value of the research study for those who are researched. 
APPENDIX 1: Letter to Samoa Ministry of Education Sports and Culture 


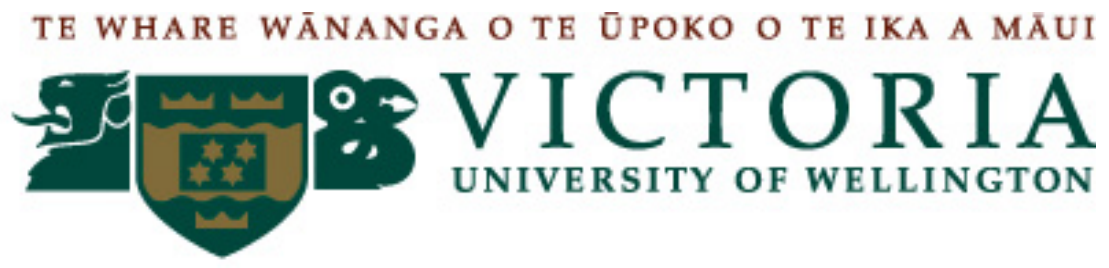

17 Nov 2007

Afioga Levaopolo Tupae Esera

Chief Executive Officer

Ministry of Education, Sports and Culture

Malifa

SAMOA

Dear Sir:

My name is Tepora Afamasaga-Wright, formerly employed as a teacher at Samoa College and Robert Louis Stevenson School. I am now in my second year of a Master of Education degree at Victoria University of Wellington.

I write to humbly request your permission to carry out a research study at Vaimauga College. The objective of my research is to explore the perspectives and administrators regarding information and communications technologies in education in Samoa. The participants will include the teaching staff and principal of Vaimauga College.

The benefit of the research study will be both individual and educational. While this research will count towards my postgraduate qualification, the results might also benefit those who seek insight into teacher perspectives regarding ICT in education, especially in light of current initiatives in this area.

If granted permission, this research will be carried out during the month of November 2007. It is foreseen that the research report will be completed in April 2008. A copy will be made available to yourself and all research participants after examination and approval of the thesis.

Your receipt of this letter on university letterhead indicates that my proposal for research has received clearance to proceed from the Victoria University of Wellington College of Education Ethics Committee.

I am most willing to answer queries you may have regarding this research, and can be reached at the address and contact number below. I thank you in advance for your consideration.

Respectfully yours

Tepora Afamasaga-Wright

Dr Kabini Sanga

Thesis supervisor

TEPORA AFAMASAGA-WRIGHT • P.O. BOX 1842 • APIA

PHONE: $7729835 \cdot$ SAMOA 
APPENDIX 2: Information for Research Participants \& Consent Form 


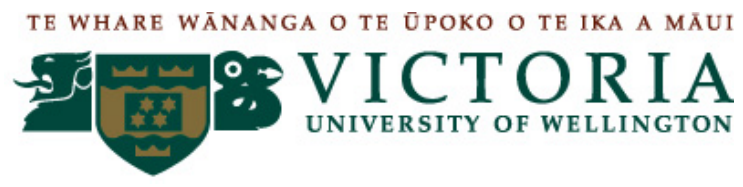

\section{INFORMATION FOR RESEARCH PARTICIPANTS}

Talofa lava, my name is Tepora Afamasaga-Wright, currently studying towards a Masters degree in Education at Victoria University of Wellington, New Zealand. My research project aims to explore the perspectives of teachers and administrators towards information and communications technologies in education in Samoa. For the purpose of this research, 'teachers' refer to teaching staff, and 'administrators' refer to school principals and Ministry of Education personnel. Little is known of what teachers and administrators think regarding this issue of ICTs in education, yet it may be one of the most important consideration sin planning for the effective integration of ICTs in Samoan schools. I therefore humbly request your participation in this research study.

Your participation in this research will involve a single fact-to-face interview conducted at a time convenient to yourself during the period of research. You are not in any way obliged to agree to this interview and are free to refuse to participate without having to provide a reason for doing so. You also have the right to change your mind and cease your research participation without having to provide reasons. You will in no way to be penalized ore regarded less for doing so. Any data provided by you will subsequently be destroyed or returned to you according to your preference.

Interviews will be taped so that I may record the richness of your conversation without having to worry about writing everything on paper. However, these will be transcribed by me; your interview will returned to you for checking, this will ensure that I do not misrepresent your words or meaning. Only after you approve the interview transcript will I use it in my study. All personal details, information and opinions will be kept confidential at all times including the writing of the final report. While I may use information provided by you in the report, these will be use with different names or no identification. All interview transcripts, tapes and observation notes will be destroyed after submission and approval of the final research report. Furthermore, while the report will remain in the form of an unpublished thesis, a copy of the final report will be made available to you/your school and research findings may be published in academic journals and or disseminated at academic/professional conferences.

This research has obtained the approval of Victoria University of Wellington College of Education Ethics Committee.

Give below are the contact details of myself and my thesis supervisor in case you want to contact one or both of us. Please feel free to seek clarification of any matters relating to this research. Thank you very much for your time.

\section{Research student}

Tepora Afamasaga-Wright

3 Florio Terrace, Tawa

Wellington, NZ

afamasfari@student.vuw.ac.nz

(064) 212314759

(0644) 2321553

Motootua, SAMOA

(0685) 7729835

(0685) 26271

\author{
Research supervisor \\ Dr Kabini Sanga \\ Associate Professor \\ School of Education Studies/He Parekereke \\ Victoria University of Wellington, NZ \\ Kabini.Sanga@vuw.ac.nz
}




\section{Research Participants consent form}

Please tick each box to indicate your agreement

I hereby consent to this research study

In doing so I acknowledge that:

I have been provided with adequate information relating to the nature and objectives of this research project

I have understood that information and have been given the opportunity to seek further clarification and explanation

I understand that I may withdraw from this study at any time before the final analysis of data without providing reasons - in which case data provided by me will be immediately destroyed or returned to me according to my preference

I understand that any information or opinions I provide will be kept confidential and reported only in a non attributable form; I will also have the opportunity to check interview transcripts before they are used in the report

I understand that the information I have provided will be used only for this research project and any further use will require my written consent

I understand that when this research is completed, the information obtained will be destroyed

I would like a copy of the final report when it is available

Date 
APPENDIX 3: Guiding questions for interviews with teachers and principals 


\section{Guiding questions for interview with teachers and principals}

1. Could you tell me about your teaching/professional background - for example, what you teach and for how long?

2. Are you aware of the government policy regarding ICT in education?

3. What do you think of this policy?

4. How has this policy been communicated to you?

5. Since this policy was written, how has it affected your work as a teacher/principal?

6. Could you describe the government initiatives to integrate ICT in education as it relates to your school?

7. What is your opinion regarding this ICT initiative?

8. How has this initiative impacted on your work as a teacher/principal?

9. How has this initiative impacted your school?

10. How do you think this initiative will impact your school in the future?

11. How do you think ICT impacts student learning?

12. Could you describe some examples from your experience?

13. How do you think ICT impacts teacher practice?

14. Could you describe some examples from your experience?

15. What do you think are the obstacles to using ICT to enhance student learning?

16. How have these obstacles manifested in your professional experience?

17. How do you deal with these obstacles?

18. What do you think are the factors that encourage using ICT to enhance student learning?

19. How have these factors manifested in your professional experience?

20. How do you make the most of these factors?

21. Would you like to comment further? 


\section{REFERENCES}

Afamasaga, G.T. (2006). The challenge in education. Samoa National Human Development Report, pp.81-99. Lepapaigalagala: National University of Samoa.

Adams, C. (2007). On the 'informed use' of PowerPoint: rejoining Vallance and Towndrow. Journal of Curriculum Studies, 39(2), pp.229-233.

Adams, C. (2006). PowerPoint, habits of mind, and classroom culture. Journal of Curriculum Studies, 38(4), pp.389-411.

Albion, P.R. \& Ertmer, P.A. (2002) Beyond the foundations: The role of vision and belief in teachers' preparation for integration of technology. Techtrends, 46(5), pp.3438.

Albion, P.R. (2003). Graduating teachers dispositions for integrating information and communications technologies into their teaching. Retrieved 05/04/07 http://www.usq.edu.au/users/albion/papers/site03/3756.pdf

Albirini, A. (2004). Teachers. attitudes toward information and communication technologies: the case of Syrian EFL teachers. Computers and Education, 47, pp.373-398.

Baylor, A.L. \& Ritchie, D. (2002). What factors facilitate teacher skill, teacher morale, and perceived student learning in technology-using classrooms? Computers and Education,39, pp.395-414.

Becker, H. (1994). How exemplary computer-using teachers differ from other teachers: implications for realizing the potential of computers in schools. Journal of Research on Computing in Education, 26(3). 
Becker, H.J. \& Ravitz, J. (1999). The influence of computer and internet use on teachers. pedagogical practices and perceptions. Journal of Research on Computing in Education, 31(4), pp.356-384.

Becker, H.J. (2000). Findings from the teaching, learning and computing survey: Is Larry Cuban right? Education Policy Analysis Archives, 8(51). Retrieved 12/07/07 http://epaa.asu.edu/epaa/v8n51/

Bitner, N. \& Bitner, J. (2002). Integrating technology into the classroom: 8 keys to success. Journal of Technology and Teacher Education, 10(1), pp.95-100.

Bogdan, R.C. \& Biklen, S.K. (2007). Qualitative research for education. (5th ed.). Boston: Pearson Education Inc.

Bottino, R.M. (2004). The evolution of ICT-based learning environments: which perspectives for the school of the future? British Journal of Educational Technology, 35(5), pp.553-567.

Brill, J.M. \& Galloway, C. (2007). Perils and promises: University instructors. integration of technology in classroom-based practices. British Journal of Educational Technology, 38(1), pp.95-105.

Bullock, D. (2004). Moving from theory to practice: An examination of the factors that preservice teachers encounter as they attempt to gain experience teaching with technology during field placement experiences. Journal of Technology and Teacher Education, 12(2), pp.211-237.

Cawthera, A. (2001). Computers in secondary schools in developing countries: costs and other issues. The Department For International Development (DFID), World Links For Development (WorLD): a part of the World Bank Institute and The Human Development Network of the World Bank. 
Churchill, D. (2006). Teachers' private theories and their design of technology-based learning. British Journal of Educational Technology, 37(4), pp.559-576.

Clift, R.T., Mullen, L., Levin, J. \& Larson, A. (2001). Technologies in contexts: Implications for teacher education. Teaching and Teacher Education, 17(2001), pp.33-50.

Cohen, D.K. (1987). Educational technology, policy and practice. Educational Evaluation and Policy Analysis, 9(2), pp.153-170.

Conlon, T. \& Simpson, M. (2003). Silicon Valley versus Silicon Glen: the impact of computers upon teaching and learning: a comparative study. British Journal of Educational Technology, 34(2), pp.137-150.

Conrad, C.F. \& Serlin, R.C. (2006). The SAGE handbook for research in education: engaging ideas and enriching inquiry.

Coupal, L.V. (2004). Constructivist learning theory and human capital theory: shifting political and educational frameworks for teachers' ICT professional development. British Journal of Educational Technology, 35(5), pp. 587-596.

Cuban, L. (1986). Teachers and machines: the classroom use of technology since 1920. New York: Teachers College Press.

Cuban, L. (2001). Oversold and underused: computers in the classroom. Cambridge: Harvard University Press.

Cuban, L., Kirkpatrick, H. \& Peck, C. (2001). High access and low use of technologies in high school classrooms: Explaining an apparent paradox. American Educational Research Journal, 38(4), pp.813-834. 
Czerniak, C.M., Lumpe, A.T., Haney, J.J. \& Beck, J. (1999). Teachers' beliefs about using educational technology in the science classroom. International Journal of $\begin{array}{llll}\text { Educational Technology, } & \text { 1(2). } & \text { Retrieved }\end{array}$ http://smi.curtin.edu.au/ijet/v1n2/rakes/index.html

Denscombe, M. (2007). The good research guide for small-scale social research projects (3rd ed.). England: Open University Press.

Dexter, S.L., Anderson, R.E. \& Becker, H.J. (1999). Teachers' views of computers as catalysts for changes in their teaching practice. Journal of Research on Computing in Education, 31(3), pp.221-239.

Dwyer, D. (1994). Apple classrooms of tomorrow: what we've learned. Educational Leadership, 51(7), pp.4-10.

Ertmer, P., Addison, P., Lane, M., Ross. E. \& Woods, D. (1999). Examining teacher beliefs about the role of technology in the elementary classroom. Journal of Research on Computing in Education, 32(1), pp.54-71.

Farell, G.M. (2003). An overview of developments and trends in the application of information and communication technologies in education. In G. Farrell \& C. Wachholz (Eds.). Meta-survey on the Use of Technologies in Education in Asia and the Pacific 2003-2004, pp.4-28. Bangkok, UNESCO Asia and Pacific Regional Bureau for Education.

Forgasz, H. (2006). Factors that encourage or inhibit computer use for secondary mathematics teaching. Journal of Computers in Mathematics and Science Teaching, 25(1), pp.77-93. 
Fullan, M. (1982). The meaning of educational change. Toronto: OISE Press/Ontario Institute for Studies in Education.

Gallini, J.K. \& Barron, D. (2001/2002). Participants' perceptions of web-infused environments: A survey of teaching beliefs, learning approaches, and communication. Journal of Research on Technology in Education, 34(2), pp.139156.

Geoghegan. W. H. (1994). What ever happened to instructional technology? Paper presented at the 22nd Annual Conference of the International Business Schools Computing Association, Baltimore Maryland. Retrieved 10/09/07 http://eprints.ecs.soton.ac.uk/10144/01/Geoghegan-1994WHAT_EVER_HAPPENED_TO_INSTRUCTIONAL_TECHNOLOGY.doc

Goodson, I.F. \& Mangan, J.M. (1995). Subject cultures and the introduction of classroom computers. British Educational Research Journal, 21(5), pp.613-628.

Government of Samoa. (2002). Samoa Information and Communication Technologies Policy and Strategic Plan. Apia: Government of Samoa.

Grbich, C. (2007). Qualitative data analysis: an introduction. London: SAGE Publications.

Hadley, M. \& Sheingold, K. (1993). Commonalities and distinctive patterns in teachers' integration of computers. American Journal of Education, 101(3), pp.261-315.

Haydn, T. \& Barton, R. (2007). 'First do no harm': Developing teachers ability to use ICT in subject teaching: some lessons from the UK. British Journal of Educational Technology, 38(2), pp.365-368. 
Henessy, S. \& Deaney, R. (2005). Sustainability and Evolution of ICT-Supported Classroom Practice. ICT Research Bursaries. Retrieved 10/09/06 http://www.becta.org.uk

Henessy, S., Ruthven, K. \& Brindley, S. (2005). Teacher perspectives on integrating ICT into subject teaching, commitment, constraints, caution and change. Journal of Curriculum Studies, 37(2), pp.155-192.

Heshusius, L. (1990). Discussion on criteria. In Guba, E.G. (Ed.). The paradigm dialog. Newbury Park: SAGE Publications.pp.198-201.

Hoepfl, M. (1997). Choosing qualitative research: A primer for technology education researchers. Journal of Technology Education, 9(1), pp.47-63.

Holstein, J.A. \& Gubrium, J.F. (1998). Phenomenology, ethnomethodology, and interpretive practice. In N.K.Denzin and Y.S.Lincoln (Eds.). Strategies of qualitative inquiry. Thousand Oaks: SAGE Publications.pp.137-157.

Hong, K.S. \& Koh, C.K. (2002). Computer anxiety and attitudes toward computers among rural secondary school teachers: A Malaysian perspective. Journal of Research on Technology in Education, 35(1), pp.27-48.

ICT Capacity Building at USP Project. (2005). ICT in Secondary Education in the Pacific Region: Status, Trends and Prospects. Suva: ICT Capacity Building at USP Project.

Jamissen, G. \& Phelps, R. (2006). The role of reflection and mentoring in ICT teacher professional development: dialogue and learning across the hemispheres. Teacher Development, 10(3), pp.293-312. 
Kerr, S.T. (2005). Why we all want it to work: towards a culturally based model for technology and educational change. British Journal of Educational Technology, 36(6), pp.1005-1016.

Kersaint, G., Horton, B., Stohl, H. and Garofalo, J. (2003). Technology beliefs and practices of mathematics education faculty. Journal of Technology and Teacher Education, 11(4), pp.549-577.

Knezek, G. \& Christensen, R. (2002). Impact of new information technologies on teachers and students. Education and Information Technologies, 7(4), pp.369376.

Lawless, K. \& Pellegrino, J. (2007). Professional development in integrating technology into teaching and learning: knowns, unknowns, and ways to pursue better questions and answers. Review of Educational Research, 77(4), pp.575-614.

Levin, T. \& Wadmany, R. (2006). Teachers' beliefs and practices in technology-based classrooms: A developmental view. Journal of Research on Technology in Education, 39(2), pp.157-181.

Lincoln, Y.S. \& Guba, E.G. (1985). Naturalistic Inquiry. London; SAGE Publications.

Lincoln, Y.S. (1990). The making of a constructivist: a remembrance of transformations past. In Guba, E.G. (Ed.). The paradigm dialog. Newbury Park: SAGE Publications.pp.67-87.

Loxley, W. \& Julien, P. (2004). Information and Communications Technologies in Education and Training in Asia and the Pacific. Asian Development Bank. Retrieved 12/ 06/06 http://www.adb.org/Documents/Reports/ICT-Education$\underline{\text { Training/ict-educationtraining.pdf }}$ 
Lumpe, A.T. \& Chambers, E. (2001). Assessing teachers' context beliefs about technology usage. Journal of Research on Technology in Education, 34(1), pp.93-107.

Marcinkiewicz, H.R. (1993/1994). Computers and teachers: Factors influencing computer use in the classroom. Journal of Research on Computing in Education, 26(2).

Marshall, C. \& Rossman, G.B. (1999). Designing qualitative research (3rd ed.). London: SAGE Publications.

Marshall, C. (1990). Goodness criteria: are they objective or judgment calls? In Guba, E.G. (Ed.). The paradigm dialog. Newbury Park: SAGE Publications.pp.188-197.

Miles, M.B. \& Huberman, A.M. (1994). Qualitative data analysis: an expanded sourcebook. Thousand Oaks: SAGE Publications.

Morse, J. M. (1998). Designing funded qualitative research. In N.K.Denzin and

Y.S.Lincoln (Eds.). Strategies of qualitative inquiry. Thousand Oaks: SAGE Publications.pp.56-85.

Moustakas, C. (1994). Phenomenological Research Methods. Thousand Oaks: SAGE Publications.

Nichol, J. \& Watson, K. (2003). Editorial. British Journal of Educational Technology,34(2),pp.131-136.

Niederhauser, D.S. \& Stoddart, T. (2001). Teachers' instructional perspectives and the use of educational software. Teaching and Teacher Education, 17, pp.15-31. 
Ogiegbaen, S.E.A. (2006). Assessment of teachers' perception of instructional media use in Colleges of Education of Southern Nigeria. Journal of Instructional Media, 33(2), pp.205-215.

Olson, J. (2000). Trojan horse or teacher's pet? Computers and the culture of the school. Journal of Curriculum Studies, 32(1), pp.1-8.

Pachler, N. (2005). Theories of learning and ICT. In M. Leask \& Pachler, N. (Eds.), Learning to teach using ICT in the secondary school (pp.189-206). New York: Routledge.

Pacific Islands Forum Secretariat. (2002a). Forum Communications Action Plan . 2002 Review. Suva: Pacific Islands Forum Secretariat.

Pacific Islands Forum Secretariat. (2002b). Pacific Islands Information and Communication Technologies Policy and Strategic Plan. Suva: Pacific Islands Forum Secretariat.

Pacific Islands Forum Secretariat. (2002c). Pacific ICT Capacity and Prospects. Suva: Pacific Islands Forum Secretariat.

Pacific Islands Forum Secretariat. (2004a). ICT for Education: The Global Agenda. Suva: Pacific Islands Forum Secretariat.

Pacific Islands Forum Secretariat. (2004b). Sub-Regional Symposium on ICTs for Development in Pacific Islands Developing Countries. Suva: Pacific Islands Forum Secretariat.

Patton. M.Q. (2002). Qualitative research \& Evaluation methods (3rd ed.). London: SAGE Publications. 
Pelgrum. W.J. (2001). Obstacles to the integration of ICT in education: results from a worldwide educational assessment. Computers and Education, 37, pp.163-178.

Polyzoi, E. (1982). Approaching a new inquiry. In V.Darroch and R.J.Silvers (Eds.). Interpretive Human Studies: an introduction to phenomenological research. Washington D.C.: University Press of America.pp.93-100.

Prasad, P. (2005). Crafting qualitative research: Working in the post-positivist traditions. New York: M.E.Sharpe Inc.

Rakes, G.C., Flowers, B.F., Casey, H.B. \& Santana, R. (1999). An analysis of instructional technology use and constructivist behaviours in K-12 teachers. International Journal of Educational Technology, 1(2). Retrieved 24/04/07 http://smi.curtin.edu.au/ijet/v1n2/rakes/index.html on 06/06/07.

Roebeck-Tuala, D. \& Esera, R. (2005). ICT in Education Country Status Report: Samoa. In ICT Capacity Building at USP Project (Eds.). ICT in Secondary Education in the Pacific Region: Status, Trends and Prospects. Suva: ICT Capacity Building at USP Project.

Samoa Ministry of Education, Sports and Culture. (2004a). MESC Education Statistical Digest, 2004. Malifa: Ministry of Education, Sports and Culture.

Samoa Ministry of Education, Sports and Culture. (2004b). Computer Studies Curriculum Statement, 2004. Malifa: Ministry of Education, Sports and Culture.

Samoa Ministry of Education, Sports and Culture. (2005). MESC Education Statistical Digest, 2005. Malifa: Ministry of Education, Sports and Culture.

Samoa Ministry of Education, Sports and Culture. (2006a). Strategic Policies and Plan July 2006 . June 2015. Malifa: Ministry of Education, Sports and Culture. 
Samoa Ministry of Education, Sports and Culture. (2006b). National Curriculum Policy Framework. Malifa: Ministry of Education, Sports and Culture.

Seale, C. (2003). Quality in qualitative research. In Y.S.Lincoln and N.K.Denzin (Eds.). Turning points in qualitative research: tying knots in a handkerchief. Maryland: Altamira Press. pp.169-184.

Smith, J.K. (1990). Alternative research paradigms and the problem of criteria. In Guba, E.G. (Ed.). The paradigm dialog. Newbury Park: SAGE Publications. pp.167-187.

Smith, L.T. (1999). Decolonizing methodologies: research and indigenous peoples. London: Zed Books.

Spitzer, K.L., Eisenberg, M.B. \& Lowe, C.A. (1998). Information literacy: Essential skills for the information age. New York: ERIC Clearinghouse on Information and Technology.

Stake, R.E. (1998). Case studies. In N.K.Denzin and Y.S.Lincoln (Eds.). Strategies of qualitative inquiry. Thousand Oaks: SAGE Publications.pp.86-109.

Strigel, C., Chan Mow, I. \& Vaa, R. (2007). Provoking change: Technology in education case studies from Samoa: Samoa Country Report. California: Research Triangle Institute International.

Sugar, W., Crawley, F. \& Fine, B. (2004). Examining teachers' decisions to adopt new technology. Educational Technology and Society, 7 (4), pp. 201-213.

Sugar, W., Crawley, F. \& Fine, B. (2004). Examining teachers' decisions to adopt new technology. Educational Technology and Society, 7(4), pp.201-213. 
Swan, B. \& Dixon, J. (2006). The effects of mentor-supported technology professional development on middle school mathematics teachers' attitudes and practice.

Contemporary Issues in Technology and Teacher Education, 6(1), pp.67-86. Tearle, P. (2003). ICT implementation: what makes the difference? British Journal of Educational Technology, 34(5), pp.567-583.

Toma, J.D. (2006). Approaching rigor in qualitative research. In C.F.Conrad \& R.C.Serlin (Eds.). The SAGE handbook for research in education: engaging ideas and enriching inquiry. Thousand Oaks: SAGE Publications.pp.405-424.

U.S. Department of Education, National Centre for Education Statistics. (2000). Teachers' tools for the 21st century: A report on teachers. use of technology. Washington DC: U.S. Department of Education Office of Educational Research and Improvement

Vaa, R. (2003). Samoa ICT use in education. In G. Farrell \& C. Wachholz (Eds.). Metasurvey on the Use of Technologies in Education in Asia and the Pacific 2003-2004, pp.207-212. Bangkok, UNESCO Asia and Pacific Regional Bureau for Education.

Vallance, M. \& Towndrow, P.A. (2007). Toward the 'informed use' of information and communication technology in education: a response to Adams' 'PowerPoint, habits of mind, and classroom culture'. Journal of Curriculum Studies, 39(2), pp.219-227.

Veen, K.V. \& Sleegers, P. (2006). How does it feel? Teachers' emotions in a context of change. Journal of Curriculum Studies, 38(1), pp.85-111.

Veen, W. (1993). How teachers use computers in instructional practice: Four case studies in a Dutch secondary school. Computers in Education, 21(1/2), pp.1-8. 
Wabuyele, L. (2003). Understanding teachers' and administrators' perceptions and experiences towards computer use in Kenyan classrooms: A case study of two schools. Unpublished doctoral dissertation: Ohio University, U.S.A.

Watson, D.M. (1998). Blame the technocentric artifact! What research tells us about problems inhibiting teacher use of IT. In G.Marshall \& M. Ruohonen (Eds.), Capacity Building for IT in Education in Developing Countries. London: Chapman \& Hall.

Willis, J.W. (2007). Foundations of qualitative research: interpretive and critical approaches. Thousand Oaks: SAGE Publications.

Wolcott, H.F. (1994). Transforming qualitative data: description, analysis and interpretation. Thousand Oaks: SAGE Publications.

Wolcott, H.F. (2001). Writing up qualitative research (2nd ed). Thousand Oaks: SAGE Publications.

Online References

http://www.lib.utexas.edu/maps/australia/samoa_rel98.jpg Retrieved 22-03-08 http://www.samoaschoolnet.edu.ws/ Retrieved 24/ 09/ 07. 